\title{
Fuel Poverty: Potentially Inconsistent Indicators and Where Next? \\ David Deller
}

Centre for Competition Policy University of East Anglia

Glen Turner

Centre for Competition Policy University of East Anglia

Catherine Waddams Price Centre for Competition Policy University of East Anglia

\section{CCP Working Paper 19-01}

This version: October 2020

The measurement of fuel poverty is critical for judgements about the significance of the problem and the design of policies to address it. Reducing fuel poverty has been a government objective in the UK for many years, and is generally seen through the lens of the government's official fuel poverty statistics. We compare the households identified as fuel poor according to three metrics: (i) the 10\% indicator; (ii) the Low Income High Consumption indicator; and (iii) whether households self-report an inability to afford to keep their home warm, using data from the British Household Panel Survey. We find substantial differences in the households identified according to each of these indicators; this highlights a lack of clarity about which households might be considered truly fuel poor. In particular, a surprisingly low proportion of those identified by the $10 \%$ and LIHC indicators report an inability to afford to keep their home warm. While this could raise concerns that current fuel poverty policies in the UK are misdirected, instead we emphasise the difficulties of drawing policy conclusions from the differences between the indicators, unless it can be combined with information on households' heating preferences and the inhome temperatures achieved.

Contact Details:

David Deller D.Deller@uea.ac.uk 


\title{
Fuel Poverty: Potentially Inconsistent Indicators and Where Next?
}

\author{
David Deller ${ }^{1}$, Glen Turner and Catherine Waddams Price
}

October 2020

\begin{abstract}
The measurement of fuel poverty is critical for judgements about the significance of the problem and the design of policies to address it. Reducing fuel poverty has been a government objective in the UK for many years, and is generally seen through the lens of the government's official fuel poverty statistics. We compare the households identified as fuel poor according to three metrics: (i) the $10 \%$ indicator; (ii) the Low Income High Consumption indicator; and (iii) whether households self-report an inability to afford to keep their home warm, using data from the British Household Panel Survey. We find substantial differences in the households identified according to each of these indicators; this highlights a lack of clarity about which households might be considered truly fuel poor. In particular, a surprisingly low proportion of those identified by the $10 \%$ and LIHC indicators report an inability to afford to keep their home warm. While this could raise concerns that current fuel poverty policies in the UK are misdirected, instead we emphasise the difficulties of drawing policy conclusions from the differences between the indicators, unless it can be combined with information on households' heating preferences and the in-home temperatures achieved.
\end{abstract}

\section{Introduction}

Fuel poverty $\left(\mathrm{FP}^{2}\right)$ alleviation is a well-established policy objective, with the UK government producing annual statistics and the European Commission having established the European Energy Poverty Observatory ${ }^{3}$. The challenges of identifying households in FP and debates about different statistical definitions of FP are also well established. The current paper uses the British Household Panel Survey (BHPS) to compare expenditure-based and perception-based FP indicators ${ }^{4}$ for around 10,000 households over a period of eight years. The analysis confirms a limited overlap between the two types of indicator and shows that each indicator identifies different types of households as fuel poor. Rather than arguing that one indicator is 'better' than others, the results are taken as illustrating a lack of precision regarding the measurement of the real-world problems faced by households that form the heart of FP. We argue that, if the core issue is identifying those living in the cold, records of household temperatures and temperature preferences need to be gathered on a large scale to supplement and reduce the uncertainties presented by existing statistics.

The paper builds on Waddams Price et al. (2012), but uses a much larger, richer and nationally representative multi-year dataset. The main indicators considered are: (i) reporting energy expenditures (ENEX) exceeding $10 \%$ of income; (ii) the Low Income-High Cost (LIHC) indicator; and (iii) reporting an inability to afford adequate warmth (IAAW). Indicators (i) and (ii) represent the two official indicators that have been used by government to assess FP in England ${ }^{5}$, albeit with reported

\footnotetext{
${ }^{1}$ Corresponding author: Dr David Deller, Centre for Competition Policy, University of East Anglia, Norwich Research Park, Norwich, Norfolk, NR4 7TJ, email: david.deller@uea.ac.uk. This paper was produced as part of the UK Energy Research Centre's (UKERC) research program and UKERC's financial support is gratefully acknowledged. We thank members of CCP's UKERC project team and CCP seminar participants for their helpful comments.

${ }^{2}$ The abbreviation FP is also used for 'fuel poor' in this paper.

${ }^{3}$ We make no distinction between energy and fuel poverty, but use the latter for consistency.

${ }^{4}$ We use the terms perception-based and expenditure-based to avoid terms that could be (mis-)interpreted as implying a judgement about the indicators' legitimacy. These correspond to the terms of 'subjective' or 'consensual' and 'objective' used elsewhere.

${ }^{5}$ The UK government is consulting on changing the English FP definition to a 'Low Income Low Energy Efficiency' metric where being identified as FP is linked directly to the energy efficiency rating of a home. See BEIS (2019).
} 
ENEX replacing 'required' (modelled ${ }^{6}$ ) ENEX; while indicator (iii) provides an intuitive self-assessment of living in a cold home. The lack of overlap between these indicators is striking: no more than $6 \%$ of those identified as FP by the expenditure-based indicators report IAAW. Similarly, no more than $45 \%$ of those reporting IAAW were identified as FP according to the LIHC indicator ${ }^{7}$. This lack of overlap raises significant questions about the phenomena identified by the expenditure-based indicators. As discussed by Deller and Waddams Price (2018), a high energy expenditure share (ENEXShr) may indicate a low income rather than a specific energy issue.

Beyond descriptive statistics, pooled cross-section logit regressions identify the household characteristics associated with being classified as FP according to each of the indicators. First, this shows that any association between a households' ENEX and reporting IAAW exists only after controlling for household income level.

Second, and crucially for policy, older households are no more or less likely to be associated with FP according to the $10 \%$ indicator; they show a higher probability of being FP according to the LIHC indicator, but are less likely to report IAAW. Similarly, while a lack of central heating is positively associated with reporting IAAW, it shows no association with the expenditure-based metrics once a comprehensive range of other variables are controlled for. These differences highlight that the indicator chosen to represent FP not only affects the apparent prevalence of FP, but also the type of households which are targeted for policy support.

However, we recommend caution before concluding one indicator is 'better' than others: in particular, that the expenditure-based metrics significantly overstate the prevalence of households struggling to afford warmth; or concluding that the indicators pick up different aspects of FP. We urge caution because drawing these conclusions relies on additional assumptions. For example, older households may be less likely to report IAAW, not because they live in 'warm' homes, but because they define lower temperatures as adequate or feel less comfortable admitting 'problems' with their living conditions.

While using modelled ENEX, rather than reported ENEX, overcomes some of the above uncertainties by using a fixed target temperature, new issues arise in terms of householders' temperature preferences being ignored and results depending on the accuracy of the models estimating ENEX. ${ }^{8}$

These issues highlight the need for temperature measurements from within homes and temperature preference information from householders to be combined with survey data producing the FP indicators, in order to advance the empirical understanding of FP, and explain why different FP indicators present diverse pictures. Concern about cold homes was a key early motivation for the term $\mathrm{FP}^{9}$ and has been associated with adverse health effects (for example, see Liddell and Morris, 2010), yet, as Hills (2012) notes, efforts to measure in-home temperatures in the UK since the mid1990s have been limited. Temperature measurement is important to ensure that the significant resources associated with FP alleviation are allocated to maximise the benefits to householders in most need. While the desirability of temperature measurements has long been recognised, it has been traditionally viewed as too difficult to obtain the required data on the necessary scale. The roll out of smart thermostats and other temperature recording devices, offer an important new route to obtain the desired data.

\footnotetext{
${ }^{6}$ The term modelled ENEX is used as a more accurate and neutral description of this form of data.

${ }^{7}$ The equivalent figure for the $10 \%$ indicator was $30 \%$.

${ }^{8}$ For example, see Deller and Waddams Price (2017) and Summerfield et al. (2019).

${ }^{9}$ For example, the title of Boardman (1991) is 'Fuel Poverty: from cold homes to affordable warmth'.
} 
As this study utilises panel data, we also present descriptive statistics on the persistence of FP in Appendix 2. While not the paper's main focus, these statistics reinforce the evidence for a further policy point: even if persistence is identified econometrically, the magnitude of this persistence is important. While the first lag of the FP indicators is always significant in our main regressions, the magnitude of the persistence appears to be limited. For example, in all but one year, more than $50 \%$ of households identified as $10 \%$ or IAAW FP in period $t$ were no longer identified as FP in period $t+1$. This compares to an exit probability from income poverty of no more than $35 \%$. Moreover, of those reporting IAAW at least once in the eight years studied, around $60 \%$ reported being unable to afford warmth only once.

These findings are important for identifying the most cost-effective means to tackle FP. ${ }^{10}$ Much attention has been given to using energy efficiency retrofits to tackle FP; however, if FP is mainly a short-term phenomenon, temporary interventions, such as income transfers, may be more appropriate. ${ }^{11}$ For FP alleviation, energy efficiency investments become preferred to income transfers when the one-off cost of an energy efficiency upgrade is lower than the present value of providing an ongoing income transfer sufficient to allow the householder to achieve the same level of warmth. ${ }^{12}$

The paper proceeds as follows: Section 2 reviews the existing literature; Section 3 describes the data; Section 4 outlines the methodology; Section 5 provides descriptive statistics, before Section 6 reports the main regression results and Section 7 provides policy conclusions. Results relating to a lack of adequate heating facilities are reported in Appendix 1.

\section{Existing Literature}

The originality of the present study results from the richness of the BHPS dataset. This richness constitutes: (i) the number of FP indicators considered, (ii) data coming from multiple years, (iii) the comprehensive range of explanatory variables, and (iv) the large sample size. This breadth enables a more comprehensive and detailed assessment of how perception and expenditure-based FP indicators overlap, allowing nuances to be explored. Since data are collected over time, including periods when energy prices experienced notable fluctuations, we can confirm that the lack of overlap between the two types of FP indicators is a consistent feature, rather than an observation driven by temporary factors.

The main previous study considering the overlap of FP indicators in the UK is Waddams Price et al (2012). Waddams Price et al. consider a sample from 2000 which, unlike the present paper, deliberately over-represented low income and pre-payment meter users. Given this focus, it is unsurprising that the discrepancies between $10 \% \mathrm{FP}$ and feeling unable to afford energy identified in Waddams Price et al. are somewhat smaller than in the present paper: $25.6 \%$ of the $10 \%$ FP felt unable to afford energy, while $44.1 \%$ of those feeling unable to afford energy were in $10 \% \mathrm{FP}^{13}$. The present paper's main regressions involve around four times as many households as in Waddams Price et al. (2012) and over 20 times more observations, enabling increased confidence around the variables found to be statistically insignificant.

\footnotetext{
${ }^{10}$ By focusing on the most cost-effective tools, more households can be moved out of FP for a given quantity of resources.

${ }^{11}$ A similar point is made by Chaton and Lacroix (2018) and hinted at by Roberts et al. (2015).

${ }^{12}$ Energy efficiency retrofits can also lead to beneficial carbon emission reductions, but this is a separate objective to FP reduction.

${ }^{13}$ The greater overlap in Waddams Price et al. may result both from the focus on low income households and the $10 \%$ indicator relying on income data taken as the mid-point of bands.
}

\section{superseded by corrected version, see CCP-19-01R}


BEIS (2020) and DECC (2009) report descriptive statistics for England, which again show a limited overlap between FP measures. Using data from the English Housing Survey, BEIS (2020) finds that only $15.9 \%$ of LIHC FP households felt unable to keep their home comfortably warm, while only $19.3 \%$ of households who felt unable to keep their home comfortably warm were LIHC FP. Also, mirroring the results in this paper, only $46.7 \%$ of those reporting an inability to keep comfortably warm put the issue down to cost, with $47.0 \%$ viewing it as not possible to reach a comfortable heating level. ${ }^{14}$ DECC (2009)'s findings of limited overlap again broadly mirror the results presented here, using similar data.

Beyond the UK, expenditure- and perception-based FP are compared in Spain by Phimister et al. (2015), in Greece by Papada and Kaliampakos (2016) and Ntaintasis et al. (2019), in Belgium by Meyer et al. (2018), in the US by Agbim et al. (2020), in France by Fizaine and Kahouli (2019) and in the Republic of Ireland by Scott et al. (2008). Direct comparison of the results is difficult due to the variations in the precise definitions of the expenditure-based indicators and different wording of the perception-based indicators, although all studies find a consistent lack of overlap between the two types of indicator.

The present paper improves on Phimister et al. (2015), Papada and Kaliampakos (2016), Meyer et al. (2018) and Ntaintasis et al. (2019) by including multivariate logit regressions identifying household characteristics associated with each type of FP. Scott et al. (2008) run logit regressions to identify factors associated with the 10\% FP and a composite perception-based indicator, but their data depends on separate Irish surveys. Our analysis has the advantage that different FP indicators are available for the same households, hence the present analysis avoids the risk that differences in relationships across indicators result from differences in sampling, variable definitions and/or households' unobservable characteristics. Nevertheless, matching our results, Scott et al. find that a household head being over 65 is unrelated to the 10\% FP and negatively associated with reporting heat affordability difficulties.

It is difficult to provide direct comparisons with the regression results in Agbim et al. (2020) and Fizaine and Kahouli (2019) because they use alternative FP definitions. Agbim et al. analyse Texan data and identify household spending above $8 \%$ of income on electricity (roughly twice the local median) as "objectively energy burdened", while also considering whether (i) households had difficulty paying their electricity bill, and (ii) their electricity bill was causing them stress or mental discomfort. The authors report that $34 \%$ of households reported (i), compared to $23 \%$ identified as objectively energy burdened. Thus, in contrast to the present study, the perception-based indicator gave a higher FP rate than the expenditure-based indicator.

Like the present paper, Fizaine and Kahouli (2019) show that different FP indicators are associated with different types of households. However, rather than directly identifying the household characteristics associated with each FP indicator, they first perform cluster analysis to identify profiles of households falling within each type of FP. Their analysis applies to only a single year, 2013. The precise definitions of FP in Fizaine and Kahouli follow those of the French Energy Poverty Observatory (OPNE), in particular a restriction is applied to the perception-based indicator so that only households in the bottom three deciles of the income distribution are identified as experiencing thermal discomfort.

Looking across Europe, Healy and Clinch (2002) and Thomson and Snell (2013) use regressions to analyse the household characteristics associated with perception-based and/or proxy indicators of

${ }^{14}$ Households were able to report both reasons simultaneously. 
FP. Both studies include an 'inability to afford adequate heat' indicator and Healy and Clinch (2002) also consider a 'lack of adequate heating facilities' indicator. Healy and Clinch (2002) report evidence, consistent with the current paper, that younger households are more likely to report an inability to achieve adequate warmth.

These papers are also part of a longer debate about how to define and measure FP. Figure 1 of Deller (2018) provides an overview of how energy affordability (FP) measures can be split between: (i) ENEX indicators, (ii) self-reports of the lived experience, and (iii) proxy indicators. While Deller (2018) and Tirado Herrero (2017) caution against focusing excessively on a single FP metric/definition, Thomson et al. (2016) highlight the appeal of headline statistics to galvanise political action; while Thomson et al. (2017) and Tirado Herrero (2017) provide overviews of alternative FP measurement approaches in the European context. ${ }^{15}$

This broader debate has been influenced by changing official expenditure-based FP metrics in the UK, and the need to utilise perception-based metrics for pan-EU assessments of FP. In terms of expenditure-based metrics, the decision to change the English FP metric from a $10 \%$ to LIHC definition was driven by Hills (2012) and received comment from Moore (2012) and Liddell et al (2012). ${ }^{16}$ Focussing on Germany, Heindl (2015) reviews different expenditure-based metrics and how their prevalence varies across households with different structures ${ }^{17}$, while Heindl and Schuessler (2015) provides a more theoretical assessment of these metrics' statistical properties.

Assessing FP in the UK sits within a larger literature mapping variations in ENEX across households and identifying the determinants of these variations. Papers using data from the Living Costs and Food Survey and its precursors include Baker et al. (1989), Baker and Blundell (1991), Crawford et al. (1993), Advani et al. (2013) and Deller and Waddams Price (2018). Meier and Rehdanz (2010) and Meier et al. (2013) use BHPS data to investigate ENEX, while Longhi (2014) utilises the more recent Understanding Society dataset. The present study differs from these papers by focussing specifically on binary FP indicators, a deliberately narrower frame to focus on the FP indicators chosen by UK policymakers when assessing energy affordability issues.

As a secondary aim, the present paper uses the panel nature of the BHPS to provide descriptive statistics regarding FP persistence. The literature relating to FP dynamics is discussed in Appendix 2.3. Other FP studies utilising panel data to address different questions include: Awaworyi Churchill and Smyth (2020) who consider ethnicity as a determinant of FP in Australia; Awaworyi Churchill et al. (2020) who assess the impact of FP on overall life satisfaction in Australia; Bohr and McCreery (2020) who consider the impact of being FP on the dynamics of wider economic poverty in the US; Charlier and Kahouli (2019) who assess how income mediates responses to energy price fluctuations and find that the FP have a high demand elasticity; and Llorca et al. (2020) who consider the link between FP and self-reported health in Spain.

\section{Data}

We use data from the British Household Panel Survey (BHPS) ${ }^{18}$ from 2001-02 to 2008-09, providing 55,772 observations from 10,465 households in an unbalanced panel. The BHPS is used for three reasons: (a) the ability to compare perception- and expenditure-based FP indicators; (b) the re-

\footnotetext{
${ }^{15}$ See also Trinomics (2016).

${ }^{16}$ The UK government recently consulted on amending the official FP definition in England again, see BEIS (2019).

${ }^{17}$ Specifically, single person households, couples with children, lone parents, couples with children and other households.

${ }^{18}$ See https://www.iser.essex.ac.uk/bhps/
} 
interview of households in multiple time periods; and (c) the richness of household information. The more recent Understanding Society ${ }^{19}$ dataset is not used as it does not contain a question specifically asking whether warmth was affordable. ${ }^{20}$

The BHPS is an annual survey administered between 1991 and 2009. The first survey wave aimed to be nationally representative of private households in Great Britain (GB) and sampled 5,500 households. To allow analysis of the devolved administrations, in 1999 two 'booster' samples of 1,500 households were added, covering Scotland and Wales respectively, while in 2001 a booster of 2,000 households was added covering Northern Ireland. In addition to households in the initial samples, households that evolved from the initial set of households ${ }^{21}$ were also interviewed where possible. Our analysis begins in 2001-02 to coincide with the introduction of the Northern Ireland booster sample. Excluding the GB-only data prior to 2001-02 simplifies the interpretation of the results, especially regarding time trends and geographic identifiers.

Inclusion of the booster samples overrepresents households from the devolved administrations and increases the proportion of self-reports of FP/heat affordability difficulties, which are relatively rare in the sample as a whole. Households in the devolved administrations are likely to be at greater risk of FP due to lower average incomes, a less extensive gas grid and cooler temperatures than in England. We incorporate these booster samples in our study because we aim to understand the household characteristics associated with FP rather than to provide population estimates of the prevalence of FP.

To be included in the analysed sample a household must provide complete data for all the explanatory and control variables listed below in at least one survey wave. Households where annual ENEX as a proportion of annual household income was zero or exceeded $100 \%$ were dropped, due to the high probability of measurement error. ${ }^{22}$

The analysis considers two expenditure-based FP indicators and three perception-based indicators. The two expenditure-based indicators are:

\section{1. $10 \%$ ENEXShr}

2. Low Income - High Cost (LIHC) metric

while the three perception-based indicators are:

3. Inability to afford to keep home adequately warm (IAAW)

4. Inability to keep home adequately warm

5. Lack of adequate heating facilities

Our main regression results relate to indicators 1 to 3 , while the results for indicator 5 are presented in Appendix 1. For the detailed definition of indicators 1 and 2, together with the relevant survey questions, see Appendix 3. The question for indicator 3 was structured so that the relevant affordability question was asked only of households that first reported an inability to keep their home adequately warm, which may influence why few households report unaffordable warmth.

\footnotetext{
${ }^{19}$ See https://www.understandingsociety.ac.uk/

20 The closest question is: "In winter, are you able to keep this accommodation warm enough?", see: https://www.understandingsociety.ac.uk/documentation/mainstage/datasetdocumentation/wave/1/datafile/a hhresp/variable/a hheat

${ }^{21}$ For example, when an adult child moved out or a relationship broke up.

22 This also means households whose ENEX is included in their rent are dropped.
} 
A key difference between indicators 1 and 2 and official FP statistics in England is that the official indicators use 'required' (or modelled) ENEX rather than reported ENEX. Modelled ENEX represents the ENEX needed to achieve a given temperature $\left(21^{\circ} \mathrm{C}\right.$ in the primary living area) according to an engineering model. The BHPS does not include modelled ENEX as a variable, while the English Housing Survey's FP dataset does not include the necessary perception-based FP indicators. ${ }^{23}$ Hence the current study compares reported ENEX FP indicators with perception-based indicators.

The FP literature ${ }^{24}$ has suggested that modelled ENEX is preferable to reported ENEX because the latter is likely to under-record FP, as the poorest households may 'restrict' their ENEX due to affordability constraints. However, Deller and Waddams Price (2017) indicate ${ }^{25}$ it is simplistic to assume that reported ENEX always under-records FP. They find that the relationship between FP rates calculated using reported and modelled ENEX is complex: for some groups and time periods FP rates based on reported ENEX appear higher. Furthermore FP statistics based on modelled ENEX can only be as good as the underlying ENEX model, for example, Summerfield et al. (2019) notes systematic discrepancies between the actual gas consumption of larger older dwelling in the UK and that predicted by standard models. Summerfield et al. suggest a range of possible explanations for this discrepancy, including householders' heating patterns differing to those in other dwellings, the thermal properties of solid walls being different than expected and the potential use of fuels other than gas or electricity for heating.

A potential issue with the current data is seasonality due to the variability in external temperatures and internal heating needs. This may be particularly significant for perception-based indicators, if responses are influenced by household experiences immediately before interview. ${ }^{26}$ To deal with seasonality, interview month dummies are included in the main regressions.

A further known issue with the BHPS ENEX data, which may affect the results regarding persistence in Appendix 2, is the potential for the data to be bunched at 'round' amounts, e.g. multiples of $£ 25$. Pudney (2008) notes this can mean over reporting of the year-to-year changes in ENEX as households move between different rounding points. While this might contribute to the limited persistence of ENEX-based FP, it does not explain the limited persistence of perception-based FP.

The explanatory variables in the main regressions are split into two groups: (i) Policymaking variables, and (ii) Best Predictor variables. The 'Policymaking' variables include the main demographic, socio-economic and housing indicators that are available to policymakers to coordinate/target large scale policies. The Best Predictor variables include factors, such as housing condition indicators, which are less likely to be available for all households. Also, many of the Best Predictor variables refer to different aspects of poverty, hence, while highly correlated with FP they may provide limited additional insight for understanding FP beyond confirming that a 'poor' household is likely to suffer deprivation across several dimensions.

The Policymaking variables are: UK nation (devolved administration), dwelling ownership, dwelling type, whether dwelling has central heating, whether dwelling has a gas connection, whether the household head is aged under $65,65-75$ or over $75^{27}$, whether the household head is unemployed,

\footnotetext{
${ }^{23}$ See the variable list in BEIS (2017).

${ }^{24}$ See Hills (2012), Liddell et al. (2012) and Thomson et al (2017).

${ }^{25}$ See Section 7 and Appendix 2.

${ }^{26}$ While reported ENEX involves an annual figure, seasonality could affect it, if households receive multiple bills a year and base their annual estimate on their most recent payment/bill.

${ }^{27}$ To ease interpretation we did not include a separate variable for retirement status. As such, the effect of the age variable will also be capturing the fact that most of these older household heads will also be retired.
} 
whether the household receives income from investments, whether incapacity benefit or housing benefit or income support is received by the household ( 3 variables), whether the household head is a single parent, whether the household contains children, the number of household members and the number of cars owned.

The Best Predictor variables are: number of rooms in dwelling ${ }^{28}$, whether a household has problems with loan repayments or housing payments ( 2 variables), whether a household states it cannot afford a holiday or to replace furniture or new clothes or to eat meat on alternate days or to invite visitors for food/drink ( 5 variables) ${ }^{29}$, whether a household has a satellite dish or cable TV or colour TV or VCR or freezer or washing machine or tumble dryer or dishwasher or microwave or CD player or home computer (11 variables), whether a household states its dwelling suffers from condensation or a leaky roof or damp walls/floors or rot in windows/floors (4 variables) and whether a household states there is crime in the local area.

In some regressions, perception-based FP indicators are also related to additional explanatory variables, namely annual household income, annual reported ENEX and annual net housing costs. ${ }^{30}$ All monetary amounts are converted to 2008 prices using the Consumer Price Index. As a control, survey wave dummies are included in all regressions.

\section{Methodology}

To identify the household characteristics associated with each FP indicator logit models are used. The dependent variable, $y_{i t}$, takes a value of 1 when household $i$ is FP in period $t$ and a value of 0 when a household is not FP. For each household the probability, $p_{i t}$, of being FP in period $t$ can be expressed as:

$$
y_{i t}=\left\{\begin{array}{ccc}
1 & \text { with probability } & p_{i t} \\
0 & \text { with probability } & 1-p_{i t}
\end{array}\right\}
$$

where the probability of being FP, $p_{i t}$, is modelled as:

$$
p_{i t}=\operatorname{Prob}\left(y_{i t}=1 \mid \boldsymbol{x}_{\boldsymbol{i t}}\right)=F\left(\boldsymbol{x}_{\boldsymbol{i t}}{ }^{\prime} \gamma\right)
$$

Here $p_{i t}$ is the probability that household $i$ is FP in period $t$ given the vector of potentially time varying explanatory variables for household $i, \boldsymbol{x}_{\boldsymbol{i} \boldsymbol{t}}$. This probability can be expressed as a function of $\boldsymbol{x}_{\boldsymbol{i t}}$ multiplied by the regression coefficients, $\boldsymbol{\gamma}$. The logit model assumes the error process for the latent variable behind the model is logistically distributed and $F($.$) is the logistic cumulative$ distribution function. The model is estimated using maximum likelihood estimation following a pooled cross-section approach. As the error terms for each household, $i$, are likely correlated through time, cluster robust standard errors are used where each household, $i$, is treated as a separate cluster.

\footnotetext{
28 The BHPS's number of rooms excludes kitchens, bathrooms and any rooms let to individuals who are not a household member.

${ }^{29}$ Prior to a household reporting an inability to afford an item they had expressed their desire to consume the item.

${ }^{30}$ Housing costs less any housing benefit received. If a dwelling is owned outright or rent free, net housing costs are zero.
} 
Average marginal effects (AMEs) are reported, which are the average percentage point increase in the probability of a household being FP associated with a change in a particular explanatory variable. For each FP indicator a range of regression specifications is used to highlight points relevant to the policy discussion. For all the FP indicators, separate regressions were run using: (i) the Policymaking variables only, and (ii) the Policymaking plus Best Predictor variables. For policy discussions, the regressions only using the Policymaking variables are most relevant.

Since the $10 \%$ and LIHC indicators are calculated directly from household income, ENEX and (for the LIHC indicator) housing costs, these three variables are not included as explanatory variables in the regressions for the expenditure-based indicators. However, for the perception-based indicators, their relationship with ENEX, income and housing costs are of central importance. Hence, before the main regressions for indicators 3 and 5 are reported, additional regressions are run to assess how the perception-based indicators relate to the component parts of the expenditure-based FP indicators. For the perception-based indicators, two separate types of main regressions are run: (a) including ENEX, income and housing cost as explanatory variables; and (b) excluding these variables to enable a direct comparison of the socio-economic groups associated with FP across the perception- and expenditure-based indicators.

As a secondary question in the current paper is FP's persistence, the main regressions are also repeated including a one-period lag of the dependent variable as an explanatory variable. Alternatively, the lag can be interpreted as controlling for unobservable household characteristics associated with FP. When a lag is included, the sample is restricted to those households that additionally have data for the four analysed FP indicators in the previous survey wave.

\section{Descriptive Statistics}

\subsection{The frequency of different fuel poverty indicators}

Figure 1 presents the unweighted percentage of households reporting each FP indicator by year.

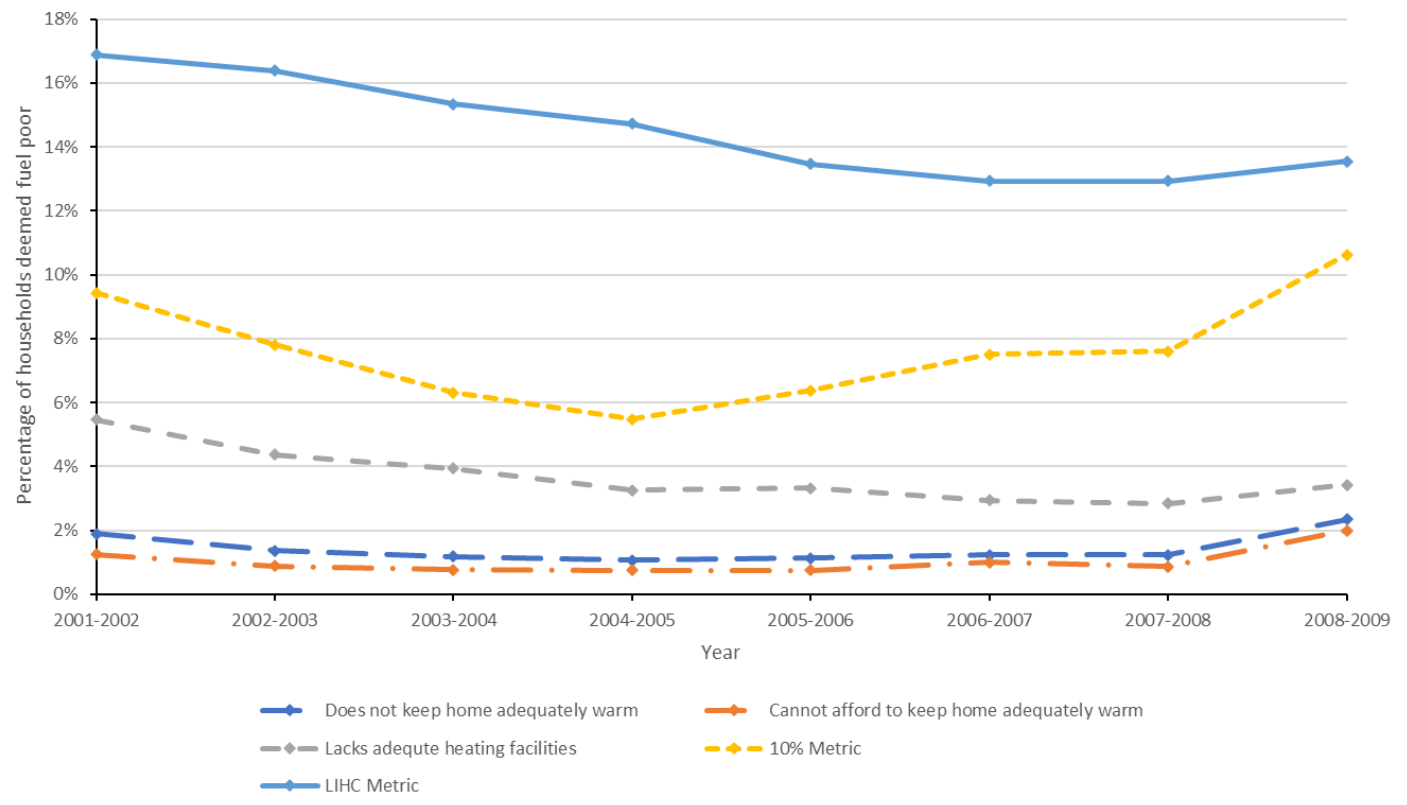

Figure 1 : Rates of alternative fuel poverty indicators in the analysed sample (unweighted), 200102 to 2008-09 
Figure 1 shows a fundamental gap between the proportion of the households identified as IAAW FP and those identified as $10 \%$ or LIHC FP. The percentage of households reporting IAAW FP is $2 \%$ or below, while the percentage of FP households according to the $10 \%$ indicator is always above $5 \%$ and for the LIHC indicator is always above $13 \%{ }^{31}$

The dip in 10\% FP around 2004-05 and its subsequent increase likely relate to the changing price of energy over the period. ${ }^{32}$ In contrast, both the LIHC and lack of adequate heating facilities indicators show a general decline across the time period. Between 2001-02 and 2008-09 the percentage of households reporting a lack of adequate heating facilities fell by 2.0 percentage points and the rate of LIHC FP fell by 3.3 percentage points. The trend in LIHC FP may be linked to the oversampling of households in the devolved administrations where incomes of the sampled households grew faster. Between 2001-02 and 2008-09 the unweighted median household income in England rose in real terms by $10.6 \%$, while in Wales it rose by $20.1 \%$, in Scotland by $26.1 \%$ and in Northern Ireland by $23.9 \%$

The last point to note regarding Figure 1 is the increase in 10\% FP and the proportion of households reporting IAAW FP between 2007-08 and 2008-09. The percentage of households in 10\% FP rose by 3.0 percentage points, while the percentage of households reporting IAAW more than doubled, rising by 1.2 percentage points. These increases coincide with a growth in ENEX that exceeded the growth in household incomes. Between 2007-08 and 2008-09 the median income of all households rose $1.8 \%$ in real terms, while median ENEX rose by $9.7 \%$ in real terms.

\subsection{The overlap between FP indicators}

The very different FP rates in Figure 1 are associated with the limited overlap between the different FP indicators. Figure 2 illustrates the extent of overlap between the three perception-based FP indicators when data is pooled across the time period. Of all the observations ${ }^{33}$ of households reporting either an inability to keep their home warm or a lack of adequate heating facilities, a clear majority, $68.5 \%$, only report a lack of adequate heating facilities. Only $20.7 \%$ of those reporting a lack of adequate heating facilities reported an inability to keep adequately warm.

The majority of households who felt unable to keep their home adequately warm, $71.6 \%$, were unable to do so because they felt it was unaffordable. Nevertheless, this implies that for almost a third of households who were unable to keep their home adequately warm, this was caused by something other than affordability. Of these, $53.5 \%$ reported a lack of adequate heating facilities.

\footnotetext{
${ }^{31}$ Figure 8 in Appendix 4 repeats Figure 1 with weights applied to provide UK population estimates. Applying weights does not alter the finding that the rates of perception-based FP are much lower than expenditurebased FP.

32 The time path of 10\% FP broadly corresponds to that in Figure 15, Deller and Waddams Price (2017), based on data for England from the Living Costs and Food Survey.

${ }^{33}$ An observation is a particular household in a particular year.
} 


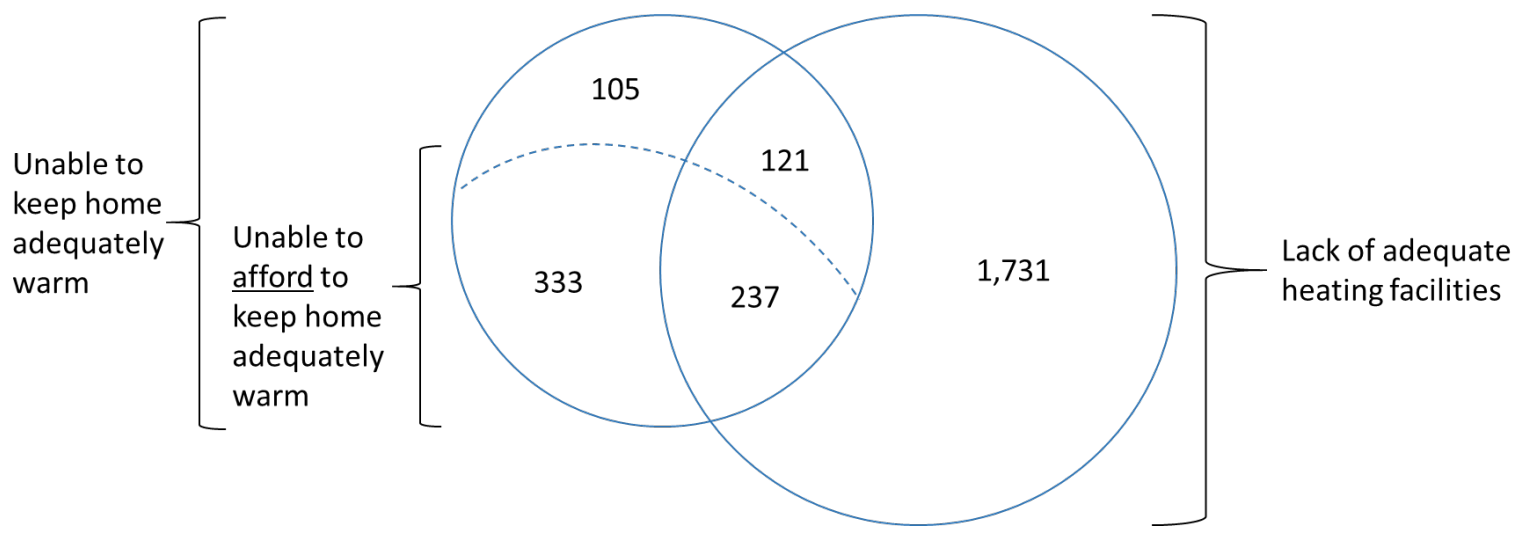

Figure 2: The overlap of the perception-based fuel poverty indicators, pooled data 2001-02 to 2008-09 (number of observations, areas not to scale)

Figure 3 shows the overlap between our main FP indicators of interest: reporting IAAW, the 10\% metric and the LIHC metric. Figure 3 emphasises the limited overlap between the main FP indicators. Of all the observations where a household reported at least one of the FP indicators, in only $1.1 \%$ of cases were all three FP indicators reported simultaneously by a household. Figure 3 also shows the asymmetric overlap between the $10 \%$ and LIHC indicators. While $77.5 \%$ of observations that were $10 \%$ FP were also LIHC FP, only $40.4 \%$ of observations that were LIHC FP were $10 \%$ FP. More generally, Table 11 in Appendix 4 reports the Pearson correlation coefficients between the five FP indicators. All of the correlation coefficients are significantly different from zero at the $1 \%$ level, but the magnitudes of the correlation coefficients vary considerably. For example, the correlation coefficient between the $10 \%$ and LIHC indicators is 0.511 , while the correlation coefficient between the $10 \%$ indicator and reporting IAAW is 0.059 .

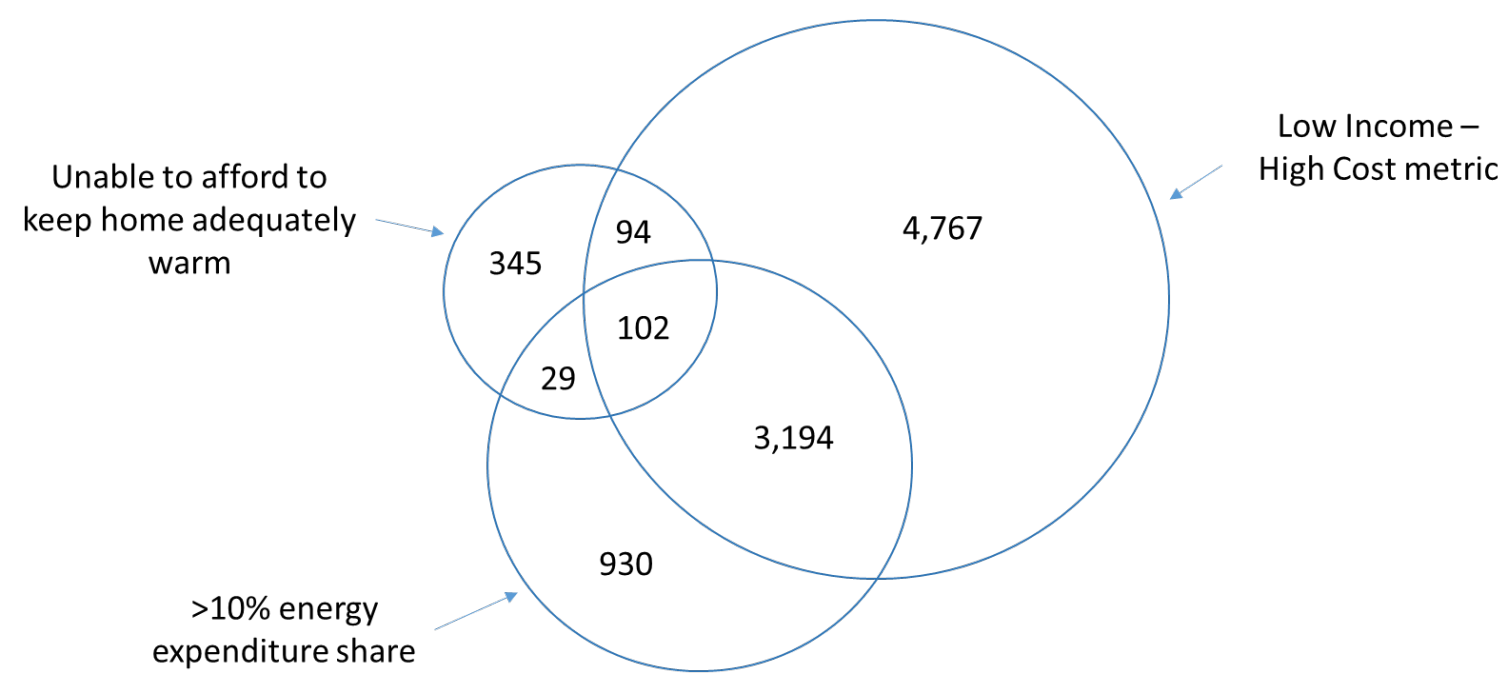

Figure 3: The overlap of the three analysed fuel poverty indicators, pooled data 2001-02 to 200809 (number of observations, areas not to scale) ${ }^{34}$

The panel nature of the BHPS confirms that the lack of overlap between $10 \%$ FP or LIHC FP and households reporting IAAW occurs in multiple time periods. Figure 4 shows that only a small proportion of households identified as $10 \%$ or LIHC FP in each survey wave also report IAAW. In none of the years studied does the proportion of $10 \%$ or LIHC FP households reporting IAAW exceed

\footnotetext{
${ }^{34}$ Note that only the indicator 'Unable to afford to keep home adequately' is common to both Figures 2 and 3. In both Figures there were a total of 570 observations of this FP indicator being reported.
} 
$5 \%$. While the overlap remains low, Figure 4 shows an uptick in the overlap between 2007-2008 and 2008-2009. ${ }^{35}$

Despite the limited overlap, the rate of perception-based FP is higher among expenditure FP households than in the general sample. For example, across the time period, the percentage of $10 \%$ FP households reporting IAAW is 2.3-3.7 times the percentage in the general sample. ${ }^{36}$

Overall, Figure 3 and Figure 4 raise fundamental questions about the phenomena identified by the expenditure-based FP indicators, and whether they effectively identify households living in the cold. Palmer et al. (2008) also find a limited overlap between 10\% FP, based on modelled ENEX, and being unable to afford warmth. Using data from the 2005 English Housing Condition Survey, they find that only $6 \%$ of those identified as $10 \%$ FP stated that their living room was not kept comfortably warm in winter and that the reason for this was cost. ${ }^{37}$

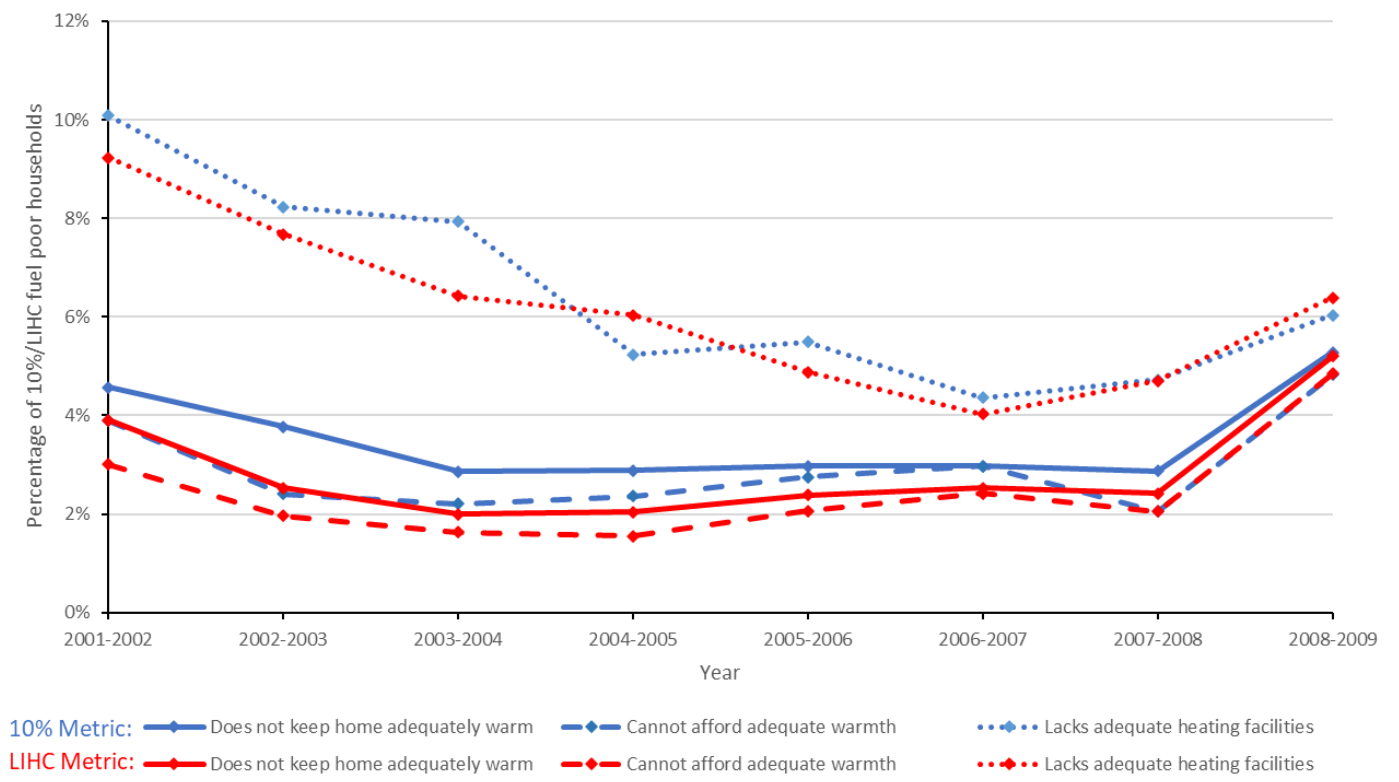

Figure 4: Percentage of 10\%/LIHC fuel poor households reporting perception-based fuel poverty in the analysed sample, 2001-02 to 2008-09

Dubois (2012), Boardman (2011) and Tirado Herrero (2017) suggest that the low rates of perceptionbased FP compared to expenditure-based FP results from households being unable or unwilling to self-identify as FP. This suggests that there is a need to further investigate and understand the discrepancies between indicators to gain additional insights about FP. In particular, the discrepancies suggest that there are benefits from turning FP from a high-level intuitive or statistical concept into a set of observable circumstances/behaviours which are closer to household's experience and which can be robustly measured and addressed.

Beyond an unwillingness to self-identify, there are a range of possible explanations for the discrepancy between the expenditure- and perception-based FP indicators. For example, the thresholds of the expenditure-based FP metrics could be a poor reflection of the boundary where the majority of householders consider energy to become unaffordable. This is possible since the

\footnotetext{
35 The increase in the overlap with 'Lacks adequate heating facilities' begins a year earlier in 2006-2007

${ }^{36}$ The percentage of LIHC FP households reporting IAAW is 2.1-2.8 times the percentage in the general sample.

37 See pg16. Also, Palmer et al. (2008) find that, of those households reporting that their living room was not kept comfortably warm in winter due to cost, only $20 \%$ were identified as $10 \%$ FP.
} 
origins of the expenditure-based indicators did not explicitly consider householders' opinions of the level of income devoted to ENEX which might be considered unaffordable. ${ }^{38}$ Alternatively, householders may view energy as a necessity and so choose to spend a high proportion of their income on energy to ensure adequate warmth. Here the main impact of high energy costs is restricting consumption of other goods. It is difficult to move beyond intuitive explanations for the discrepancies without collecting temperature data for individual households.

It seems unlikely that the lack of overlap is due to the data coming from a period of relatively low energy prices and easy energy affordability. While Deller and Waddams Price (2018) ${ }^{39}$ show that the period 2001-02 to 2008-09 corresponded with a long-term low for median ENEXShr in the UK, they also show that median ENEXShr had largely returned to its long-term level by 2009. Although the proportion of $10 \%$ FP households reporting IAAW rose from $2.1 \%$ to $4.8 \%$ between $2007-08$ and 2008-09, the overlap remains low.

In terms of the BHPS dataset, one factor that may contribute to the lack of overlap is that IAAW is the result of a binary Yes/No question, whereas householders may view energy affordability as a spectrum. This may be compounded by the question structure which first requires households to state they were unable to achieve adequate warmth in their home, before asking whether this was due to it being unaffordable.

Figure 5 depicts the converse overlap to that shown in Figure 4, i.e. the percentage of households reporting perception-based FP who are also identified as being expenditure FP. A higher proportion of those reporting perception-based FP are also FP by expenditure based measures than vice versa. Among the perception-based FP indicators, Figure 5 shows those reporting IAAW have the highest rates of expenditure FP, with a noticeably higher overlap with LIHC FP than with $10 \%$ FP: among those reporting IAAW, the rate of LIHC FP is between 7.3 and 15.2 percentage points higher than the rate of $10 \%$ FP. The higher rate of overlap with LIHC FP is unsurprising given that Figure 1 shows that a greater proportion of households are in LIHC FP than $10 \%$ FP.

It seems likely that a household reporting IAAW, but devoting a low proportion of income to ENEX, will be restricting their energy consumption for affordability reasons. However, as the temperature deemed adequate by these households is unknown, one cannot be certain of appropriate policy interventions across the households in this situation. Some of the discrepancy could result from relatively well-off households seeking particularly high temperatures.

\footnotetext{
${ }^{38}$ Boardman (1991) chose the 10\% indicator as in the 1988 UK Food and Expenditure Survey devoting 10\% of expenditure to energy corresponded to the average ENEXShr of the $30 \%$ of households with the lowest incomes and was twice the average ENEXShr for the population as a whole.

${ }^{39}$ See Figure 5 and Figure A2.3.
} 


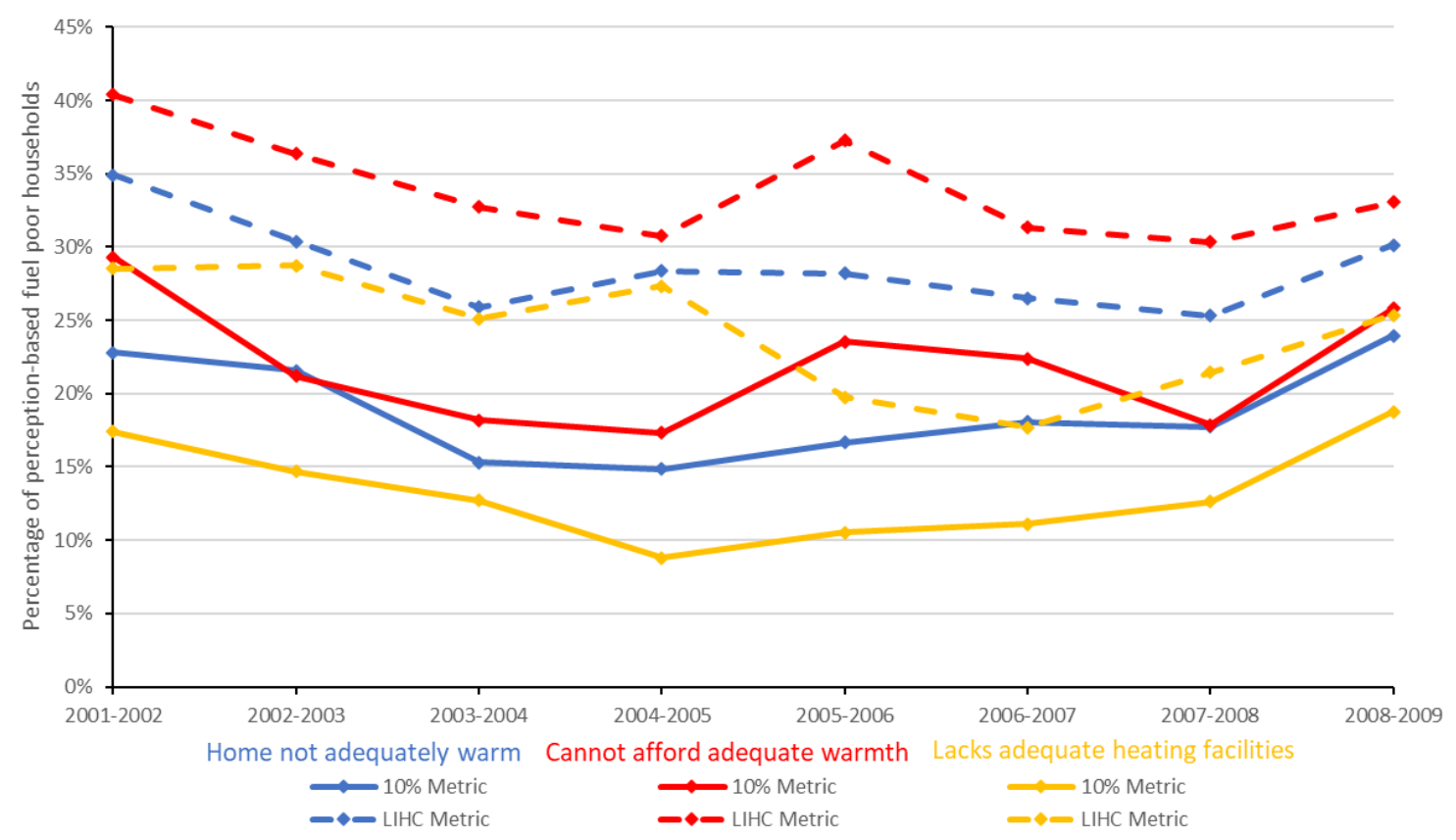

Figure 5: Percentage of perception-based fuel poor households identified as $10 \%$ or LIHC fuel poor in the analysed sample, 2001-02 to 2008-09

\subsection{Characteristics of Households by Fuel Poverty Indicator}

Table 1 details the substantial differences in the characteristics of households identified as FP according to each of the indicators. As expected, FP households have lower average incomes than the whole sample regardless of indicator, although the $10 \%$ metric is associated with a particularly low median income of $£ 7,483$, only $55 \%$ of the median income of IAAW households.

Households in 10\% FP also have the highest median ENEX and ENEXShr. ${ }^{40}$ Perhaps more surprising is that the median ENEX for IAAW households is close to the whole sample average ( $£ 776$ vs $£ 797$ ) and the median ENEXShr for this group is above that of the whole sample (5.9\% vs 3.2\%), providing little direct evidence of any 'rationing' of energy consumption among IAWW households. However, IAAW households may still be failing to achieve an adequate home temperature if their dwelling characteristics and/or unit energy price mean this expenditure translates into less heat than for other households.

${ }^{40}$ These households could be paying for their high ENEX by drawing down assets or borrowing money. 


\begin{tabular}{|c|c|c|c|c|c|}
\hline Household Characteristic & $\begin{array}{l}\text { Whole } \\
\text { sample }\end{array}$ & $\begin{array}{l}\text { Inability to } \\
\text { afford warmth }\end{array}$ & $\begin{array}{l}\text { Lack of adequate } \\
\text { heating facilities }\end{array}$ & $10 \%$ Metric & LIHC Metric \\
\hline Median household income ( $f, 2008$ prices) & 25,499 & 1313,714 & 18,967 & 7,483 & 11,550 \\
\hline Median energy expenditure ( $f, 2008$ prices) & 797 & 776 & 767 & 1,124 & 1,033 \\
\hline Median energy expenditure share (\%) & 3.2 & 5.9 & 4.0 & 13.6 & 8.9 \\
\hline Median net housing cost ( $f, 2008$ prices) & 2,042 & 678 & 2,246 & 0 & 173 \\
\hline$\%$ in Northern Ireland & 18.6 & 27.2 & 21.5 & 43.1 & 33.6 \\
\hline $\begin{array}{l}\% \text { renting from local authority/housing } \\
\text { association }\end{array}$ & 17.8 & 40.4 & 36.1 & 28.5 & 35.6 \\
\hline$\%$ with household head aged over 65 & 25.4 & 17.2 & 16.2 & 37.1 & 29.7 \\
\hline$\%$ containing children & 31.6 & 27.5 & 35.4 & 23.1 & 39.3 \\
\hline$\%$ with no central heating & 5.8 & 22.8 & 34.2 & 9.2 & 7.5 \\
\hline$\%$ with no gas connection & 25.1 & 42.6 & 49.9 & 42.4 & 35.9 \\
\hline Mean number of household members & 2.5 & 2.1 & 2.5 & 1.9 & 2.6 \\
\hline Mean number of rooms & 4.6 & 4.0 & 3.9 & 4.5 & 4.4 \\
\hline$\%$ stating can't afford holiday & 13.9 & 68.6 & 38.0 & 29.5 & 31.2 \\
\hline$\%$ stating can't afford to replace furniture & 7.3 & 58.1 & 21.4 & 15.2 & 15.8 \\
\hline$\%$ stating can't afford visitors for food/drink & 4.3 & 32.5 & 14.1 & 10.1 & 10.4 \\
\hline$\%$ reporting a leaky roof & 3.3 & 13.7 & 16.0 & 5.0 & 4.4 \\
\hline$\%$ reporting damp walls/floors & 7.0 & 31.6 & 33.8 & 9.4 & 10.3 \\
\hline$\%$ reporting rot in windows/floors & 5.1 & 21.9 & 24.7 & 7.5 & 7.6 \\
\hline Number of observations & 55,772 & 570 & 2,089 & 4,255 & 8,157 \\
\hline Number of households & 10,465 & 380 & 1,293 & 2,192 & 3,547 \\
\hline
\end{tabular}

Table 1: Characteristics of those classified as fuel poor according to each indicator

\section{Results}

The main regression results, incorporating the full set of explanatory variables, are provided in Table 4 and Table 6. Table 4 is the first analysis of IAAW FP using the BHPS. ${ }^{41}$ In Table 6 results for the $10 \%$ and LIHC indicators are presented. Appendix 1 reports equivalent regression results for households reporting a lack of adequate heating facilities. When discussing Table 6 we focus on the differences to the household characteristics associated with reporting IAAW.

Prior to these main regression tables, univariate regressions are reported between the different FP indicators and, for the perception-based indicators, simplified multivariate regressions indicate the associations with ENEX, income and ENEXShr.

\subsection{Self-Reports of Unaffordable Warmth}

Table 2 indicates that all three alternative FP indicators, in univariate regressions, are positively associated with reporting IAAW at the $1 \%$ level. However, the magnitude of the association is stronger between the two perception-based indicators: on average reporting a lack of adequate heating facilities is associated with a 10.7 percentage point increase in the probability of reporting IAAW, whereas being LIHC FP is only associated with a 1.6 percentage point increase. Table 2 also indicates persistence, as reporting IAAW in period $t-1$ increases the probability of reporting IAAW in period $t$ by 32.7 percentage points. The argument made in Appendix 2 is that, if persistence is identified, its magnitude may influence the appropriateness of alternative FP remedies.

\footnotetext{
${ }^{41}$ Roberts et al. (2015) use the same dataset to consider the dynamics of $10 \%$ FP.
} 


\begin{tabular}{|c|c|c|c|c|}
\hline \multirow[b]{2}{*}{ Explanatory Variable } & \multicolumn{4}{|c|}{$\begin{array}{c}\text { Inability to afford adequate warmth } \\
\text { indicator }\end{array}$} \\
\hline & (1) & (2) & (3) & (4) \\
\hline 1. 10\% fuel poor & $0.022^{* * *}$ & & & \\
\hline 2. LIHC fuel poor & & $0.016^{* * *}$ & & \\
\hline 3. Reports a lack of adequate heating facilities & & & $0.107^{* * *}$ & \\
\hline 4. Reports an inability to afford adequate warmth, period t-1 & & & & $0.327^{* * *}$ \\
\hline Log likelihood & $-3,113.96$ & $-3,109.59$ & $-2,763.33$ & $-2,183.16$ \\
\hline P-value, likelihood ratio test of joint significance & 0.000 & 0.000 & 0.000 & 0.000 \\
\hline Policymaking variables & No & No & No & No \\
\hline Best predictor variables & No & No & No & No \\
\hline Number of observations & 55,772 & 55,772 & 55,772 & 47,493 \\
\hline Number of households & 10,465 & 10,465 & 10,465 & 9,400 \\
\hline
\end{tabular}

Notes: * indicates statistical significance at the $10 \%$ level, ** indicates significance at the $5 \%$ level and *** indicates significance at the $1 \%$ level. The table reports average marginal effects on the probability of a household reporting an inability to afford to keep their home adequately warm. A blank space indicates a variable was not included in the regression. In column (4) 8,279 observations were dropped as the sample is restricted to observations where the four analysed fuel poverty indicators are available in period $\mathrm{t}-1$.

Table 2: Average marginal effects of alternative fuel poverty indicators on the probability of reporting an inability to afford to keep one's home adequately warm, univariate regressions

The $10 \%$ and LIHC indicators are binary indicators which are formed from income and ENEX, and regressions exploring the relationship of IAAW to these underlying variables are reported in Table 3.

\begin{tabular}{|c|c|c|c|c|c|c|c|c|c|c|}
\hline \multirow[b]{2}{*}{ Explanatory Variable } & \multicolumn{10}{|c|}{ Inability to afford adequate warmth indicator } \\
\hline & (1) & (2) & (3) & (4) & (5) & (6) & (7) & (8) & (9) & (10) \\
\hline 1. Energy expenditure share (\%) - linear & $0.000 * * *$ & & & & & & & & & \\
\hline 2. Energy expenditure share $(\%)$ - quadratic ${ }^{1}$ & & $0.001 * * *$ & & & & & & & & \\
\hline 3. Annual energy expenditure ( $f$ hundreds, & & & -0.000 & & & & $0.000 * * *$ & & & \\
\hline (U) - hundreds & & & & & & & & & & \\
\hline $\begin{array}{l}\text { 4. Annual energy expenditure ( } \mathrm{f} \text { hundreds, } \\
\text { 2008) - quadratic }\end{array}$ & & & & -0.000 & & & & $0.000^{* * *}$ & $0.000^{* * *}$ & $0.000 * * *$ \\
\hline $\begin{array}{l}\text { 5. Annual household income ( } \mathrm{f} \text { thousands, } \\
\text { 2008) - linear }\end{array}$ & & & & & $-0.001^{* * *}$ & & $-0.001 * * *$ & & & \\
\hline $\begin{array}{l}\text { 6. Annual household income ( } f \text { thousands, } \\
2008 \text { ) - quadratic }\end{array}$ & & & & & & $-0.001^{* * *}$ & & $-0.001 * * *$ & $-0.000 * * *$ & $-0.000 * * *$ \\
\hline $\begin{array}{l}\text { 7. Annual net housing costs ( } f \text { hundreds, 2008)- } \\
\text { quadratic }\end{array}$ & & & & & & & & & $0.000 * * *$ & $0.000 * * *$ \\
\hline $\begin{array}{l}\text { 8. Reports an inability to afford adequate } \\
\text { warmth, period t-1 }\end{array}$ & & & & & & & & & $0.231^{* * *}$ & $0.201^{* * *}$ \\
\hline 9. No central heating & & & & & & & & & & $0.011 * * *$ \\
\hline 10. No gas connection & & & & & & & & & & $0.003^{* * *}$ \\
\hline Log likelihood & $-3,136.51$ & $-3,067.88$ & $-3,179.30$ & $-3,179.29$ & $-3,020.21$ & $-3,018.51$ & $-3,013.75$ & $-3,009.61$ & $-2,103.10$ & $-2,074.73$ \\
\hline $\begin{array}{l}\text { P-value, likelihood ratio test of joint } \\
\text { significance }\end{array}$ & 0.000 & 0.000 & 0.555 & 0.678 & 0.000 & 0.000 & 0.000 & 0.000 & 0.000 & 0.000 \\
\hline Policymaking variables & No & No & No & No & No & No & No & No & No & No \\
\hline Best predictor variables & No & No & No & No & No & No & No & No & No & No \\
\hline Number of observations & 55,772 & 55,772 & 55,772 & 55,772 & 55,772 & 55,772 & 55,772 & 55,772 & 47,973 & 47,973 \\
\hline Number of households & 10,465 & 10,465 & 10,465 & 10,465 & 10,465 & 10,465 & 10,465 & 10,465 & 9,400 & 9,400 \\
\hline
\end{tabular}

Notes: ${ }^{*}$ indicates statistical significance at the $10 \%$ level, ${ }^{* *}$ indicates significance at the $5 \%$ level and ${ }^{* * *}$ indicates significance at the $1 \%$ level. The table reports average marginal effects on the probability of a household reporting an inability to afford to keep their home adequately warm. A blank space indicates the variable was not included in the regression. In columns (9) and (10) 8,279 observations were dropped as the sample is restricted to cases where the lags of the four analysed fuel poverty indicators are available. In many of the regressions some observations where households reported they could afford adequate warmth were completely determined. In column (5) 29 obervations were completely determined, in (6) it was 10 observations, in (7) it was 31 observations, in (8) it was 12 observations, in (9) it was 22 observations and in (10) it was 16 observations.

${ }^{1}$ Where a variable is labelled as quadratic the regression included both a linear and squared term of the variable; the reported average marginal effect for such variables is the combined change in probability associated with the linear and squared terms.

Table 3: Average marginal effects of income and energy expenditure on the probability of reporting an inability to afford to keep one's home adequately warm, alternative specifications

In Table 3 columns 1 to 6 report univariate regressions when ENEXShr, ENEX and income are treated separately as linear relationships (columns 1, 3 and 5) and quadratic relationships (columns 2, 4 and 6). First, in columns 3 and 4 the relationship between ENEX and IAAW is insignificant. Second, there 
is a positive relationship between ENEXShr and IAAW, and a negative relationship between household income and IAAW. Third, while both quadratic and linear relationships between ENEXShr, income and IAAW are statistically significant at the 1\% level, Figure 11 and Figure 12 in Appendix 4 show that the actual relationships are non-linear.

Furthermore, using ENEXShr as an explanatory variable places a restriction on the relationship between ENEX, income and IAAW; ENEXShr implies the coefficient on income is the inverse of the coefficient on ENEX. In columns 8 to 10 this restriction is relaxed, with ENEX and household income included separately both as linear and squared terms. Statistical tests reject the equality of the coefficients on income and ENEX (used separately as absolute values in column 8) confirming that they should be included as separate variables. Columns 8-10 indicate that, once household income is controlled for, there is a statistically significant relationship between ENEX and IAAW. Table 3 also shows that the magnitude of the relationship between ENEX, income and IAAW is low. For example, equation 8 implies that a $f 1,000$ increase in household income is associated with a 0.1 percentage point drop in the probability of reporting IAAW; while a $f 100$ increase in ENEX is associated with less than a 0.05 percentage point increase in the probability of IAAW. The U-shaped relationship between ENEX and IAAW in Figure 10 in Appendix 4 is consistent with both particularly high and particularly low ENEX levels being associated with FP.

In columns 9 and 10, annual net housing costs are included, since housing costs are the third component of the LIHC indicator, while the first lag of IAAW is introduced as a control. A positive non-linear relationship is found between net housing costs and IAAW. In column 10 indicator variables for lacking central heating or a gas connection are included; that both variables are significant at the $1 \%$ level indicates that reporting these heating system characteristics increases the probability of reporting IAAW, even after controlling for how these characteristics can increase ENEX.

Table 4 reports a further 8 regressions; columns 1, 2, 5 and 6 include income, ENEX and net housing costs, while columns $3,4,7$ and 8 exclude these variables to enable a direct comparison with the regression results for the $10 \%$ and LIHC indicators in Table 6 . In columns 2, 4, 6, and 8 the first lag of IAAW is included. Columns 1 to 4 consider the 'Policymaking' explanatory variables, while columns 5 to 8 also include the 'Best Predictor' variables. Wald tests indicate that in all four regression specifications, the inclusion of the Best Predictor variables improves the specification, i.e. the coefficients of these additional variables are jointly different from zero at the $1 \%$ significance level.

Compared to the simpler regressions in Table 3, one difference in Table 4 is that both ENEX and net housing costs are statistically insignificant. The insignificance of at ENEX is partly linked to the inclusion of survey wave dummies which likely control for most of the intertemporal variation in ENEX. In a regression using the Policymaking variables but without the lag of IAAW or the wave dummies, ENEX is statistically significant at the $1 \%$ level. That net housing costs is insignificant likely results from the detailed housing characteristic variables included in the Table 4 regressions being better predictors of IAAW than the more general housing costs variable. 


\begin{tabular}{|c|c|c|c|c|c|c|c|c|}
\hline \multirow[b]{3}{*}{ Explanatory Variable } & \multicolumn{8}{|c|}{ Inability to afford adequate warmth indicator } \\
\hline & \multicolumn{4}{|c|}{ Policymaking Explanatory Variables } & \multicolumn{4}{|c|}{$\begin{array}{c}\text { Policymaking plus Best Predictor } \\
\text { Explanatory Variables }\end{array}$} \\
\hline & (1) & (2) & (3) & (4) & (5) & (6) & (7) & (8) \\
\hline $\begin{array}{l}\text { 1. Unable to afford adequate warmth in the } \\
\text { home, period t-1 }\end{array}$ & & $0.148^{* * *}$ & & $0.159 * * *$ & & $0.062 * * *$ & & $0.063^{* * *}$ \\
\hline $\begin{array}{l}\text { 2. Annual household income ( } f \text { thousands, } \\
\text { 2008) - quadratic }\end{array}$ & $-0.000 * * *$ & $-0.000 * * *$ & & & $-0.000 * * *$ & $-0.000 * *$ & & \\
\hline $\begin{array}{l}\text { 3. Annual energy expenditure ( } f \text { hundreds, } \\
\text { 2008) - quadratic }\end{array}$ & 0.000 & 0.000 & & & -0.000 & -0.000 & & \\
\hline $\begin{array}{l}\text { 4. Annual net housing costs ( } f \text { hundreds, 2008) } \\
\text { - quadratic }\end{array}$ & 0.000 & 0.000 & & & 0.000 & 0.000 & & \\
\hline 5. 2001-02 wave & $0.003^{* *}$ & $0.003^{*}$ & $0.003^{* *}$ & $0.003^{*}$ & $0.003^{* *}$ & $0.004^{* *}$ & $0.003^{* * *}$ & $0.004^{* *}$ \\
\hline 6. 2003-04 wave & -0.001 & 0.000 & -0.001 & 0.000 & 0.001 & 0.001 & 0.001 & 0.001 \\
\hline 7. 2004-05 wave & -0.000 & 0.001 & -0.000 & 0.001 & 0.001 & 0.002 & 0.001 & 0.002 \\
\hline 8. 2005-06 wave & -0.000 & 0.001 & -0.000 & 0.001 & 0.001 & 0.002 & 0.001 & 0.002 \\
\hline 9. 2006-07 wave & 0.002 & $0.004^{* *}$ & 0.002 & $0.004^{* *}$ & $0.004^{* * *}$ & $0.005^{* * *}$ & $0.004^{* * *}$ & $0.005^{* * *}$ \\
\hline 10. 2007-08 wave & 0.002 & 0.001 & 0.002 & 0.001 & $0.004 * *$ & $0.003^{*}$ & $0.003 * *$ & 0.002 \\
\hline 11. 2008-09 wave & $0.014 * * *$ & $0.014 * * *$ & $0.014 * * *$ & $0.014^{* * *}$ & $0.014 * * *$ & $0.014^{* * *}$ & $0.014 * * *$ & $0.013^{* * *}$ \\
\hline 12. Wales & 0.003 & 0.002 & $0.003^{*}$ & $0.003^{*}$ & $0.003^{*}$ & $0.003^{*}$ & $0.003^{*}$ & $0.003^{* *}$ \\
\hline 13. Scotland & 0.001 & 0.001 & 0.002 & 0.001 & $0.004 * *$ & $0.004^{* * *}$ & $0.004 * *$ & $0.004^{* * *}$ \\
\hline 14. Northern Ireland & -0.001 & 0.000 & 0.000 & 0.001 & 0.003 & $0.004^{* *}$ & 0.003 & $0.004 *$ \\
\hline 15. Owned with mortgage & 0.000 & -0.000 & -0.001 & -0.000 & 0.000 & 0.000 & 0.001 & 0.001 \\
\hline 16. Social housing & 0.004 & 0.002 & $0.004^{*}$ & 0.003 & -0.000 & 0.000 & 0.001 & 0.001 \\
\hline 17. Private rented & $0.006 * *$ & $0.005^{*}$ & $0.007^{* * *}$ & $0.006^{* * *}$ & 0.001 & 0.001 & 0.002 & 0.002 \\
\hline 18. Semi-detached house/bungalow & -0.000 & -0.000 & 0.000 & 0.000 & 0.001 & 0.001 & 0.001 & 0.001 \\
\hline 19. End terraced house & -0.002 & -0.001 & -0.001 & -0.001 & -0.002 & -0.002 & -0.002 & -0.001 \\
\hline 20. Terraced house & -0.000 & -0.001 & -0.000 & -0.000 & -0.001 & -0.001 & -0.001 & -0.001 \\
\hline 21. Purpose built flat & -0.002 & -0.002 & -0.003 & -0.002 & -0.003 & -0.002 & -0.003 & -0.002 \\
\hline 22. Converted flat & 0.004 & 0.004 & 0.003 & 0.003 & 0.001 & 0.001 & 0.001 & 0.001 \\
\hline 23. Bedsit & 0.000 & 0.000 & 0.000 & 0.000 & 0.000 & 0.000 & 0.000 & 0.000 \\
\hline 24. No central heating & $0.021^{* * *}$ & $0.012^{* * *}$ & $0.022^{* * *}$ & $0.012^{* * *}$ & $0.013^{* * *}$ & $0.009^{* * *}$ & $0.014^{* * *}$ & $0.009^{* * *}$ \\
\hline 25. No gas connection & $0.005^{* *}$ & 0.003 & $0.005^{* *}$ & $0.003^{*}$ & $0.005^{* * *}$ & $0.003^{*}$ & $0.005^{* * *}$ & $0.003^{* *}$ \\
\hline 26. Household head aged 65 to 75 & $-0.005^{* * *}$ & -0.002 & $-0.004^{* *}$ & -0.002 & -0.000 & 0.001 & -0.000 & 0.001 \\
\hline 27. Household head aged $75+$ & $-0.008^{* * *}$ & $-0.005^{* * *}$ & $-0.007^{* * *}$ & $-0.005 * * *$ & $-0.004^{* *}$ & -0.002 & $-0.003^{*}$ & -0.002 \\
\hline 28. Household head unemployed & $0.009^{* * *}$ & $0.008^{* * *}$ & $0.012^{* * *}$ & $0.010^{* * *}$ & $0.004^{*}$ & $0.004^{* *}$ & $0.004^{* *}$ & $0.004^{* *}$ \\
\hline 29. Has investment income & $-0.004^{* * *}$ & $-0.002 * *$ & $-0.005^{* * *}$ & $-0.003 * * *$ & -0.000 & 0.000 & -0.001 & 0.000 \\
\hline 30. Receives incapacity benefit & $0.007^{* * *}$ & $0.006 * * *$ & $0.009 * * *$ & $0.007^{* * *}$ & 0.002 & 0.002 & 0.002 & 0.001 \\
\hline 31. Receives housing benefit & $0.003 *$ & 0.002 & $0.003 *$ & 0.001 & 0.000 & -0.000 & -0.000 & -0.001 \\
\hline 32. Receives income support & 0.001 & 0.001 & 0.001 & 0.001 & 0.000 & 0.000 & 0.000 & 0.000 \\
\hline 33. Contains single parent(s) & 0.004 & $0.004 *$ & $0.005^{*}$ & $0.005^{* *}$ & 0.000 & 0.001 & 0.001 & 0.001 \\
\hline 34. Contains children & $-0.005 * * *$ & $-0.005^{* * *}$ & $-0.004 * *$ & $-0.003 * *$ & $-0.003 * *$ & $-0.003 *$ & $-0.003^{*}$ & -0.002 \\
\hline 35. Number of household members: 2 & -0.003 & -0.001 & $-0.005^{* * *}$ & $-0.003^{* *}$ & $-0.003^{*}$ & -0.001 & $-0.004^{* *}$ & -0.002 \\
\hline 36. Number of household members: 3 & 0.002 & 0.003 & -0.002 & -0.000 & 0.000 & 0.001 & -0.002 & -0.000 \\
\hline 37. Number of household members: 4 & -0.000 & 0.001 & $-0.005^{*}$ & -0.003 & -0.002 & -0.001 & $-0.004^{*}$ & -0.003 \\
\hline 38. Number of household members: 5 & 0.005 & 0.006 & -0.001 & 0.001 & -0.000 & 0.003 & -0.002 & 0.000 \\
\hline 39. Number of household members: 6 & 0.001 & 0.004 & -0.005 & -0.002 & -0.004 & -0.001 & $-0.006 * *$ & -0.004 \\
\hline 40. Number of household members: $7+$ & -0.000 & 0.003 & -0.006 & -0.003 & -0.005 & -0.002 & $-0.008 * *$ & -0.004 \\
\hline 41. Has home computer & & & & & 0.002 & 0.001 & 0.002 & 0.001 \\
\hline 42. Number of rooms: 1 & & & & & $-0.009^{* * *}$ & 0.000 & $-0.009^{* * *}$ & 0.000 \\
\hline 43. Number of rooms: 3 & & & & & 0.002 & -0.000 & 0.002 & -0.000 \\
\hline 44. Number of rooms: 4 & & & & & 0.001 & -0.000 & 0.001 & -0.001 \\
\hline 45. Number of rooms: 5 & & & & & -0.000 & -0.000 & -0.000 & -0.001 \\
\hline 46. Number of rooms: 6 & & & & & 0.003 & 0.002 & 0.002 & 0.001 \\
\hline 47. Number of rooms: $7+$ & & & & & 0.004 & 0.004 & 0.003 & 0.003 \\
\hline
\end{tabular}




\begin{tabular}{|c|c|c|c|c|c|c|c|c|}
\hline \multirow[b]{2}{*}{ Explanatory Variable } & \multicolumn{3}{|c|}{ (Continued from previous page) } & $\begin{array}{l}\text { ge) } \\
\text { ariables }\end{array}$ & \multicolumn{4}{|c|}{$\begin{array}{l}\text { Policymaking plus Best Predictor } \\
\text { Explanatory Variables }\end{array}$} \\
\hline & (1) & (2) & (3) & (4) & (5) & (6) & (7) & (8) \\
\hline $\begin{array}{l}\text { 48. Loan/hire payments somewhat of a } \\
\text { burden }\end{array}$ & & & & & -0.000 & -0.001 & -0.000 & -0.001 \\
\hline 49. Loan/hire payments a heavy burden & & & & & 0.003 & $0.004^{* *}$ & 0.002 & $0.004^{* *}$ \\
\hline 50. Problems paying for housing & & & & & 0.001 & 0.002 & 0.002 & $0.002^{*}$ \\
\hline 51. Cannot afford holiday & & & & & $0.010^{* * *}$ & $0.008^{* * *}$ & $0.011^{* * *}$ & $0.008^{* * *}$ \\
\hline 52. Cannot afford to replace furniture & & & & & $0.016^{* * *}$ & $0.014^{* * *}$ & $0.017^{* * *}$ & $0.014 * * *$ \\
\hline 53. Cannot afford new clothes & & & & & $0.007^{* * *}$ & $0.005^{* * *}$ & $0.007^{* * *}$ & $0.005^{* * *}$ \\
\hline $\begin{array}{l}\text { 54. Cannot afford to eat meat on alternate } \\
\text { days }\end{array}$ & & & & & $0.009 * * *$ & $0.006 * * *$ & $0.009 * * *$ & $0.006 * * *$ \\
\hline 55. Cannot afford visitors for food/drink & & & & & $0.003^{* *}$ & $0.003^{* *}$ & $0.003^{* *}$ & $0.003 * *$ \\
\hline 56. Has condensation & & & & & 0.002 & 0.001 & 0.002 & 0.001 \\
\hline 57. Has a leaky roof & & & & & $0.006 * *$ & $0.006 * *$ & $0.006 * *$ & $0.006 * *$ \\
\hline 58. Has damp wall/floors & & & & & $0.006 * * *$ & $0.005^{* * *}$ & $0.006 * * *$ & $0.005^{* * *}$ \\
\hline 59. Has rot in windows/floors & & & & & $0.007^{* * *}$ & $0.005^{* *}$ & $0.008^{* * *}$ & $0.005^{* *}$ \\
\hline 60. Has crime in the local area & & & & & $0.003 * * *$ & $0.003 * *$ & $0.003 * * *$ & $0.003 * *$ \\
\hline Log likelihood & $-2,702.39$ & $-1,942.31$ & $-2,734.80$ & $-1,961.54$ & $-2,163.27$ & $-1,610.77$ & $-2,170.26$ & $-1,615.66$ \\
\hline $\begin{array}{l}\text { P-value, likelihood ratio test of joint } \\
\text { significance }\end{array}$ & 0.000 & 0.000 & 0.000 & 0.000 & 0.000 & 0.000 & 0.000 & 0.000 \\
\hline Policymaking variables & Yes & Yes & Yes & Yes & Yes & Yes & Yes & Yes \\
\hline Best predictor variables & No & No & No & No & Yes & Yes & Yes & Yes \\
\hline Number of observations & 55,708 & 47,849 & 55,708 & 47849 & 55,708 & 47,673 & 55,708 & 47,673 \\
\hline Number of households & 10,461 & 9,388 & 10,461 & 9,388 & 10,461 & 9,367 & 10,461 & 9,367 \\
\hline
\end{tabular}

Notes: * indicates statistical significance at the $10 \%$ level, $* *$ indicates significance at the $5 \%$ level and $* * *$ indicates significance at the $10 \%$ level. The table reports average marginal effects on the probability of a household reporting an inability to afford to keep their home adequately warm. A blank space indicates a variable was not included in the regression. Where a variable is labelled as quadratic the regression included both a linear and squared term of the variable; the reported average marginal effect for such variables is the combined change in probability associated with the linear and squared terms. In columns (2), (4), (6), (7) and (8) 8,279 observations were dropped as the sample is restricted to cases where the first lag of the four analysed fuel poverty indicators are available. Selected base categories: rows 5-11 = 2002-03 wave; rows 12-14 = England; rows 15-17 = owned outright; rows $18-23=$ detached house/bungalow; rows 26 and 27 = Household head aged less than 65; rows 35-40= household contains 1 person; rows 42 47 = dwelling has 2 rooms; rows 28-34 and 50-60 are all binary variables where the base category is the opposite of the variable statement. Columns (3), (4) and (7) and (8) exclude the energy expenditure, income and housing cost variables to allow comparison with the expenditure-based fuel poverty indicators. In columns (1), (3), (5) and (7) 5 observations were dropped for May perfectly predicting being able to afford warmth and for the same reason 59 observations were dropped for living in a bed sit. In columns (2), (4), (6) and (8) 82 observations were dropped for April perfectly predicting being able to afford warmth and for the same reason 4 observations were dropped for May and 38 observations were dropped for living in a bedsit. In columns (6) and (8) 176 observations were dropped for living in a single room perfectly predicting being able to afford warmth. In column (1) 10 observations of being able to afford warmth were completely determined and the same is true of 9 observations in columns (2) and (6), and 13 observations in column (5). Variables/categories frequently significant at the $10 \%$ level or above (direction in brackets) but not reported are: interview month - April (negative), has two or more cars (negative), has a satellite dish (negative), has a colour TV (negative) and has a tumble dryer (negative).

\section{Table 4: Average marginal effects on the probability of reporting an inability to afford to keep one's home adequately warm (Policymaking and/or Best Predictor variables included)}

The most notable results in Table 4 relate to age. In columns 5 to 8 , where the full set of housing and deprivation variables are included, households with a head aged 65 to 75 show no statistically significant difference in reporting IAAW from households with a head aged below 65 . In the Best Predictor regressions a household head aged over 75 only has a statistically significant difference at the $5 \%$ level to a household head aged below 65 when income and expenditure are included but the lag of IAAW is excluded (column 5). However, in column 5, as in the Policymaking regressions (columns 1 to 4), a household with a head over 75 years old is less likely to report IAAW than one headed by an under 65 year old. This negative relationship also holds for households with a head aged 65-75 in the regressions with policymaking variables when the lag of the dependent variable is 
excluded (columns 1 and 3). This result is consistent with the descriptive statistics reported in Figure 9 and Healy and Clinch (2002) ${ }^{42}$.

Why are older households associated with a lower probability of reporting IAAW? The key factor appears to be that whether older households report IAAW is correlated with their reporting of other forms of deprivation or problems with their home, since a head of household over 65 has a strong negative association with reporting IAAW only when the deprivation and housing condition variables are excluded. ${ }^{43}$ The unanswered question is whether the deprivation and housing condition variables are controlling for households' substantive characteristics or a reporting bias, where older households are less willing to disclose any form of deprivation.

Regarding the possibility of a reporting bias, in the current dataset all of the deprivation and poor housing condition indicators show a lower incidence rate among households headed by someone over 65 than for households with a younger head. ${ }^{44}$ Dominy and Kempson (2006) report that research has shown that, for a given level of income, older households are less likely to report material deprivation than younger households. More specifically, Berthoud et al. (2009) indicate that while older cohorts are less likely to report material deprivation compared to more recent cohorts, this is offset by individuals tending to become relatively poorer as they age. This highlights the extra value that data on in-home temperatures and householders' temperature preferences could add, to help tease out which households are living in 'low' temperatures and whether they would appreciate interventions to achieve higher temperatures.

Reporting IAWW is also positively associated with the head of household being unemployed across all the equations, unsurprisingly with a more significant and numerically greater effect when deprivation and housing condition indicators are omitted. It is noticeable that this relationship exists even after controlling for household income.

Regarding the deprivation and housing condition indicators, there is a strong association between them and reporting IAAW (columns 5 to 8 ). The highest increase in the probability of reporting IAAW is associated with being unable to afford to replace furniture, with an increase of 1.4-1.7 percentage points. Among the housing condition indicators, reporting condensation does not show a statistically significant association with IAAW. When the deprivation and housing condition indicators are removed, i.e. only the policymaking variables are included, other variables, which are likely proxies for these issues, become significant. For example, in columns 1-4, investment income is negatively associated with reporting IAAW, while receiving incapacity benefit is positively associated with IAAW.

When the housing and deprivation indicators are removed, private renting, compared to owning one's home outright, is positively associated with IAAW. However, renting from a social housing provider does not show a statistically significant relationship with IAAW at the 5\% level, compared to owning a home outright. When policymaking variables are included, the presence of children in a household is associated with a reduced probability of reporting IAAW, though this relationship is weaker when controlling for housing and deprivation factors.

\footnotetext{
42 See Tables 15 and 16.

${ }^{43}$ This is seen by comparing columns 1-4 with 5-8. More specifically, when the regressions in columns 5-8 are repeated without the other 'cannot afford' indicators (rows 51-55) and housing deprivation indicators (rows 56-59), a household head over 75 is negatively associated with reporting IAAW at the $1 \%$ level in all the regressions and a household head aged $65-75$ has a negative association significant at the $5 \%$ level in the regressions where the lag of IAAW is not included.

${ }^{44}$ In all instances the difference was statistically significant at the $1 \%$ level.
} 
Columns 2, 4, 6 and 8 indicate some persistence in reporting IAAW, since reporting IAAW in one period is associated with a higher probability of that household having reporting IAAW in the previous period. While the magnitude of the AMEs for the lag of IAAW are large relative to those of the other explanatory variables in Table 4, they are noticeably smaller than in Table 3 after controlling for the full set of housing condition and deprivation indicators.

This apparent persistence might be explained by households reporting IAAW having particular 'unobservable' characteristics. For example, the lagged variable could be picking up that some households have a greater predilection to report fuel poverty. The lag of IAAW also reflects some characteristics which change little over time, and which are otherwise associated with FP. For example, comparing columns 1 and 2 (and 5 and 6), introducing the lag of IAAW reduces the statistical significance of not having a gas connection. Similarly, the magnitude of the AME associated with the presence of central heating falls when the lagged dependent variable is included.

\subsection{Expenditure-based Indicators}

In Table 5 AMEs from univariate regressions for the associations between different FP indicators and at different times are reported. Without controlling for other factors, reporting IAAW is associated with an increase in the probability of being $10 \%$ FP of 15.5 percentage points and an increase in the probability of being LIHC FP of 20.0 percentage points. As in the case of IAAW discussed above, there is evidence of persistence, since the one period lags of the two expenditure-based FP indicators are statistically significant at the $1 \%$ level. One striking correlation is that being $10 \% \mathrm{FP}$ is associated with a 68 percentage point increase in the probability of being LIHC FP, reflecting the large proportion of 10\% FP observations in Figure 3.

\begin{tabular}{|c|c|c|c|c|c|c|c|c|}
\hline \multirow[b]{2}{*}{ Explanatory Variable } & \multicolumn{4}{|c|}{$10 \%$ Indicator } & \multicolumn{4}{|c|}{ LIHC Indicator } \\
\hline & (1) & (2) & (3) & (4) & (5) & (6) & (7) & (8) \\
\hline $\begin{array}{l}\text { 1. Unable to afford adequate warmth } \\
\text { in the home }\end{array}$ & $0.155^{* * *}$ & & & & $0.200 * * *$ & & & \\
\hline 2. Lack of adequate heating facilities & & $0.064 * * *$ & & & & $0.108 * * *$ & & \\
\hline 3. LIHC fuel poor, period t & & & $0.384^{* * *}$ & & & & & \\
\hline 4. $10 \%$ fuel poor, period $t$ & & & & & & & $0.680^{* * *}$ & \\
\hline 5. $10 \%$ fuel poor, period $t-1$ & & & & $0.417^{* * *}$ & & & & \\
\hline 6.LIHC fuel poor, period t-1 & & & & & & & & $0.452 * * *$ \\
\hline Log likelihood & $-14,971.61$ & $-14,988.89$ & $-10,197.12$ & $-9,833.07$ & $-23,140.04$ & $-23,129.01$ & $-18,369.92$ & $-15,681.40$ \\
\hline $\begin{array}{l}\text { P-value, likelihood ratio test of joint } \\
\text { significance }\end{array}$ & 0.000 & 0.000 & 0.000 & 0.000 & 0.000 & 0.000 & 0.000 & 0.000 \\
\hline Policymaking variables & No & No & No & No & No & No & No & No \\
\hline Best predictor variables & No & No & No & No & No & No & No & No \\
\hline Number of observations & 55,772 & 55,772 & 55,772 & 47,973 & 55,772 & 55,772 & 55,772 & 47,973 \\
\hline Number of households & 10,465 & 10,465 & 10,465 & 9,400 & 10,465 & 10,465 & 10,465 & 9,400 \\
\hline
\end{tabular}

Notes: * indicates statistical significance at the $10 \%$ level, $* *$ indicates significance at the $5 \%$ level and $* * *$ indicates significance at the $1 \%$ level. The table reports average marginal effects on the probabilities of: (i) being $10 \%$ fuel poor, columns (1)-(4); and (ii) being LIHC fuel poor, columns (5)-(8). In columns (4) and (8) 8,279 observations are dropped as the sample is restricted tocases where the first lags of the analysed fuel poverty indicators are available. A blank space indicates a variable was not included in the regression.

\section{Table 5: Average marginal effects of alternative fuel poverty indicators on the probabilities of} being identified as $10 \%$ fuel poor or LIHC fuel poor, univariate regressions

The present study's focus is to highlight differences between the characteristics of households reporting IAAW and those identified as 10\% FP and LIHC FP. To do this the regressions in Table 6 are compared with columns 3, 4, 7 and 8 of Table 4 . Wald tests show that, for both the $10 \%$ and LIHC indicators, the coefficients of the additional variables in the Best Predictor regressions (columns 3, 4, 7 and 8 ) are significantly different to zero at the $1 \%$ level, indicating that the Best Predictor specifications offer an improvement over the Policymaking specifications. In columns 2, 4, 6 and 8 of 
Table 6 the first lag of the dependent variable is included. In general, the AMEs' magnitudes in Table 6 are noticeably larger than in Table 4, probably reflecting the higher proportion of households classified as $10 \%$ FP or LIHC FP rather than unable to afford adequate warmth.

From a policy perspective, the most interesting difference between Tables 4 and 6 are the associations between older households and each FP indicator. As noted above, for the IAAW indicator, in the Best Predictor regressions (columns 7 and 8) there is little association with the household head being aged 65 or over; while in the Policymaking regressions (columns 3 and 4) the household head being aged over 75 is associated with a reduction in the probability of reporting IAAW at the 1\% level. In contrast, columns 1-4 of Table 6 show no association between older household heads and $10 \% \mathrm{FP}$, while older household heads are positively associated with LIHC FP (columns 5-8). A household head aged 65-75, on average, is associated with 3.4-4.2 percentage points increase in the probability of LIHC FP compared to a household head under 65 , with a similar but wider range for a household head over 75 .

These associations for IAAW and 10\% FP reflect the patterns in Figure 9 in Appendix 4. However, Figure 9 shows that the rate of 10\% FP is noticeably higher among households with a head aged 65 or over than for households with a younger head (11.2\% vs $6.4 \%)$. That the age variables are insignificant for 10\% FP in Table 6 suggest that the pattern for 10\% FP in Figure 9 is driven by household characteristics positively correlated with age, rather than by age itself. The contrast in the relationship between age and, respectively, the $10 \%$ indicator and reporting an IAAW, is consistent with descriptive statistics in DECC (2009) ${ }^{45}$.

45 See Chart 38, pg42, comparing the figures for "one person under 60" with those for "one person aged 60 or over". 


\begin{tabular}{|c|c|c|c|c|c|c|c|c|}
\hline \multirow[b]{2}{*}{ Explanatory Variable } & \multicolumn{4}{|c|}{$10 \%$ Indicator } & \multicolumn{4}{|c|}{ LIHC Indicator } \\
\hline & (1) & (2) & (3) & (4) & (5) & (6) & (7) & (8) \\
\hline 1. $10 \%$ fuel poor, period $t-1$ & & $0.213^{* * *}$ & & $0.201^{* * *}$ & & & & \\
\hline 2. LIHC fuel poor, period $t-1$ & & & & & & $0.303 * * *$ & & $0.290 * * *$ \\
\hline 3. 2001-02 wave & $0.010^{* * *}$ & 0.007 & $0.009 * * *$ & $0.007^{*}$ & 0.000 & -0.006 & -0.002 & -0.006 \\
\hline 4. 2003-04 wave & $-0.008^{* *}$ & -0.003 & $-0.007^{* *}$ & -0.003 & -0.006 & -0.003 & -0.003 & -0.002 \\
\hline 5. 2004-05 wave & $-0.014 * * *$ & $-0.007^{* *}$ & $-0.012 * * *$ & $-0.007^{* *}$ & -0.007 & -0.005 & -0.003 & -0.003 \\
\hline 6. 2005-06 wave & -0.002 & $0.007^{*}$ & -0.000 & $0.007^{*}$ & $-0.016 * * *$ & $-0.013 * *$ & $-0.012 * *$ & $-0.011 * *$ \\
\hline 7. 2006-07 wave & $0.010 * *$ & $0.015 * * *$ & $0.012 * * *$ & $0.015^{* * *}$ & $-0.023 * * *$ & $-0.016 * * *$ & $-0.018 * * *$ & $-0.014^{* * *}$ \\
\hline 8. 2007-08 wave & $0.013^{* * *}$ & $0.015^{* * *}$ & $0.015^{* * *}$ & $0.015^{* * *}$ & $-0.019 * * *$ & $-0.009 *$ & $-0.013^{* *}$ & -0.007 \\
\hline 9. 2008-09 wave & $0.044^{* * *}$ & $0.045^{* * *}$ & $0.046 * * *$ & $0.044^{* * *}$ & $-0.013 * *$ & -0.002 & -0.009 & -0.002 \\
\hline 10. Wales & $0.013^{* * *}$ & $0.007^{* *}$ & $0.011^{* * *}$ & $0.006^{* *}$ & $0.031^{* * *}$ & $0.017^{* * *}$ & $0.028^{* * *}$ & $0.016^{* * *}$ \\
\hline 11. Scotland & $0.026^{* * *}$ & $0.016^{* * *}$ & $0.030 * * *$ & $0.019 * * *$ & $0.050 * * *$ & $0.026 * * *$ & $0.055^{* * *}$ & $0.031 * * *$ \\
\hline 12. Northern Ireland & $0.072 * * *$ & $0.038^{* * *}$ & $0.068 * * *$ & $0.038^{* * *}$ & $0.091 * * *$ & $0.050 * * *$ & $0.084 * * *$ & $0.049 * * *$ \\
\hline 13. Owned with mortgage & $-0.066^{* * *}$ & $-0.043^{* * *}$ & $-0.060 * * *$ & $-0.041 * * *$ & $-0.048^{* * *}$ & $-0.026 * * *$ & $-0.041^{* * *}$ & $-0.024^{* * *}$ \\
\hline 14. Social Housing & $-0.027^{* * *}$ & $-0.021 * * *$ & $-0.023 * * *$ & $-0.017 * * *$ & $0.037^{* * *}$ & $0.020^{* * *}$ & $0.032^{* * *}$ & $0.017^{* * *}$ \\
\hline 15. Private rented & $-0.024 * * *$ & $-0.019 * * *$ & $-0.022 * * *$ & $-0.018 * * *$ & $0.043^{* * *}$ & $0.030 * * *$ & $0.038^{* * *}$ & $0.025^{* * *}$ \\
\hline 16. Semi-detached house/bungalow & $-0.042^{* * *}$ & $-0.026 * * *$ & $-0.031 * * *$ & $-0.021 * * *$ & $-0.027^{* * *}$ & $-0.015^{* * *}$ & $-0.020 * * *$ & $-0.011^{* *}$ \\
\hline 17. End terraced house & $-0.040 * * *$ & $-0.025 * * *$ & $-0.028 * * *$ & $-0.019 * * *$ & $-0.025 * * *$ & $-0.016^{* *}$ & $-0.017^{* *}$ & -0.010 \\
\hline 18. Terraced house & $-0.037^{* * *}$ & $-0.022 * * *$ & $-0.025 * * *$ & $-0.016 * * *$ & $-0.026 * * *$ & $-0.014^{* *}$ & $-0.018^{* *}$ & -0.008 \\
\hline 19. Purpos & $-0.067 * * *$ & $-0.043 * * *$ & $-0.044 * * *$ & $-0.030 * * *$ & $-0.079 * * *$ & $-0.048 * * *$ & $-0.051^{* * *}$ & $-0.030 * * *$ \\
\hline 20. Converted flat & $-0.056 * * *$ & $-0.034^{* * *}$ & $-0.031 * * *$ & $-0.020 * *$ & $-0.059 * * *$ & $-0.034 * * *$ & $-0.026^{*}$ & -0.015 \\
\hline 21. Bedsit & $-0.086^{* * *}$ & $-0.053^{* *}$ & $-0.056 * *$ & -0.033 & $-0.096^{* * *}$ & -0.009 & -0.034 & 0.043 \\
\hline 22. No central heating & 0.007 & 0.005 & 0.001 & 0.003 & 0.006 & 0.000 & -0.001 & -0.003 \\
\hline 23. No gas connection & 0.005 & $0.007^{* *}$ & $0.007 *$ & $0.008^{* * *}$ & 0.009 & 0.006 & $0.013^{* *}$ & $0.008^{*}$ \\
\hline 24. Househ & -0.004 & 0.001 & -0.004 & 0.001 & $0.042^{* * *}$ & $0.035^{* * *}$ & $0.042^{* * *}$ & $0.036^{* * *}$ \\
\hline 25. Household head aged $75+$ & -0.001 & -0.000 & 0.001 & 0.002 & $0.048^{* * *}$ & $0.032 * * *$ & $0.050 * * *$ & $0.036^{* * *}$ \\
\hline 26. Household head unemployed & $0.097^{* * *}$ & $0.054^{* * *}$ & $0.085^{* * *}$ & $0.050^{* * *}$ & $0.086^{* * *}$ & $0.057^{* * *}$ & $0.069 * * *$ & $0.047^{* * *}$ \\
\hline 27. Has investment income & $-0.043 * * *$ & $-0.029 * * *$ & $-0.042 * * *$ & $-0.029 * * *$ & $-0.078 * * *$ & $-0.051 * * *$ & $-0.072^{* * *}$ & $-0.047^{* * *}$ \\
\hline 28. Receives incapacity benefit & $0.035^{* * *}$ & $0.028^{* * *}$ & $0.028 * * *$ & $0.024^{* * *}$ & $0.078 * * *$ & $0.055^{* * *}$ & $0.065^{* * *}$ & $0.047^{* * *}$ \\
\hline 29. Receives housing benefit & $-0.014 * * *$ & $-0.008^{* *}$ & $-0.019 * * *$ & $-0.009 * *$ & $0.019 * * *$ & $0.010^{*}$ & 0.008 & 0.004 \\
\hline 30. Receives income support & $0.035^{* * *}$ & $0.015^{* * *}$ & $0.028 * * *$ & $0.013^{* * *}$ & $0.051 * * *$ & $0.026 * * *$ & $0.034 * * *$ & $0.017^{* * *}$ \\
\hline 31. Contains single parent(s) & $0.047^{* * *}$ & $0.031^{* * *}$ & $0.039 * * *$ & $0.026^{* * *}$ & $0.062^{* * *}$ & $0.040 * * *$ & $0.051^{* * *}$ & $0.033^{* * *}$ \\
\hline 32. Contains children & $0.029 * * *$ & $0.023 * * *$ & $0.030 * * *$ & $0.024^{* * *}$ & $0.021 * * *$ & $0.018^{* * *}$ & $0.023 * * *$ & $0.020 * * *$ \\
\hline 33. Number of household $\mathrm{m}$ & $-0.079 * * *$ & $-0.051^{* * *}$ & $-0.085^{* * *}$ & $-0.056^{* * *}$ & -0.001 & 0.000 & -0.006 & -0.003 \\
\hline 34. Number of household members: 3 & $-0.103 * * *$ & $-0.074 * * *$ & $-0.111 * * *$ & $-0.082 * * *$ & 0.007 & 0.000 & -0.003 & -0.007 \\
\hline 35. Number of household members: 4 & $-0.108 * * *$ & $-0.078 * * *$ & $-0.117^{* * *}$ & $-0.086 * * *$ & $0.030 * * *$ & $0.015^{*}$ & $0.017^{*}$ & 0.006 \\
\hline 36. Number of household me & $-0.108 * * *$ & $-0.075^{* * *}$ & $-0.119 * * *$ & $-0.085 * * *$ & $0.057^{* * *}$ & $0.025^{* * *}$ & $0.037 * * *$ & 0.013 \\
\hline 37. Number of household m & $-0.128 * * *$ & $-0.094^{* * *}$ & $-0.139 * * *$ & $-0.103^{* * *}$ & $0.109 * * *$ & $0.057^{* * *}$ & $0.081^{* * *}$ & $0.042^{* * *}$ \\
\hline 38. Number of household members: $7+$ & $-0.114 * * *$ & $-0.077 * * *$ & $-0.128 * * *$ & $-0.090 * * *$ & $0.218^{* * *}$ & $0.110 * * *$ & $0.168^{* * *}$ & $0.082^{* * *}$ \\
\hline 39. Has home computer & & & $-0.010 * * *$ & -0.004 & & & $-0.013^{* * *}$ & $-0.007^{*}$ \\
\hline 40. Number of rooms: 1 & & & 0.010 & -0.008 & & & -0.018 & -0.016 \\
\hline 41. Number of rooms: 3 & & & $0.027^{* * *}$ & $0.018^{* * *}$ & & & $0.046 * * *$ & $0.029 * * *$ \\
\hline 42. Number of rooms: 4 & & & $0.040 * * *$ & $0.026 * * *$ & & & $0.068^{* * *}$ & $0.042^{* * *}$ \\
\hline 43. Number of rooms: 5 & & & $0.047^{* * *}$ & $0.031 * * *$ & & & $0.081 * * *$ & $0.051^{* * *}$ \\
\hline 44. Number of rooms: 6 & & & $0.057^{* * *}$ & $0.033^{* * *}$ & & & $0.088^{* * *}$ & $0.057^{* * *}$ \\
\hline 45. Number of rooms: 7+ & & & $0.073 * * *$ & $0.040 * * *$ & & & $0.088 * * *$ & $0.053^{* * *}$ \\
\hline
\end{tabular}

(Continued on following page) 


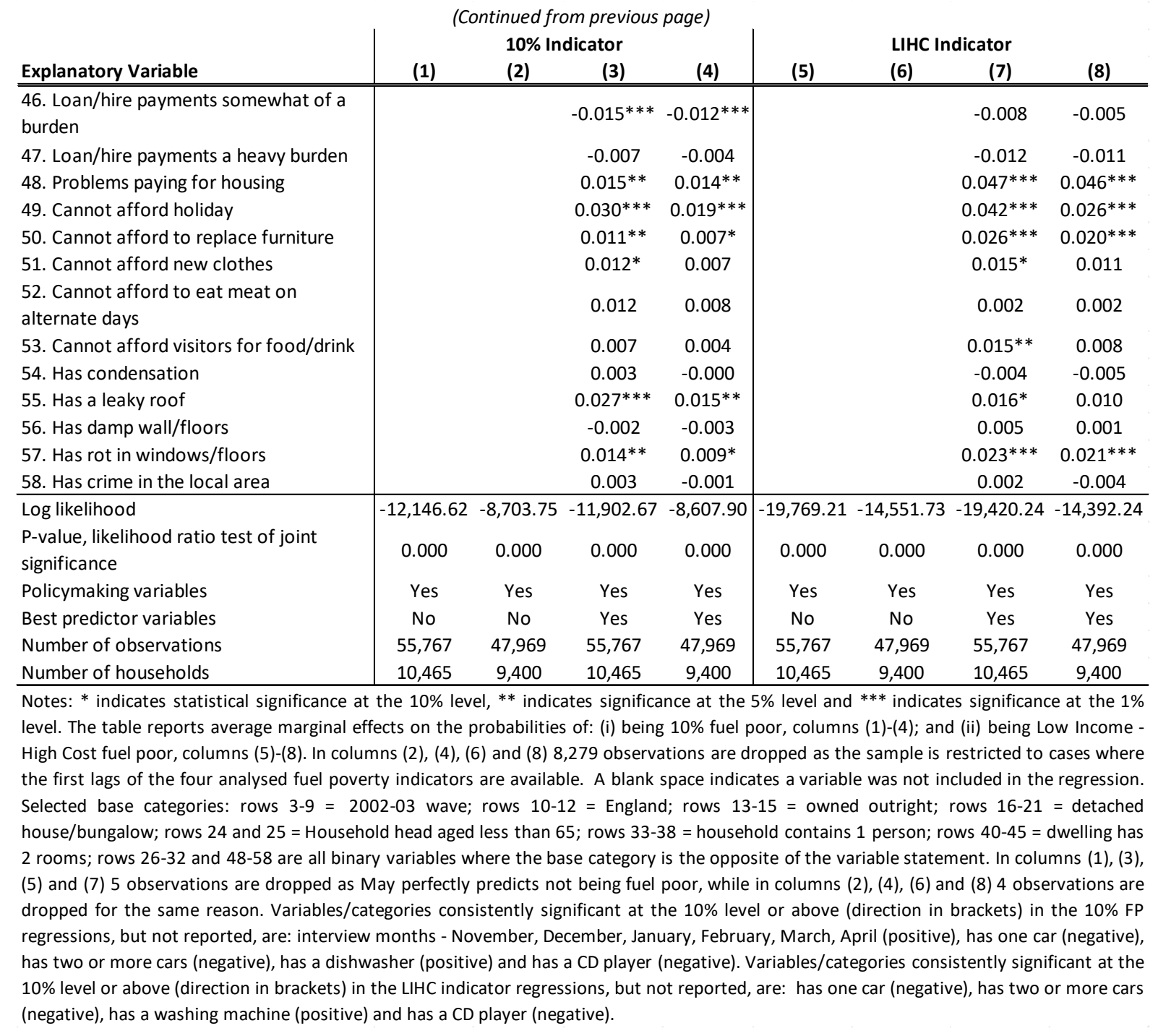

\section{Table 6: Average marginal effects on the probability of a household being identified as Fuel Poor according to: (i) the $10 \%$ indicator and (ii) the LIHC indicator}

Another policy point is that while tenure and dwelling type show limited association with the probability of IAAW, they show considerable association with the expenditure-based indicators. For the $10 \%$ indicator all tenure types are associated with a lower probability of being FP than households owning their property outright; and all dwelling types are associated with a lower probability of being FP than households living in a detached house/bungalow.

The pattern of association between tenure and the LIHC FP indicator is more complex, though unsurprising given its direct relationship with low income, with households in social housing and private rented accommodation being associated with a higher probability of LIHC FP than households who are owner occupiers, though as with the $10 \%$ indicator, owning a property with a mortgage is negatively associated with being LIHC FP. The signs of these AMEs appear to be driven by variations in incomes between tenure types rather than by variations in ENEX. For example, households with a mortgage had a median household income of $£ 37,242$ compared to $£ 19,392$ for 
households owning their property outright. ${ }^{46}$ The importance of income in the relation between LIHC FP and social housing/ private renting is emphasised by their relative low ENEX median values, f699.99 and $f 687.07$ respectively, compared with $f 789.07$ for households owning their property outright.

Another difference between the expenditure-based indicators and reporting IAAW is the influence of children in a household. While the presence of children is negatively associated with reporting IAAW, it is positively associated with both $10 \%$ and LIHC FP. Again, temperature data would be valuable to understand whether these differences are due to households with children choosing to allocate a higher proportion of their income to ENEX to achieve comfortable temperatures for a longer part of the day, or due to households with children being unwilling to admit IAAW.

Neither is any association found between lacking central heating and $10 \%$ or LIHC FP in Table 6, unlike the positive association between IAAW FP and lacking central heating. Moreover descriptive statistics indicate a higher rate of expenditure based FP among those without central heating (10\% FP: $12.1 \%$ vs $7.4 \%$; LIHC FP: $19.0 \%$ vs $14.4 \%)$, differences which are significant at the $1 \%$ level. Factors correlated with a lack of central heating rather than the absence of central heating itself seem to be driving the descriptive statistics. This conclusion is reinforced for the LIHC indicator since median ENEX (although not ENEXShr) is higher among households with central heating, namely f799.73 compared with $\mathrm{f} 712.35$ for the sample as a whole.

Another difference across the indicators are the associations with the number of household members: there is limited association with IAAW, a negative association with $10 \%$ FP and a positive association with LIHC FP for households with 4 or more members. The negative association with the $10 \%$ indicator may be because larger households, after controlling for factors such as dwelling size, contain more potential income earners and so, on average, have higher incomes. For example, the mean unequivalised income for a 1-person household is $£ 15,274$ compared to $£ 39,330$ for a 7 person household. In contrast, the positive association between large households and LIHC FP is likely to be a mechanical consequence of equivalising income and deducting housing costs; the equivalised after gross housing costs income for a 1-person household is $f 23,640$ compared to $£ 13,431$ for a seven person household.

Furthermore, the expenditure-based indicators in Table 6 show stronger associations with some of the low income proxies and less association with the self-assessed affordability indicators, than for IAAW in Table 4. Within the Best Predictor regressions (columns 5 to 8 in Table 4 and columns 3, 4, 7 and 8 in Table 6), having an investment income, receiving incapacity benefit and receiving income support all have associations with the $10 \%$ and LIHC FP indicators significant at the $1 \%$ level, but lack statistically significant associations with IAAW. ${ }^{47}$ In contrast, in Table 4 reporting an inability to afford new clothes or to eat meat on alternate days or to invite visitors for food/drink are positively associated with IAAW at the 5\% significance level or above, while in Table 6 they show limited significance. The housing problem indicators also show a reduction in their significance for $10 \%$ and LIHC FP compared to IAAW. Dwellings reported as suffering from damp or being in areas suffering crime, were significant at the $5 \%$ level or above in Table 4, but are not statistically associated with $10 \%$ and LIHC FP.

\footnotetext{
${ }^{46}$ The lower income of those owning properties outright is explained by the greater proportion of these households who had a head aged over 65 , i.e. likely to be retired, compared to households who were still paying off a mortgage. $2.9 \%$ of households owning with a mortgage had head aged over 65 , compared to $43.5 \%$ of households owning their property outright.

${ }^{47}$ The significance of a household head being unemployed also increases in Table 6.
} 
Dummies representing the devolved administrations have a more consistent pattern of high statistical significance in Table 6 than Table 4. In Table 4 only living in Scotland (compared to England) has statistically significant association with IAAW at the $1 \%$ level, and this is only when the first lag of IAAW and the Best Predictor variables are included; i.e. living in Scotland is only positively associated with IAAW after controlling for affordability/housing condition problems. In contrast, living in any devolved administration, compared to England, is positively associated with $10 \%$ and LIHC FP in all the regressions in Table 6.

We note that the variations in the significance and signs of the survey wave dummies across the different FP indicators broadly follow the time trends for each FP indicator in Figure 1.

\section{Policy Discussion and Conclusions}

\subsection{The implications of using different FP indicators}

First, using expenditure-based FP indicators, especially the LIHC indicator, implies a higher prevalence of FP being identified than if perception-based indicators are used. Second, the present analysis confirms earlier studies in demonstrating limited overlap between perception-based and expenditure-based indicators. This limited overlap holds regardless of whether the $10 \%$ or LIHC indicator is used.

This limited overlap means the choice of FP indicator has a material impact on the type of households which would receive support under policies targeted using the different indicators. Most significantly, given the prominence of the age-related Winter Fuel Payment (WFP) in the UK, which involves $\mathrm{f} 2$ billion of expenditure per annum ${ }^{48}$, the indicators show noticeably different associations with households headed by someone aged 65 or older. While no association is found between older households and $10 \% \mathrm{FP}$, reporting IAAW is negatively associated with older households, while LIHC FP is positively associated with older households.

While the positive association between older households and LIHC FP may be used to justify WFP ${ }^{49}$, this association does not make LIHC FP a 'better' FP indicator, unless the efficacy of support for older households has been pre-determined. Similarly, the positive association between LIHC FP and larger households is a mechanical result of equivalising income, and so is linked to the metric's design rather than an independent empirical result. It is also interesting to consider whether the 'labelling' of WFP itself has influenced older households' perception of the affordability of energy and warmth. ${ }^{50}$

One way to explain the lack of overlap between the indicators is to suggest they are measuring different aspects of FP. The expenditure-based indicators, by identifying households with high ENEXShr/ENEX, may pinpoint households who achieve a reasonable heating standard only by restricting other forms of consumption; conversely reporting IAAW might identify situations when heating expenditure is being limited to enable other forms of consumption. Evidence to confirm such an intuitive interpretation depends on observing the temperatures achieved by the households identified by each indicator.

\footnotetext{
${ }^{48}$ See Table 4.17, pg 100, Office for Budget Responsibility (2019).

${ }^{49}$ WFP is available to those of pensionable age.

${ }^{50}$ Beatty et al. (2014) find evidence that, despite the WFP being a cash transfer, households spend a disproportionate amount of the transfer on fuel compared to a simple income increase suggesting the WFP 'label' is influencing their behaviour.
} 


\subsection{The importance of directly assessing in-home temperatures and heating preferences}

Rather than identifying a 'best' FP indicator or confirming that different indicators are useful for different purposes, the results above suggest a lack of precision in moving from an intuitive understanding of FP to its practical identification. Rather than forming a composite FP indicator, which would sacrifice the information contained by the differences between the indicators, we propose adding an additional crucial piece of information which is currently unrecorded.

Current FP indicators do not assess either the temperatures achieved within homes or householders' preferences around the temperatures to be achieved. Ultimately householders' welfare depends on the services that energy provides, i.e. heat and light, for which energy consumption and energy expenditure provide only proxies. Without direct assessments of temperatures current FP indicators risk significant errors of both inclusion and exclusion, leading to a distorted picture regarding the prevalence and nature of cold homes. These errors will likely reduce the effectiveness of interventions designed to reduce the number of households living in the cold. In order to advance the research and policy agenda, datasets which combine temperatures, temperature preferences and the data to construct both perception-based and expenditure-based FP indicators are needed.

A householder self-reporting IAAW is indicating dissatisfaction with the temperature in their home, but does not necessarily identify the appropriate policy response. It could be that the householder prefers a particularly high temperature, where it is unclear that a policy intervention is justified. Equally, householders may report that warmth is affordable because they view a relatively low temperature as adequate; if this low temperature is associated with poor health, particularly in older respondents, policy intervention may nevertheless be justified.

High ENEX may again result from a household preferring a particularly high temperature, leading to an indication of FP. Moreover, a household might be identified as FP because they have a low income rather than elevated ENEX, where justification for an energy-specific intervention, rather than income support, may not be clear. Using modelled ENEX raises other issues. For example, if a household prefers low temperatures they may be wrongly identified as FP since modelled ENEX incorporates a standard the temperature to be achieved.

While the challenge of identifying FP/cold homes is not new, and the desirability of in-home temperatures is widely appreciated, much of the FP literature takes as given the unavailability of large datasets on in-home temperatures. ${ }^{51}$ We argue that if is both possible and important to address this gap. First, as expenditure on FP alleviation increases the economic case for additional expenditure on FP measurement also increases: inadequate FP measurement now risks a greater misallocation of public money. Second, devices such as smart thermostats mean that in-home temperature and temperature preference data are already being collected on a large scale.

Given the political prominence of FP and the billions of pounds devoted by UK governments to alleviate FP/energy affordability, there is a strong case to gather temperature data and link it to FP statistics on a routine basis, say at 5 year intervals. The analysis of this paper and recommendations support the second Technical Recommendation in Hills' (2012) official FP review, which states "The Government should reinstate a component to its surveys that allows an up-to-date assessment of contemporary behaviour in terms of the temperatures of people's homes." Yet this change has not been implemented.

Some data on household temperatures had previously been collected. Hughes et al. (2019) note that the last very large scale collection of nationally representative (English) temperature data was in

${ }^{51}$ For example, see Thomson et al. (2017) and Tirado Herrero (2017). 
1996 when the English Housing Condition Survey recorded indoor spot temperatures for 17,511 households. ${ }^{52}$ Huebner et al. (2019) note that as a follow-up to the English Housing Survey in 201112 temperature data for 823 households, intended to be broadly nationally representative, was collected $^{53}$, while Oreszczyn et al. (2006) report data from 1,604 households in urban areas which received Warm Front interventions in the winters of 2001-02 and 2002-03.

These studies contain results which speak to the present analysis, but they do not allow a comparison of temperatures for the households reporting both perception- and expenditure-based FP indicators. Huebner et al. (2019) finds that LIHC FP is negatively associated with the number of hours households had a temperature above $18^{\circ} \mathrm{C}$ in the bedroom. Hamilton et al. (2017) report descriptive statistics showing that households in 10\% FP had lower temperatures in their living room and bedroom than non-FP households. ${ }^{54}$ Turning to perception-based indicators, Oreszcyzn et al. (2006) find that households reporting it was fairly or very difficult to pay bills had lower temperatures in their living room and bedroom, while lower temperatures were also recorded for those who were fairly or very dissatisfied with their heating, compared to those who were fairly or very satisfied. Last, looking at the effectiveness of FP interventions, Angelini et al. (2019) consider the impact of WFP on indoor temperatures as recorded by nurse visits for around 12,000 individuals. Using a regression discontinuity design they conclude that WFP eligibility did not result in an increase in home temperatures.

New technologies seem likely to lower the cost of obtaining large scale in-home temperature measurements. In particular, smart thermostats, as a by-product of their core function, seem to be gathering home temperature data at scale. For example, British Gas indicates that over 1.5 million households have its Hive system installed ${ }^{55}$ and its privacy policy indicates that data on "rooms' temperatures, temperature settings, heating schedules" ${ }^{56}$ is likely to be collected. Although the early adopters of smart thermostats may be on relatively high incomes, and so at low risk of FP, there are systems specifically targeted at social landlords, such as Switchee, used by over 45 housing associations. ${ }^{57}$ In the long-term, widespread adoption of smart technologies may enable the direct identification of households living in the 'cold' who may warrant FP assistance, assuming privacy and data protection issues can be overcome. ${ }^{58}$

A number of papers already harness these new technologies in areas related to FP. For example, Huchuk et al. (2018) analyse data from over 10,000 Ecobee thermostats in North America to understand how households change their temperature settings according to season, climate and energy prices. Indeed, Ecobee runs a specific 'Donate your Data' programme ${ }^{59}$ to encourage its users to provide anonymised data for scientific research, with Meier et al. (2019) providing further detail on this dataset. Turning to a different source of data, looking at older households in the UK, Kennard

\footnotetext{
52 Hills (2012) implies the data collection actually took place in 1991. Vadodaria et al. (2014) suggests that 1991 analysis involved 25,000 households, while there was separate analysis in 1996.

53 This data is used in Hamilton et al. (2017) and Huebner et al. (2018).

${ }^{54} \mathrm{~A}$ similar result is found for LIHC FP, although, the living room temperature difference is only significant at the $10 \%$ level.

${ }^{55}$ See https://www. britishgas.co.uk/smart-home/hive-heating.html (accessed on 30 July 2020).

${ }^{56}$ See the bullet "How you use Hive products" under "Personal information we collect", https://www.hivehome.com/privacy (accessed on 30 July 2020).

${ }^{57}$ See 'Affordable housing industry switching on to Switchee's innovative data tools', CITY A.M., Tuesday 21 April 2020, available at: https://www.cityam.com/affordable-housing-industry-switching-on-to-switcheesinnovative-data-tools/ (accessed on 30 July 2020).

58 Fergus and Chalmers (2020) move in this direction, but focus on appliance use rather than heat.

${ }^{59}$ See https://www.ecobee.com/donate-your-data/
} 
et al. (2020) consider data from 77,743 UK Biobank participants who wore an activity tracker that took temperature readings of their environment. They consider how temperatures vary according to socio-economic variables and home heating type.

Of course such technologies do not offer a panacea to FP measurement issues and will present their own methodological issues regarding the precise way temperatures are captured etc. Furthermore, at least initially, smart thermostats are likely to be distributed unevenly across households so that some groups, such as private renters, may be under-represented. Another fundamental challenge will be for researchers to obtain permission to access to the temperature datastreams being captured. Another complication is that since smart thermostats are designed to reduce the cost of achieving a particular temperature, the temperatures achieved in smart thermostat homes will likely be higher than in other homes. Nevertheless they do offer a potential step change in understanding heating preferences and the prevalence of 'cold' homes.

\subsection{Why the magnitude of FP's persistence matters}

Appendix 2 presents descriptive statistics on the magnitude of FP's persistence. Whether households remain consistently FP for long periods of time has clear implications for the design of FP alleviation policies. A key observation of this paper, confirming Phimister et al.'s 2015 finding, is that households have a noticeably higher exit probability from FP than from income poverty. While there are reasons to be cautious about this observation, it is worth considering its implications. FP alleviation policies in the UK generally focus on permanent interventions, either energy efficiency improvements to dwellings or WFP which is available to older households on an annual basis. This contrasts to the most prominent income poverty interventions which are temporary and contingent on having a low income.

Both WFP and energy efficiency improvements should improve the welfare of recipient households. The policy question we highlight, but leave open, is whether non-permanent interventions, quite possibly income transfers, offer a more effective means to minimise the number of households living in the cold/FP. Shifting resources to time limited income transfers may enable a greater number of households temporarily living in the cold to be helped, or an increase in the size of assistance per household. While overall investments in home energy efficiency may be justified by their ability to reduce carbon emissions, this is a different policy objective to minimising FP. If the main objective is minimising the duration for which households live in FP, other interventions beyond energy efficiency interventions may be more appropriate.

\section{Appendices}

\section{Appendix 1 - Lack of Adequate Heating Facilities}

The discussion here follows the format of the equivalent discussion for IAAW in section 6.1. In Table 7 univariate regressions showing relationships with the other FP indicators are reported, before in Table 8 basic regressions are shown identifying associations with ENEX and household income, while in Table 9 the main regressions are reported.

Table 7 shows positive associations between the other FP indicators and reporting a lack of adequate heating facilities significant at the $1 \%$ level. The magnitude of the AME for the other perception-based indicator, IAAW, is more than ten times higher for IAAW than for the two expenditure-based indicators. 


\begin{tabular}{l|cccc} 
& \multicolumn{4}{|c}{ Lack of adequate heating facilities } \\
Explanatory Variable & \multicolumn{4}{c}{ indicator } \\
\hline \hline 1. $10 \%$ fuel poor & (1) & (2) & (3) & (4) \\
2. LIHC fuel poor & $0.033^{* * *}$ & & $0.031^{* * *}$ \\
3. Reports an inability to afford adequate warmth & \multicolumn{4}{c}{$0.382^{* * *}$} \\
4. Reports a lack of adequate heating facilities, period t-1 & \multicolumn{4}{c}{$0.372^{* * *}$} \\
\hline Log likelihood & $-8,862.50$ & $-8,829.83$ & $-8,494.60$ & $-5,662.82$ \\
P-value, likelihood ratio test of joint significance & 0.000 & 0.000 & 0.000 & 0.000 \\
Policymaking variables & No & No & No & No \\
Best predictor variables & No & No & No & No \\
Number of observations & 55,772 & 55,772 & 55,772 & 47,493 \\
Number of households & 10,465 & 10,465 & 10,465 & 9,400 \\
\hline
\end{tabular}

Notes: * indicates statistical significance at the $10 \%$ level, $* *$ indicates significance at the $5 \%$ level and *** indicates significance at the $1 \%$ level. The table reports average marginal effects on the probability of a household reporting a lack of adequate heating facilities in their home. A blank space indicates a variable was not included in the regression. In column (4) 8,279 observations were dropped as the sample is restricted to those cases where the lags of the four analysed fuel poverty indicators are available.

\section{Table 7: Average marginal effects of alternative fuel poverty indicators on the probability of reporting a lack of adequate heating facilities in one's home, univariate regressions}

An interesting feature of the regressions reported in Table 8 and Table 9 is the changing sign and significance of ENEX. The univariate regressions in columns 1 and 2 of Table 8 show a positive association between ENEXShr and reporting a lack of adequate heating facilities, however, the univariate regressions in columns 3 to 6 indicate that both ENEX and household income have a negative relationship with reporting a lack of adequate heating facilities. However, as discussed in section 6.1, treating income and ENEX as separate variables is the more appropriate specification. Column 8 of Table 8 indicates that the positive relationship between ENEXShr and reporting a lack of adequate heating facilities is driven by the dependent variable's negative relationship with household income. After controlling for household income, column 8 shows an insignificant relationship between ENEX and reporting a lack of adequate heating facilities. However, Table 9 indicates that when a larger number of control variables are included there is a statistically significant positive association with ENEX. 


\begin{tabular}{|c|c|c|c|c|c|c|c|c|c|c|}
\hline \multirow[b]{2}{*}{ Explanatory Variable } & \multicolumn{10}{|c|}{ Lack of adequate heating facilities indicator } \\
\hline & (1) & (2) & (3) & (4) & (5) & (6) & (7) & (8) & (9) & $(10)$ \\
\hline 1. Energy expenditure share (\%) - linear & $0.001^{* * *}$ & & & & & & & & & \\
\hline 2. Energy expenditure share (\%) - quadratic & & $0.002 * * *$ & & & & & & & & \\
\hline 3. Annual energy expenditure ( $f$ hundreds, 2008) & & & $-0,001 * *$ & & & & 0.000 & & & \\
\hline - linear & & & 0.001 & & & & & & & \\
\hline $\begin{array}{l}\text { 4. Annual energy expenditure ( } \mathrm{f} \text { hundreds, 2008) } \\
\text { - quadratic }\end{array}$ & & & & $-0.001 * * *$ & & & & 0.000 & 0.000 & 0.000 \\
\hline $\begin{array}{l}\text { 5. Annual household income ( } f \text { thousands, 2008) } \\
\text { - linear }\end{array}$ & & & & & $-0.001 * * *$ & & $-0.001 * * *$ & & & \\
\hline $\begin{array}{l}\text { 6. Annual household income ( } \mathrm{f} \text { thousands, 2008) } \\
\text { - quadratic }\end{array}$ & & & & & & $-0.001 * * *$ & & $-0.001 * * *$ & * $-0.000 * * *$ & $-0.000 * * *$ \\
\hline $\begin{array}{l}\text { 7. Annual net housing costs ( } \mathrm{f} \text { hundreds, 2008) - } \\
\text { quadratic }\end{array}$ & & & & & & & & & $0.000 * * *$ & $0.000 * * *$ \\
\hline $\begin{array}{l}\text { 8. Reports a lack of adequate heating facilities, } \\
\text { period t-1 }\end{array}$ & & & & & & & & & $0.348 * * *$ & $0.233^{* * *}$ \\
\hline 9. No central heating & & & & & & & & & & $0.075^{* * *}$ \\
\hline 10. No gas connection & & & & & & & & & & $0.023 * * *$ \\
\hline Log likelihood & $-8,871.79$ & $-8,835.31$ & $-8,905.42$ & $-8,904.31$ & $-8,784.43$ & $-8,773.63$ & $-8,784.08$ & $-8,773.07$ & $-5,608.59$ & $-5,238.54$ \\
\hline P-value, likelihood ratio test of joint significance & 0.000 & 0.000 & 0.019 & 0.016 & 0.000 & 0.000 & 0.000 & 0.000 & 0.000 & 0.000 \\
\hline Policymaking variables & No & No & No & No & No & No & No & No & No & No \\
\hline Best predictor variables & No & No & No & No & No & No & No & No & No & No \\
\hline Number of observations & 55,772 & 55,772 & 55,772 & 55,772 & 55,772 & 55,772 & 55,772 & 55,772 & 47,973 & 47,973 \\
\hline Number of households & 10,465 & 10,465 & 10,465 & 10,465 & 10,465 & 10,465 & 10,465 & 10,465 & 9,400 & 9,400 \\
\hline
\end{tabular}

Notes: ${ }^{*}$ indicates statistical significance at the $10 \%$ level, $* *$ indicates significance at the $5 \%$ level and $* * *$ indicates significance at the $1 \%$ level. The table reports average marginal effects on the probability of a household reporting a lack of adequate heating facilities in the home. A blank space indicates a variable was not included in the regression. In columns (9) and (10) 8,279 observations were dropped as the sample is restricted to cases where the lags of the four analysed fuel poverty indicators are available. In regressions (5) and (7) 1 obervation was completely determined, in regressions (9) it was 9 observations and (10) it was 8 observations.

Table 8: Average marginal effects of income and energy expenditure on the probability of reporting a lack of adequate heating facilities in one's home, alternative specifications

The positive association between ENEX and a lack of adequate heating facilities in Table 9 contrasts with the lack of statistical association between ENEX and IAAW in Table 4. Another interesting feature of Table 9 is that once the Best Predictor variables are added, a lack of adequate heating facilities no longer has a statistically significant association with household income.

Compared to the IAAW regressions, any positive association between living in Wales and Scotland and reporting inadequate heating facilities disappears. However, in Table 9 there is a consistent negative association between living in Northern Ireland and reporting inadequate heating facilities which is statistically significant at the $1 \%$ level. One might think this is surprising since Northern Ireland has higher than average heating costs due to a limited gas grid and a reliance on heating oil. However, in Table 9 not having a gas connection is controlled for directly, so the negative relationship with being located in Northern Ireland is after the impact of the limited gas grid is accounted for. This may indicate that Northern Irish households view what constitutes 'adequate heating facilities' in a differently to English households.

Another difference with the IAAW results is that renting one's home, compared to owning it outright, is consistently associated with a higher probability of reporting inadequate heating facilities. That the AMEs' magnitudes for tenure type roughly double when only the Policymaking explanatory variables are used suggests a correlation between tenure type and perceived housing condition issues. Similarly, while no association is found between dwelling type and IAAW, those living in terraced houses or flats have a greater likelihood of reporting inadequate heating facilities than those living in detached properties. That the flat indicators have reduced statistical significance when the Best Predictor variables are added suggests a correlation between flats and perceived housing condition problems. Wald tests on the regressions coefficients confirm that including the Best Predictor variables offers an improvement in specification over the Policymaking regressions. 


\begin{tabular}{|c|c|c|c|c|c|c|c|c|}
\hline \multirow[b]{3}{*}{ Explanatory Variable } & \multicolumn{8}{|c|}{ Lack of adequate heating facilities indicator } \\
\hline & \multicolumn{4}{|c|}{ Policymaking Explanatory Variables } & \multicolumn{4}{|c|}{$\begin{array}{l}\text { Policymaking plus Best Predictor } \\
\text { Explanatory Variables }\end{array}$} \\
\hline & (1) & (2) & (3) & (4) & $(5)$ & $(6)$ & $(7)$ & $(8)$ \\
\hline $\begin{array}{l}\text { 1. Lack of adequate heating facilities, } \\
\text { period t-1 }\end{array}$ & & $0.170 * * *$ & & $0.172^{* * *}$ & & $0.120 * * *$ & & $0.120 * * *$ \\
\hline $\begin{array}{l}\text { 2. Annual household income ( } f \text { thousands, } \\
\text { 2008) - quadratic }\end{array}$ & $-0.000 * *$ & $-0.000 * * *$ & & & -0.000 & -0.000 & & \\
\hline $\begin{array}{l}\text { 3. Annual energy expenditure ( } f \text { hundreds, } \\
\text { 2008) - quadratic }\end{array}$ & $0.001 * * *$ & $0.001 * * *$ & & & $0.001 * *$ & $0.001 * *$ & & \\
\hline $\begin{array}{l}\text { 4. Annual net housing costs ( } f \text { hundreds, } \\
2008 \text { ) - quadratic }\end{array}$ & -0.000 & 0.000 & & & 0.000 & 0.000 & & \\
\hline 5. 2001-02 wave & $0.005^{* *}$ & -0.002 & $0.006 * *$ & -0.002 & $0.005^{* *}$ & -0.001 & $0.005^{* *}$ & -0.001 \\
\hline 6. 2003-04 wave & -0.000 & 0.000 & -0.000 & 0.000 & 0.004 & 0.003 & 0.004 & 0.004 \\
\hline 7. 2004-05 wave & $-0.005^{*}$ & -0.004 & $-0.005^{*}$ & -0.004 & -0.000 & 0.000 & -0.000 & 0.000 \\
\hline 8. 2005-06 wave & -0.003 & -0.003 & -0.003 & -0.003 & 0.002 & -0.000 & 0.002 & 0.000 \\
\hline 9. 2006-07 wave & $-0.008^{* * *}$ & $-0.006 * *$ & $-0.007 * *$ & $-0.005^{*}$ & -0.002 & -0.001 & -0.001 & -0.000 \\
\hline 10. 2007-08 wave & $-0.007 * *$ & -0.005 & $-0.006 * *$ & -0.004 & -0.003 & -0.001 & -0.002 & -0.000 \\
\hline 11. 2008-09 wave & -0.000 & 0.001 & 0.002 & 0.003 & 0.003 & 0.003 & 0.005 & 0.005 \\
\hline 12. Wales & 0.003 & 0.002 & 0.005 & 0.002 & 0.002 & -0.000 & 0.002 & -0.000 \\
\hline 13. Scotland & -0.005 & -0.003 & -0.002 & -0.002 & 0.000 & -0.001 & 0.001 & 0.000 \\
\hline 14. Northern Ireland & $-0.023 * * *$ & $-0.018 * * *$ & $-0.020 * * *$ & $-0.015^{* * *}$ & $-0.017^{* * *}$ & $-0.014 * * *$ & $-0.015 * * *$ & $-0.013 * * *$ \\
\hline 15. Owned with mortgage & 0.003 & 0.003 & -0.000 & 0.001 & 0.004 & 0.004 & $0.005^{*}$ & $0.005^{* *}$ \\
\hline 16. Social housing & $0.028 * * *$ & $0.016 * * *$ & $0.027^{* * *}$ & $0.016^{* * *}$ & $0.014^{* * *}$ & $0.008 * * *$ & $0.015^{* * *}$ & $0.010 * * *$ \\
\hline 17. Private rented & $0.036 * * *$ & $0.019 * * *$ & $0.033^{* * *}$ & $0.018^{* * *}$ & $0.017^{* * *}$ & $0.009 * *$ & $0.018^{* * *}$ & $0.010 * * *$ \\
\hline 18. Semi-detached house/bu & 0.004 & $0.004^{*}$ & 0.003 & 0.003 & 0.002 & 0.002 & 0.002 & 0.001 \\
\hline 19. End terraced house & $0.021 * * *$ & $0.013 * * *$ & $0.020 * * *$ & $0.012 * * *$ & $0.014^{* * *}$ & $0.010^{* * *}$ & $0.014^{* * *}$ & $0.009 * * *$ \\
\hline 20. Terraced house & $0.016^{* * *}$ & $0.012^{* * *}$ & $0.015^{* * *}$ & $0.011^{* * *}$ & $0.009 * *$ & $0.006^{* *}$ & $0.008^{* *}$ & $0.006^{*}$ \\
\hline 21. Purpose built flat & $0.019 * * *$ & $0.016^{* * *}$ & $0.016^{* * *}$ & $0.013^{* * *}$ & 0.006 & $0.006^{*}$ & 0.005 & 0.005 \\
\hline 22. Converted flat & $0.039 * * *$ & $0.031 * * *$ & $0.035 * * *$ & $0.028 * * *$ & $0.015^{* *}$ & $0.012 * *$ & $0.014 * *$ & $0.012 * *$ \\
\hline 23. Bedsit & 0.048 & 0.030 & 0.045 & 0.029 & $0.056 *$ & 0.040 & $0.056^{*}$ & 0.040 \\
\hline 24. No central heating & $0.142^{* * *}$ & $0.078^{* * *}$ & $0.143^{* * *}$ & $0.078^{* * *}$ & $0.107^{* * *}$ & $0.062^{* * *}$ & $0.107^{* * *}$ & $0.062^{* * *}$ \\
\hline 25. No gas connection & $0.041 * * *$ & $0.028 * * *$ & $0.041 * * *$ & $0.028^{* * *}$ & $0.038^{* * *}$ & $0.027^{* * *}$ & $0.038^{* * *}$ & $0.028^{* * *}$ \\
\hline 26. Household head aged 65 to 75 & $-0.016^{* * *}$ & $-0.007 * * *$ & $-0.015^{* * *}$ & $-0.007^{* * *}$ & $-0.007^{* *}$ & -0.002 & $-0.007^{* *}$ & -0.002 \\
\hline 27. Household head aged 75+ & $-0.019 * * *$ & $-0.010 * * *$ & $-0.018 * * *$ & $-0.010 * * *$ & $-0.008^{* *}$ & -0.003 & $-0.008 * *$ & -0.003 \\
\hline 28. Household head unemployed & $0.010^{* *}$ & 0.004 & $0.012^{* *}$ & 0.005 & 0.003 & -0.001 & 0.003 & -0.001 \\
\hline 29. Has investment income & -0.003 & -0.001 & $-0.004 * *$ & -0.002 & 0.000 & 0.001 & -0.000 & 0.001 \\
\hline 30. Receives incapacity benefit & 0.002 & 0.006 & 0.004 & $0.007^{*}$ & -0.003 & 0.001 & -0.003 & 0.002 \\
\hline 31. Receives housing benefit & 0.003 & 0.005 & 0.004 & $0.005^{*}$ & -0.001 & 0.001 & -0.001 & 0.001 \\
\hline 32. Receives income support & 0.004 & 0.002 & $0.006^{*}$ & 0.003 & 0.001 & -0.000 & 0.002 & 0.000 \\
\hline 33. Contains single parent(s) & -0.000 & 0.002 & 0.001 & 0.003 & -0.003 & -0.000 & -0.003 & -0.000 \\
\hline 34. Contains children & 0.001 & 0.000 & 0.002 & 0.001 & -0.000 & 0.001 & -0.000 & 0.001 \\
\hline 35. Number of household members: 2 & $0.005^{*}$ & 0.003 & $0.005^{*}$ & 0.003 & 0.001 & 0.001 & 0.002 & 0.001 \\
\hline 36. Number of household members: 3 & $0.011^{* *}$ & $0.007^{* *}$ & $0.011 * * *$ & $0.007^{* *}$ & 0.005 & 0.003 & 0.006 & 0.004 \\
\hline 37. Number of household members: 4 & 0.005 & 0.002 & 0.006 & 0.003 & -0.001 & -0.002 & 0.000 & -0.001 \\
\hline 38. Number of household members: 5 & $0.011^{*}$ & 0.006 & $0.011^{*}$ & 0.007 & 0.002 & 0.000 & 0.004 & 0.001 \\
\hline 39. Number of household members: 6 & 0.008 & 0.008 & 0.009 & 0.010 & 0.001 & 0.003 & 0.002 & 0.005 \\
\hline 40. Number of household members: $7+$ & 0.001 & -0.002 & 0.003 & 0.000 & -0.010 & -0.010 & -0.008 & -0.008 \\
\hline 41. Has home computer & & & & & $0.004^{*}$ & 0.002 & $0.004^{*}$ & 0.002 \\
\hline 42. Number of rooms: 1 & & & & & $-0.014^{* *}$ & $-0.013^{* *}$ & $-0.014^{* *}$ & $-0.012^{* *}$ \\
\hline 43. Number of rooms: 3 & & & & & 0.005 & 0.001 & 0.006 & 0.001 \\
\hline 44. Number of rooms: 4 & & & & & -0.003 & -0.004 & -0.002 & -0.003 \\
\hline 45. Number of rooms: 5 & & & & & -0.005 & -0.004 & -0.003 & -0.003 \\
\hline 46. Number of rooms: 6 & & & & & -0.007 & $-0.010 * *$ & -0.006 & $-0.008 *$ \\
\hline 47. Number of rooms: $7+$ & & & & & -0.010 & $-0.010 * *$ & -0.008 & $-0.008^{*}$ \\
\hline
\end{tabular}




\begin{tabular}{|c|c|c|c|c|c|c|c|c|}
\hline \multirow[b]{2}{*}{ Explanatory Variable } & \multicolumn{4}{|c|}{ (Continued from previous page) } & \multicolumn{4}{|c|}{$\begin{array}{c}\text { Policymaking plus Best Predictor } \\
\text { Explanatory Variables }\end{array}$} \\
\hline & (1) & (2) & (3) & (4) & $(5)$ & $(6)$ & $(7)$ & $(8)$ \\
\hline $\begin{array}{l}\text { 48. Loan/hire payments somewhat of a } \\
\text { burden }\end{array}$ & & & & & $0.008 * * *$ & $0.008 * * *$ & $0.008 * * *$ & $0.008 * * *$ \\
\hline 49. Loan/hire payments a heavy burden & & & & & 0.002 & -0.002 & 0.002 & -0.002 \\
\hline 50. Problems paying for housing & & & & & $0.009 * * *$ & $0.007^{* *}$ & $0.009 * * *$ & $0.007^{* *}$ \\
\hline 51. Cannot afford holiday & & & & & $0.014 * * *$ & $0.009 * * *$ & $0.014 * * *$ & $0.009 * * *$ \\
\hline 52. Cannot afford to replace furniture & & & & & $0.007^{* *}$ & $0.005^{* *}$ & $0.007^{* *}$ & $0.005^{* *}$ \\
\hline 53. Cannot afford new clothes & & & & & 0.003 & 0.003 & 0.003 & 0.003 \\
\hline $\begin{array}{l}\text { 54. Cannot afford to eat meat on } \\
\text { alternate days }\end{array}$ & & & & & 0.000 & 0.002 & 0.000 & 0.001 \\
\hline 55. Cannot afford visitors for food/drink & & & & & $0.007^{* *}$ & 0.003 & $0.007 * *$ & 0.003 \\
\hline 56. Has condensation & & & & & $0.036^{* * *}$ & $0.025 * * *$ & $0.036 * * *$ & $0.025^{* * *}$ \\
\hline 57. Has a leaky roof & & & & & $0.037^{* * *}$ & $0.037^{* * *}$ & $0.037 * * *$ & $0.038^{* * *}$ \\
\hline 58. Has damp wall/floors & & & & & $0.023 * * *$ & $0.017^{* * *}$ & $0.023 * * *$ & $0.017^{* * *}$ \\
\hline 59. Has rot in windows/floors & & & & & $0.027^{* * *}$ & $0.019 * * *$ & $0.028 * * *$ & $0.019 * * *$ \\
\hline 60. Has crime in the local area & & & & & $0.016^{* * *}$ & $0.013 * * *$ & $0.016^{* * *}$ & $0.013^{* * *}$ \\
\hline Log likelihood & $-7,228.25$ & $-4,996.21$ & $-7,247.72$ & $-5,011.10$ & $-6,336.22$ & $-4,460.87$ & $-6,341.54$ & $-4,466.56$ \\
\hline $\begin{array}{l}\text { P-value, likelihood ratio test of joint } \\
\text { significance }\end{array}$ & 0.000 & 0.000 & 0.000 & 0.000 & 0.000 & 0.000 & 0.000 & 0.000 \\
\hline Policymaking variables & Yes & Yes & Yes & Yes & Yes & Yes & Yes & Yes \\
\hline Best predictor variables & No & No & No & No & Yes & Yes & Yes & Yes \\
\hline Number of observations & 55,767 & 47,969 & 55,767 & 47,969 & 55,767 & 47,969 & 55,767 & 47,969 \\
\hline Number of households & 10,465 & 9,400 & 10,465 & 9,400 & 10,465 & 9,400 & 10,465 & 9,400 \\
\hline
\end{tabular}

Notes: * indicates statistical significance at the $10 \%$ level, ${ }^{* *}$ indicates significance at the $5 \%$ level and $* * *$ indicates significance at the $1 \%$ level. The table reports average marginal effects on the probability of a household reporting that their dwelling lacks adequate heating facilities. A blank space indicates a variable was not included in the regression. Where a variable is labelled as quadratic the regression included both a linear and squared term of the variable, the reported average marginal effect for such variables is the combined change in probability associated with the linear and squared terms. In columns (2), (4), (6) and (8) 8,279 observations were dropped as the sample is restricted to cases where the lags of all four fuel poverty indicators. Selected base categories: rows 5-11 = 2002-03 wave; rows 12-14 = England; rows $15-17=$ owned outright; rows $18-23=$ detached house/bungalow; rows 26 and 27 = Household head aged under 65; rows 35-40 = household contains 1 person; rows 42-47= dwelling has 2 rooms; rows 28-34 and 50-60 are all binary variables where the base category is the opposite of the variable statement. Columns (3), (4), (7) and (8) exclude the expenditure, income and housing cost variables to allow comparison with the energy expenditure based fuel poverty indicators. In columns (1), (3), (5) and (7) 5 observations were dropped for May perfectly predicting adequate heating facilities, while in columns (2), (4), (6) and (8) 4 observations were dropped for the same reason. In columns (5) and (6) 4 observations of having adequate heating facilities were completely determined. Variables/categories frequently significant at the $10 \%$ level or above (direction in brackets) but not reported are: interview month - October, November, December and January (positive), has two or more cars (negative), has a dishwasher (negative).

\section{Table 9: Average marginal effects on the probability of a household reporting a lack of adequate heating facilities}

Comparing the lack of adequate heating facilities results with the expenditure-based FP indicators, while being in a flat or terraced house is frequently associated with a higher probability of reporting inadequate heating facilities, Table 6 shows these types of dwelling are generally associated with a lower probability of expenditure-based FP. Similarly, for the $10 \%$ indicator, having a housing tenure other than outright ownership is associated with a lower probability of FP, however, in Table 9 being in a rented property is positively associated with reporting inadequate heating facilities .

As one might expect, there is a positive relationship between lacking central heating and/or a gas connection and reporting inadequate heating facilities. The AMEs for the absence of central heating are particularly large, with this issue being associated with around a 14 percentage point increase in the probability of reporting a lack of adequate heating facilities in the Policymaking regressions when the lag of the dependent variable is excluded. In the same two regressions, lacking a gas 
connection is associated with a 4.1 percentage point increase in the probability of reporting a lack of adequate heating facilities.

As with reporting IAAW, reporting a lack of adequate heating facilities has a negative association with households headed by those over 65. Compared to the IAAW regressions, the Best Predictor regressions in Table 9 show an increase in the statistical significance of the household head age variables when the lagged dependent variable is not included. This is particularly true for households with a head aged 65 to 75 . In contrast to the other FP indicators, the receipt of benefits and a household containing children have almost no statistically significant associations with reporting a lack of adequate heating facilities.

Further differences to the IAAW regressions include that reporting an inability to afford clothes or to afford to eat meat on alternate days do not have statistically significant associations with reporting inadequate heating facilities. This pattern is more in keeping with the expenditure-based FP indicators, however, unlike the expenditure-based FP indicators, all the housing condition problem indicators are positively associated with reporting a lack of adequate heating facilities at the $1 \%$ level.

\section{Appendix 2 - Evidence on the persistence of fuel poverty}

The BHPS' panel nature enables an assessment of FP's persistence. The magnitude of persistence is important as there has been an emphasis on tackling FP through energy efficiency interventions which are 'permanent', i.e. they increase heat affordability over a large number of time periods. If households are only in FP for limited time, one may question whether other 'temporary' interventions, such as time limited income transfers, may be a more cost-effective.

Here we only report descriptive statistics rather than conducting a full panel data analysis. However, these descriptives fit with our questioning of some of the foundations of FP policy in the UK.

\section{A2.1 Persistence Descriptive Statistics}

Figure 6 reports the percentage of households who were FP in period $t$ that were not FP in period $t+1 .{ }^{60}$ To provide context to the FP exit probabilities, the probability of exiting income poverty ${ }^{61}$ is also reported. Figure 6 shows that: (i) the exit probabilities for all FP types are noticeably higher than for income poverty; and (ii) in all years, except 2007-08, a majority of households who lived in IAAW or $10 \% \mathrm{FP}$ in one year had exited FP by the following year. Both observations question whether permanent energy efficiency interventions are the lowest cost method of alleviating FP, when income poverty, which is more persistent, is primarily alleviated through temporary income related cash transfers. As one might expect, given that it is a 'relative' metric ${ }^{62}$, in all years, apart from 200708, the LIHC indicator had the lowest exit probability of the FP indicators. The differences between the FP and income poverty exit probabilities are all significant in all years at the $1 \%$ level, with the exception of the comparison with IAAW FP in 2007-08 where the difference is significant at the 5\% level.

\footnotetext{
60 This graph uses a dataset of 42,241 observations (9,011 households) where households were required to have sufficient data to be in the analysed sample for at least two consecutive waves. The results are very similar if one restricts analysis to households who did not move house between waves, or uses a larger dataset where households simply need to report the FP indicators (and not explanatory variables) in adjacent waves.

${ }^{61}$ We follow the UK definition of income poverty: the income poor are those with an income below $60 \%$ of median income, where income is equivalised.

${ }^{62} \mathrm{~A}$ movement in a household's relative position in the income or ENEX distributions over time is less likely than an absolute movement in income or ENEX, as relative movements exclude movements that are common to all households.
} 


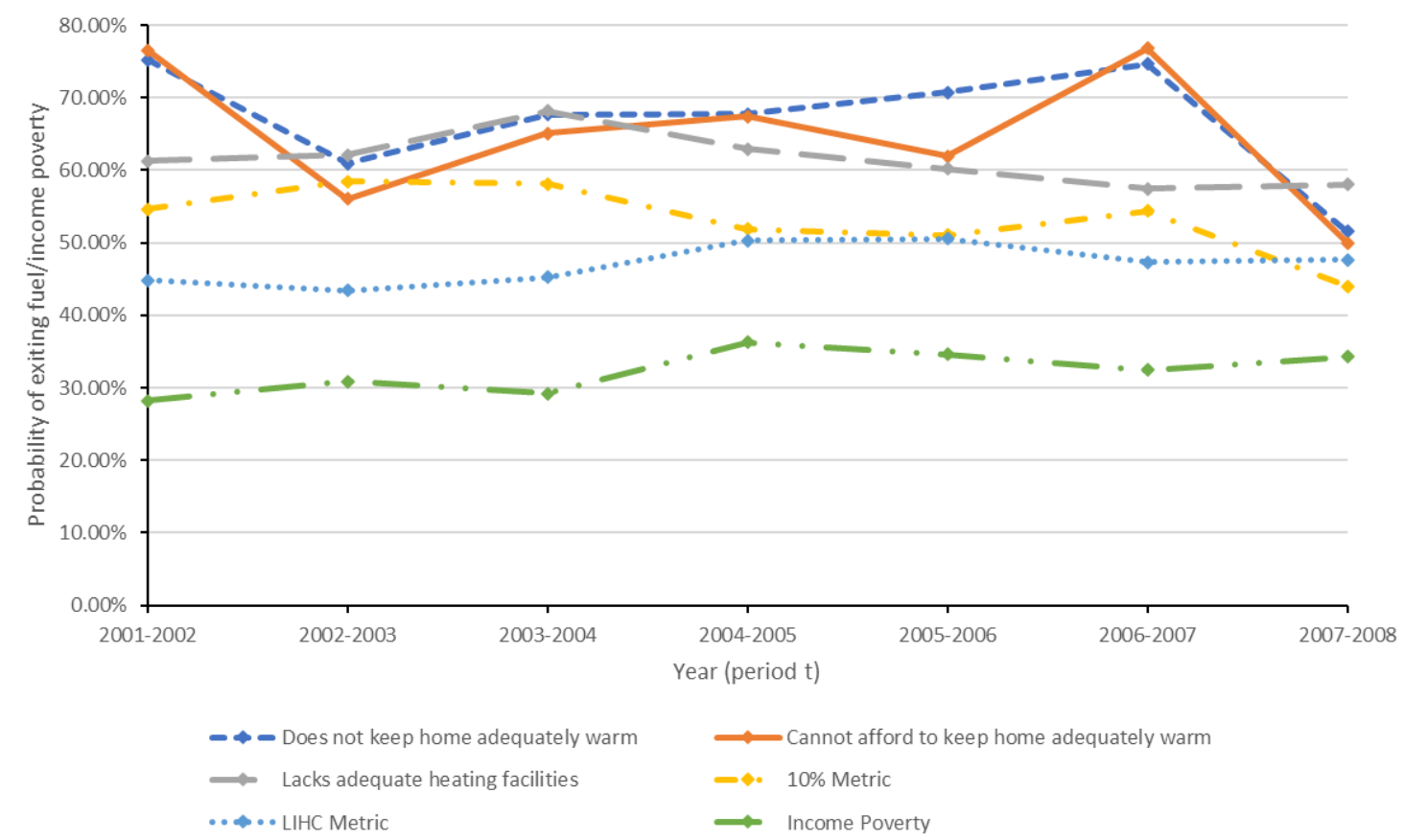

Figure 6: Percentage of fuel/income poor households in period t that were not fuel/income poor in period $t+1$ in the analysed sample, 2001-02 to 2007-08

Figure 7 reports the number of time periods in which a particular household identified themselves as FP conditional on being identified as FP at least once. To be considered for inclusion Figure 7 a household had to provide sufficient data to be included in the analysed sample in all eight waves. ${ }^{63}$ Of the households with sufficient data, 3.75\% reported IAAW in at least one year, $22.8 \%$ were $10 \%$ FP in at least one year and $37.3 \%$ were LIHC FP in at least one year.

Figure 7 again shows comparatively low persistence in the perception-based FP indicators. $61.3 \%$ of those who reported IAAW at least once reported that they faced this problem only once, while $85.7 \%$ reported this issue in no more than two waves. There also appears to be limited persistence with $10 \%$ FP since $69.4 \%$ of households in this type of FP at least once experienced it in no more than two periods. However, LIHC FP is noticeably more persistent: only $33.2 \%$ of those LIHC FP at least once were LIHC FP only once and $22.7 \%$ of households in LIHC FP at least once were in FP for between 5 and 8 waves.

633,197 households met this condition. 


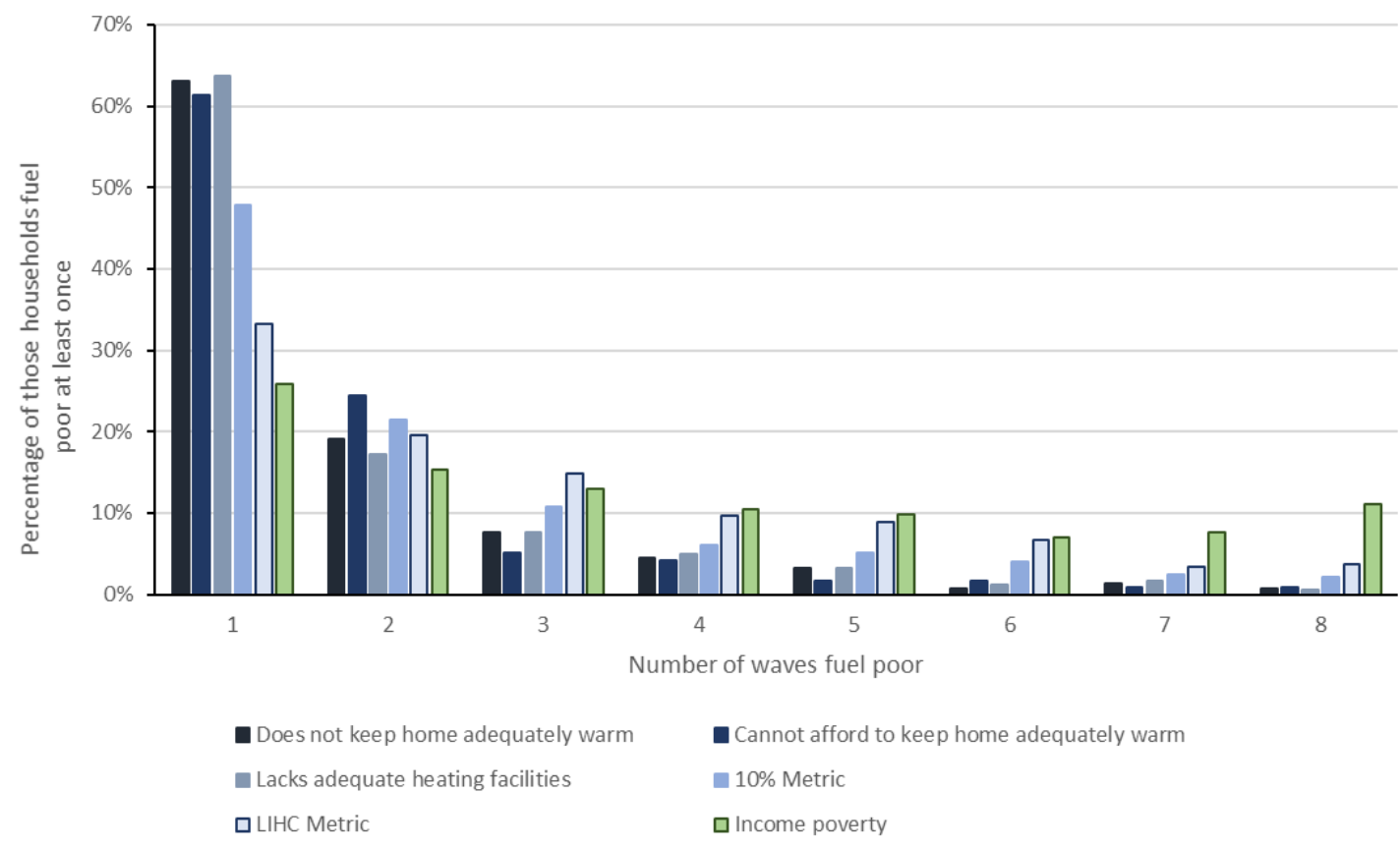

Figure 7: Number of waves in which a household was identified as fuel poor, conditional on being identified as fuel poor at least once and present in all waves 2001-02 to 2008-09

\section{A2.2 Robustness of the persistence statistics}

It is important to consider whether the persistence results above are robust. In broad terms the finding that FP is less persistent than income poverty seems reasonably solid.

First, the BHPS does not indicate whether households received interventions that reduced the persistence of their FP spell. Overall, the results show the persistence of FP after FP alleviation policies have been applied to households. However, for the comparison with income poverty it is important to note that the persistence of income poverty is also shown after policy interventions. For policy interventions to explain the gap in persistence, it must be that FP interventions are noticeably more effective than income poverty interventions. However, this seems unlikely given the FP literature's conclusion that it is hard to effectively target FP households ${ }^{64}$.

Another concern is that FP persistence is reduced by attrition, i.e. households dropping out of the survey. Again, differences in attrition across the poverty indicators matter, rather than the absolute level of attrition. Table 10 reports the average rate of attrition per period for households reporting each poverty indicator. The table also reports the differences in attrition rates between the various types of FP and income poverty. One can adjust the exit probabilities in Figure 6 by assuming all those who drop out after being identified as FP/income poverty in period $t$, would have remained in $\mathrm{FP} /$ income poverty, if they had remained in the survey. After this adjustment it is still possible to state that, at the $1 \%$ significance level, in each survey wave the FP indicators have a higher exit probability than income poverty significant.

${ }^{64}$ For example, see Walker et al. (2013). 


\begin{tabular}{l|cc} 
Group of respondents & $\begin{array}{c}\text { Percentage of those identified as } \\
\text { fuel poor at period t recorded as } \\
\text { missing in period t+1 }\end{array}$ & $\begin{array}{c}\text { Difference to attrition rate } \\
\text { for income poverty }\end{array}$ \\
\hline \hline All respondents & 14.7 & -2.7 \\
Does not keep home adequately warm & 18.2 & 0.8 \\
Cannot afford adequate warmth in the home & 18.6 & 1.2 \\
Lacks adequate heating facilities & 20.5 & 3.0 \\
10\% Metric & 18.0 & 0.6 \\
LIHC Metric & 16.3 & -1.2 \\
Income poverty & 17.4 & - \\
\hline
\end{tabular}

Data is pooled across all analysed time periods. The last period $t$ is 2007-2008 and the number of observations is 49,535 . To be included in period $t$ a household had to have all the data required for the main regressions. A household is classed as missing in period $t+1$ if it did not provide all the data required for the main regressions.

Table 10: Percentage of respondents identified as fuel poor according to different fuel poverty indicators in period $t$ that lacked the required data to be part of the analysis in period $t+1$

One might think the persistence results could be affected by the trajectory of energy prices and, therefore, ENEX over the sampled period. As noted previously, Deller and Waddams Price (2018) indicate that the period 2001-02 to 2004-05 was a period when median ENEXShr was unusually low and, hence, was a time of particularly easy energy affordability. It seems likely that this relative affordability does affect the results above. Between 2006-07 and 2007-08 (a period of rising energy prices) the FP exit probabilities fell by 10.4 percentage points for the $10 \%$ indicator and by 26.8 percentage points for the IAAW indicator. However, Deller and Waddams Price indicate that, by 2009, median ENEXShr was roughly back to its long-run level. Significantly, the exit probabilities for the FP indicators in $2007-08^{65}$ in Figure 6 remain noticeably above the exit probability for income poverty.

The lower persistence of perception-based FP relative to expenditure-based FP/income poverty may be elevated by two factors. First, the perception-based indicators may be particularly context dependent. A report of IAAW may be disproportionately influenced by the conditions at, or in the days immediately prior to, interview. If so, differences in reports of IAAW may be influenced by, for example, variations in weather conditions between interview days rather than by a change in the fundamental position of a household. Second, it is not certain that the same household member answered the questions for the perception-based indicators in all years. This highlights a further complexity in identifying FP in multi-person households: views about what constitutes adequate warmth and affordability may vary between household members. However, the expenditure-based FP indicators (and income poverty) may themselves have inflated exit probabilities, due to the tendency to round ENEX, as discussed in section 3.

Last, statistics from our sample might overstate income poverty persistence. This is because median income is weighted to represent the median income for the UK as a whole. The analysed data significantly oversamples devolved administrations which have lower household incomes than England, hence, that a small proportion of households exit income poverty between periods may be structural. However, using unweighted median incomes, i.e. removing the structural element, indicates the impact of this issue is small. Averaged across all time periods, an unweighted median income increases the income poverty exit rate by only 1.0 percentage points. Similarly, using unweighted medians increases the percentage of households in Figure 6 that were income poor in only one period by only 1.8 percentage points.

${ }^{65}$ In this year the $t+1$ period is $2008-09$. 


\section{A2.3 Existing Literature on Fuel Poverty Persistence}

A number of existing papers consider FP dynamics. While these papers often provide full econometric models of FP dynamics, the descriptive statistics nevertheless highlight that for policymaking the magnitude, as well as the existence of persistence, is important. Compared to some of the papers the analysis benefits from analysing a greater number of time periods.

Roberts et al. (2015) use BHPS data between 1997 and 2008 to consider persistence in expenditurebased FP with a discrete hazard model. Compared to Roberts et al., we consider perception-based indicators and use a 10\% FP metric that matches the official English FP definition. ${ }^{66}$ The exit probabilities for our $10 \%$ metric are similar to Roberts et al. In their regressions, Roberts et al. find greater persistence among urban than rural households. The authors note that, depending on the extent of persistence, different households may require different FP interventions.

The other assessment of FP persistence in the UK is BEIS (2018). However, as BEIS acknowledges their analysis is weakened by the fact that it does not actually track individual households through time. Instead, they predict 'churn' in FP households by running their model projecting headline rates of LIHC FP multiple times. This methodology may explain why they predict only $16 \%$ LIHC FP households moved out of FP between 2016 and 2017.

Turning to studies in other countries, Phimister et al. (2015) look at persistence in expenditure-based FP and a composite perception-based indicator ${ }^{67}$, using Spanish panel data covering 4 years. Again, Phimister et al. find the exit probability from $10 \%$ FP is higher than for income poverty $(55.9 \%$ vs 30.6\%). That Phimister et al. report a noticeably lower exit probability from perception-based FP than the present paper data probably reflects the broader definition of Phimister et al.'s composite indicator.

Chaton and Lacroix (2018) consider FP dynamics in France using perception-based FP indicators. They find that households further up the income distribution have higher odds of moving out of $\mathrm{FP} /$ severe FP, although, their analysis uses only three years of data. In a similar vein to ourselves, they suggest direct subsidies for energy costs may be most appropriate if FP is transitory whereas energy efficiency improvements are more suitable where FP is a chronic phenomenon.

Extending the study of FP dynamics to less developed economies and a different set of indicators, Alem and Demeke (2020) find persistence in FP for Ethiopian households in a dynamic probit model. Last, Poggi and Florio (2010) consider the dynamics of households reporting arrears on their utility bills using pan-European data between 1994 and 2001. Using a dynamic probit model, they identify a positive relationship between the first lag of utility bill arrears and reporting utility bill arrears in the current period. ${ }^{68}$

\footnotetext{
${ }^{66}$ Unlike the official $10 \%$ indicator, Roberts et al.'s indicator uses equivalised after housing costs income as the denominator.

${ }^{67}$ The composite indicator classifies a household as FP if they cannot afford an appropriate temperature in winter or their dwelling suffers from leaks, damp or rot or the household has been late with their water, energy or community cost bill in the last year.

${ }^{68}$ A positive relationship is also found between utility bill arrears in 1994 and utility bill arrears in the present period.
} 


\section{Appendix 3 - Fuel poverty indicators A3.1 Official fuel poverty definitions}

DECC/BRE (2016) describes the official English FP statistics' methodology.

$10 \%$ metric $A$ household is $\mathrm{FP}$ if the value of the following ratio exceeds 0.1 :

$$
\text { FP Ratio }=\frac{\text { Required Fuel Costs }}{\text { Income }}
$$

Income is net of tax and benefits.

LIHC metric This definition involves two thresholds, a household is FP if both:

1. Required fuel costs are above the national median

AND

2. Income remaining after the deduction of required fuel costs is below the official poverty line.

Income is net income after the deduction of housing costs and equivalisation ${ }^{69}$, where housing costs are restricted to mortgage and rent payments (net of housing benefit). The official poverty line is defined as $60 \%$ of median equivalised disposable income ${ }^{70}$. When calculating the LIHC metric required fuel costs are also equivalised using a different equivalisation factor.

The official annual FP statistics are based on English Housing Survey (EHS) data from two consecutive waves which combines a household interview with a physical survey for around 6,000 households. Required energy use is based on the EHS's physical survey and aggregates four estimates reflecting: space heating, water heating, lights and appliances, and cooking. Each of these estimates is calculated based on an engineering model and a set of assumptions, such as, that all households aim to heat their main living space to the same temperature. In contrast, the present analysis is based on households' self-reports of their ENEX, which will vary according to households' differing preferences etc.

\section{A3.2 BHPS data for the expenditure-based indicators}

The ENEX used to calculate the $10 \%$ and LIHC indicators in our analysis refers to the 12 months prior to a household's interview. Four questions separately record expenditures on electricity, gas, oil and coal/other fuels. For example, for electricity, the question was:

"In the last year, since September $1^{\text {st }} 1999$, approximately how much has your household spent on domestic fuel starting with...Electricity" ${ }^{11}$

The expenditures on each fuel are then summed to give total ENEX.

The $10 \%$ indicator is calculated from total ENEX divided by household income. Calculating the LIHC indicator is more involved as median ENEX and the income poverty line need to be estimated for each year. Since the booster samples mean the devolved administrations are oversampled, household weights supplied with the BHPS are applied to make the median estimates representative of the population of UK households. Also, to ensure representativeness, the medians are calculated

\footnotetext{
${ }^{69}$ For after housing costs equivalisation factors see Table 10, pg 50, DECC/BRE (2016).

${ }^{70}$ Equivalised after housing costs net income.

${ }^{71}$ The reference year changed with each survey wave. If an interview occurred in a month other than September, it is unclear how this question was adjusted.
} 
using all households that answer the questions required to produce the LIHC indicator. This is a less restrictive requirement than for the main analysed sample where a household must provide answers for all the variables detailed in Section 3.

\section{A3.3 Perception-based survey questions}

The 'Inability to keep home adequately warm' indicator comes from the question:

"Here is a list of things which people might have or do. Please look at this card and tell me which things you (and your household) have or do? Keep your home adequately warm"

A household responding No to this question, is marked as being unable to keep their home adequately warm. If a household answered No to the question above, they were then asked the following question:

"Would you like to be able to keep your home adequately warm, but must do without because you cannot afford it?"

If a household responded Yes to this second question, they have been marked as IAAW FP.

A household was marked as lacking adequate heating facilities if they answered Yes to the following question:

"Does your accommodation have any of the following problems? Lack of adequate heating facilities"

\section{Appendix 4 - Additional Materials}

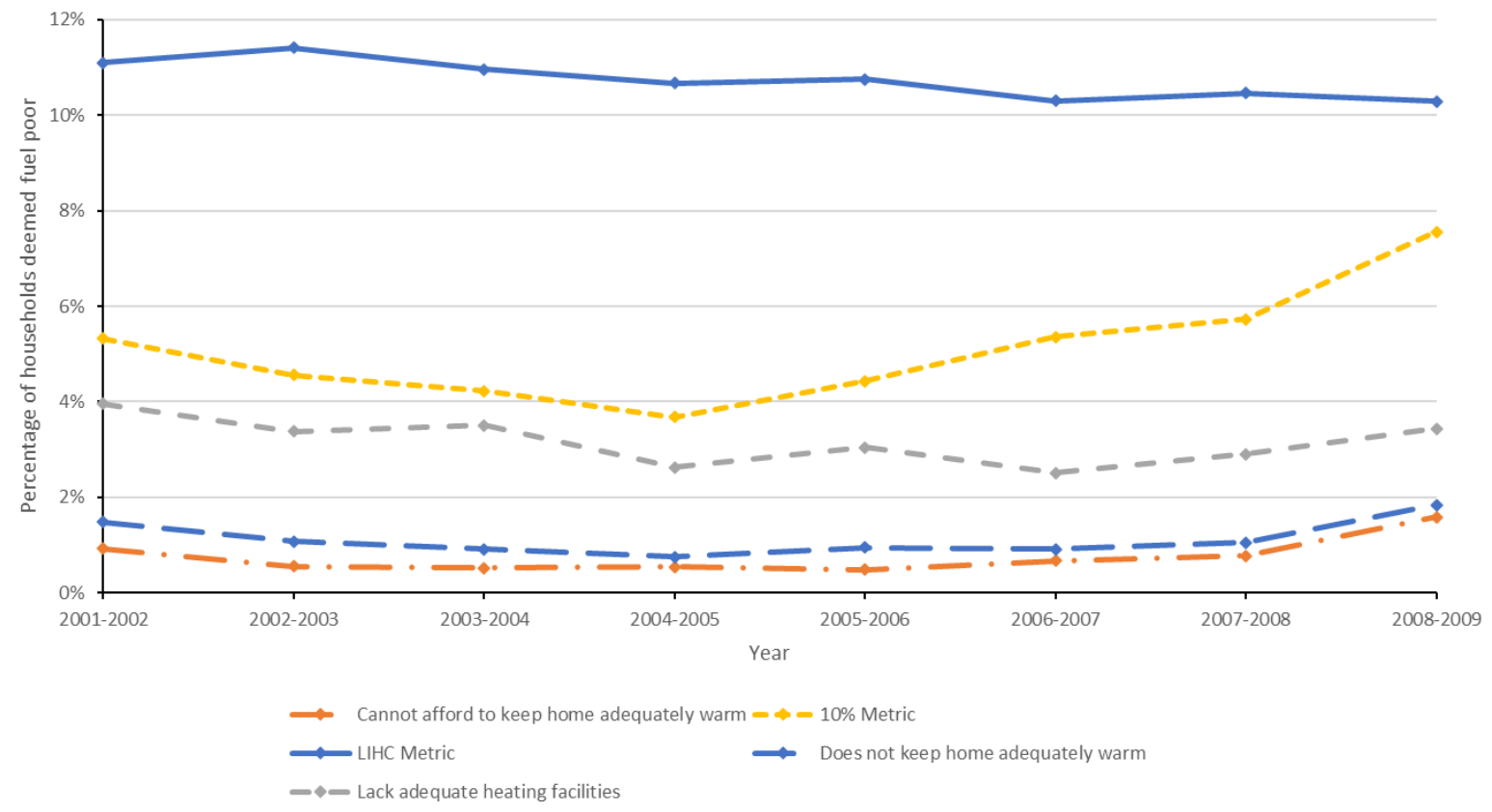

Figure 8: UK population estimates of rates of alternative fuel poverty indicators, 2001-02 to 2008- 


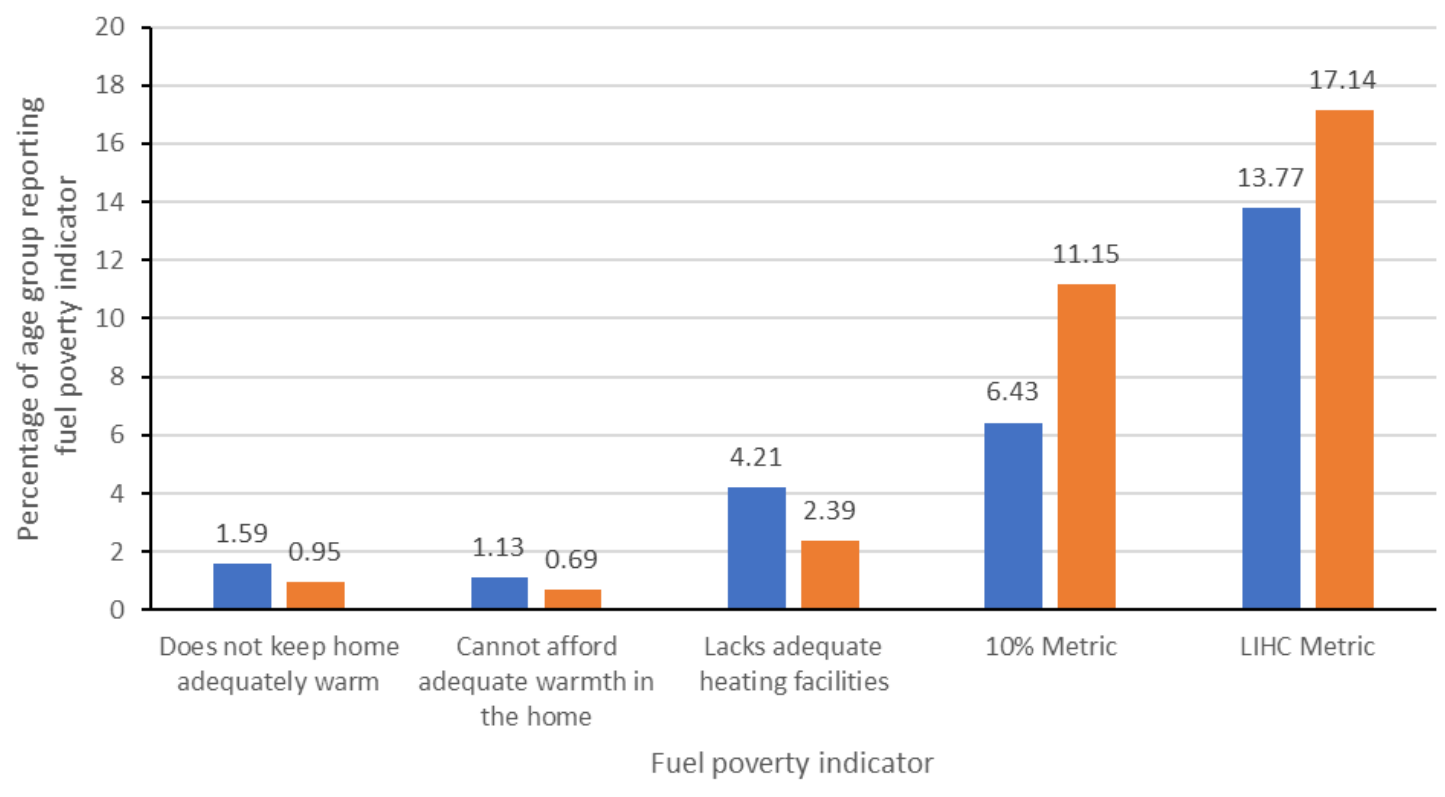

- Household head under 65 Household head 65 or over

Figure 9: The percentage of households in fuel poverty by age of household head, pooled data 2001-02 to 2008-0972

\begin{tabular}{|c|c|c|c|c|c|}
\hline & $\begin{array}{c}\text { Does not keep } \\
\text { home adequately } \\
\text { warm }\end{array}$ & $\begin{array}{l}\text { Cannot afford to } \\
\text { keep home } \\
\text { adequately warm }\end{array}$ & $\begin{array}{l}\text { Lacks adequate } \\
\text { heating facilities }\end{array}$ & $\begin{array}{l}10 \% \\
\text { Metric }\end{array}$ & $\begin{array}{l}\text { LIHC } \\
\text { Metric }\end{array}$ \\
\hline $\begin{array}{l}\text { Does not keep home } \\
\text { adequately warm }\end{array}$ & 1.000 & & & & \\
\hline $\begin{array}{l}\text { Cannot afford to keep } \\
\text { home adequately warm }\end{array}$ & $0.845^{* * *}$ & 1.000 & & & \\
\hline $\begin{array}{l}\text { Lacks adequate heating } \\
\text { facilities }\end{array}$ & $0.261^{* * *}$ & $0.203^{* * *}$ & 1.000 & & \\
\hline 10\% Metric & $0.055^{* * *}$ & $0.059 * * *$ & $0.046 * * *$ & 1.000 & \\
\hline LIHC Metric & $0.050 * * *$ & $0.057^{* * *}$ & $0.058^{* * *}$ & $0.511 * * *$ & 1.000 \\
\hline
\end{tabular}

Notes: The table reports Pearson's correlation co-efficients for each pair of fuel poverty indicators. ${ }^{* * *}$ indicates the correlation is significantly different from zero at the $1 \%$ level. The high correlation co-efficient between 'Does not keep home adequately warm' and 'Cannot afford to keep home adequately' results from the survey's question structure. The data covers 55,772 observations from 10,465 households.

Table 11: Pearson's correlation coefficients between pairs of fuel poverty indicators, pooled data 2001-02 to 2008-09

\footnotetext{
72 The equality of the fuel poverty rates between households with a head aged under 65 and those aged 65 and over is rejected at the $1 \%$ significance level for all five indicators.
} 


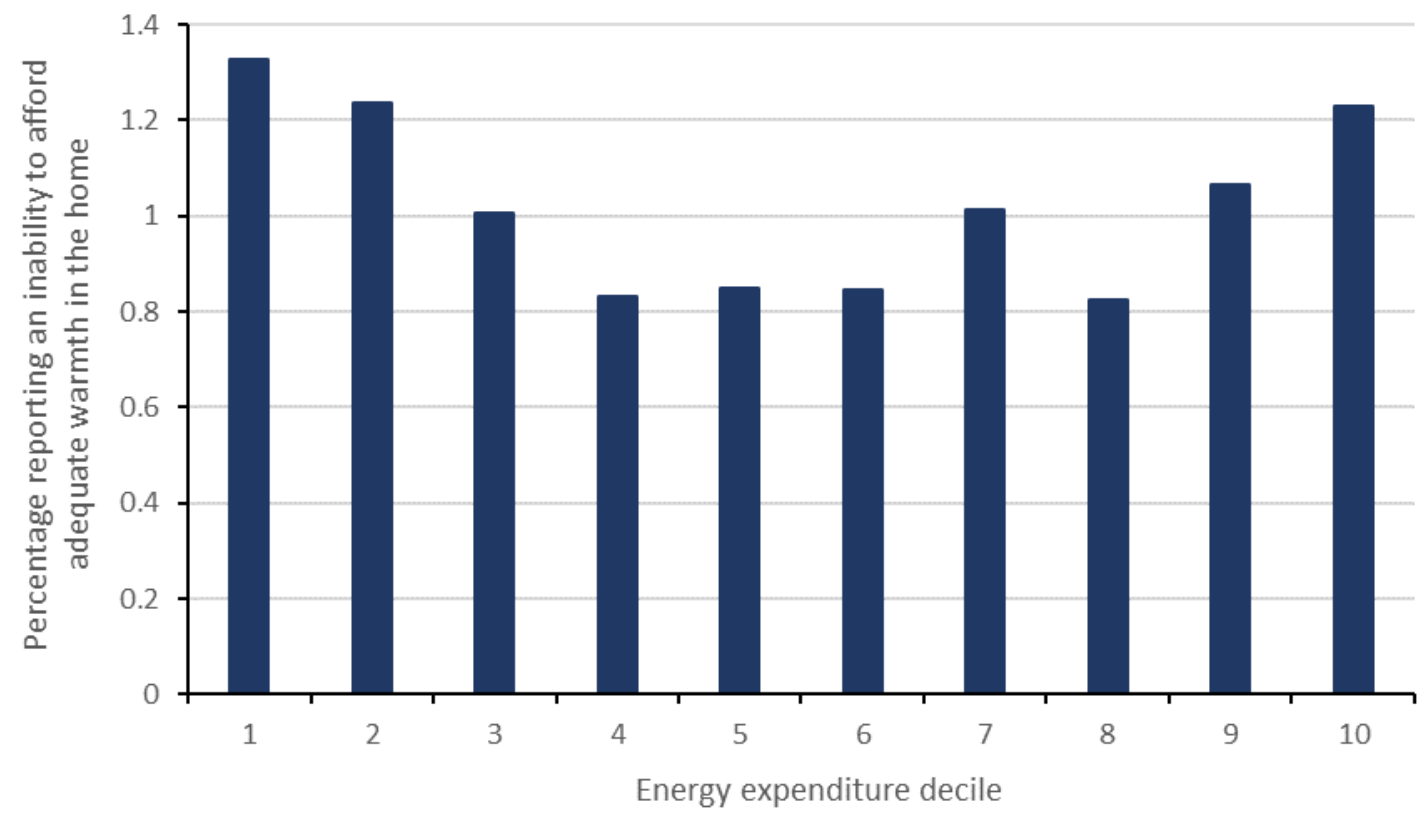

Figure 10: Percentage of observations where an inability to afford adequate warmth in the home is reported by energy expenditure decile, pooled data 2001-02 to 2008-09

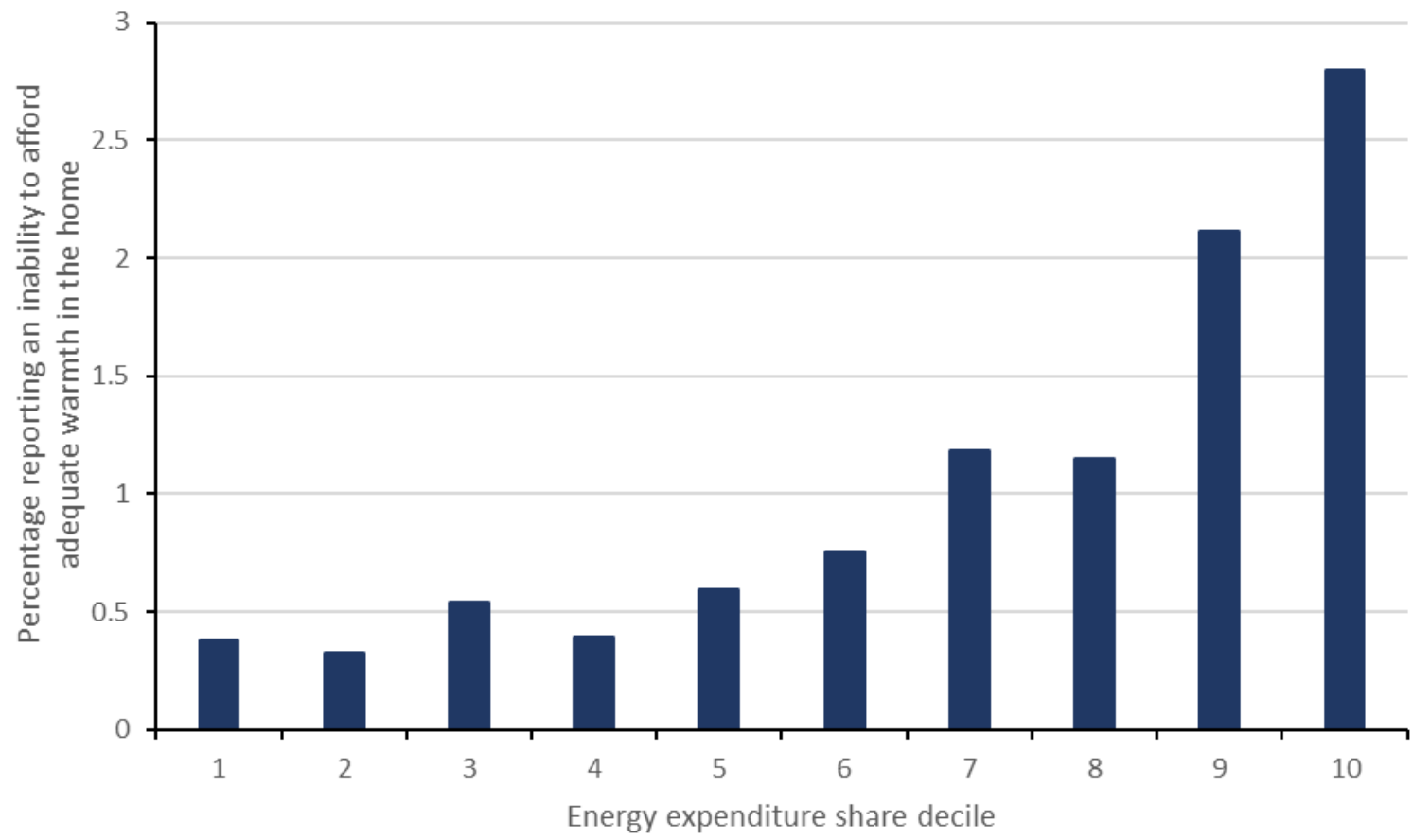

Figure 11: Percentage of observations where an inability to afford adequate warmth in the home is reported by energy expenditure share decile, pooled data 2001-02 to 2008-09 


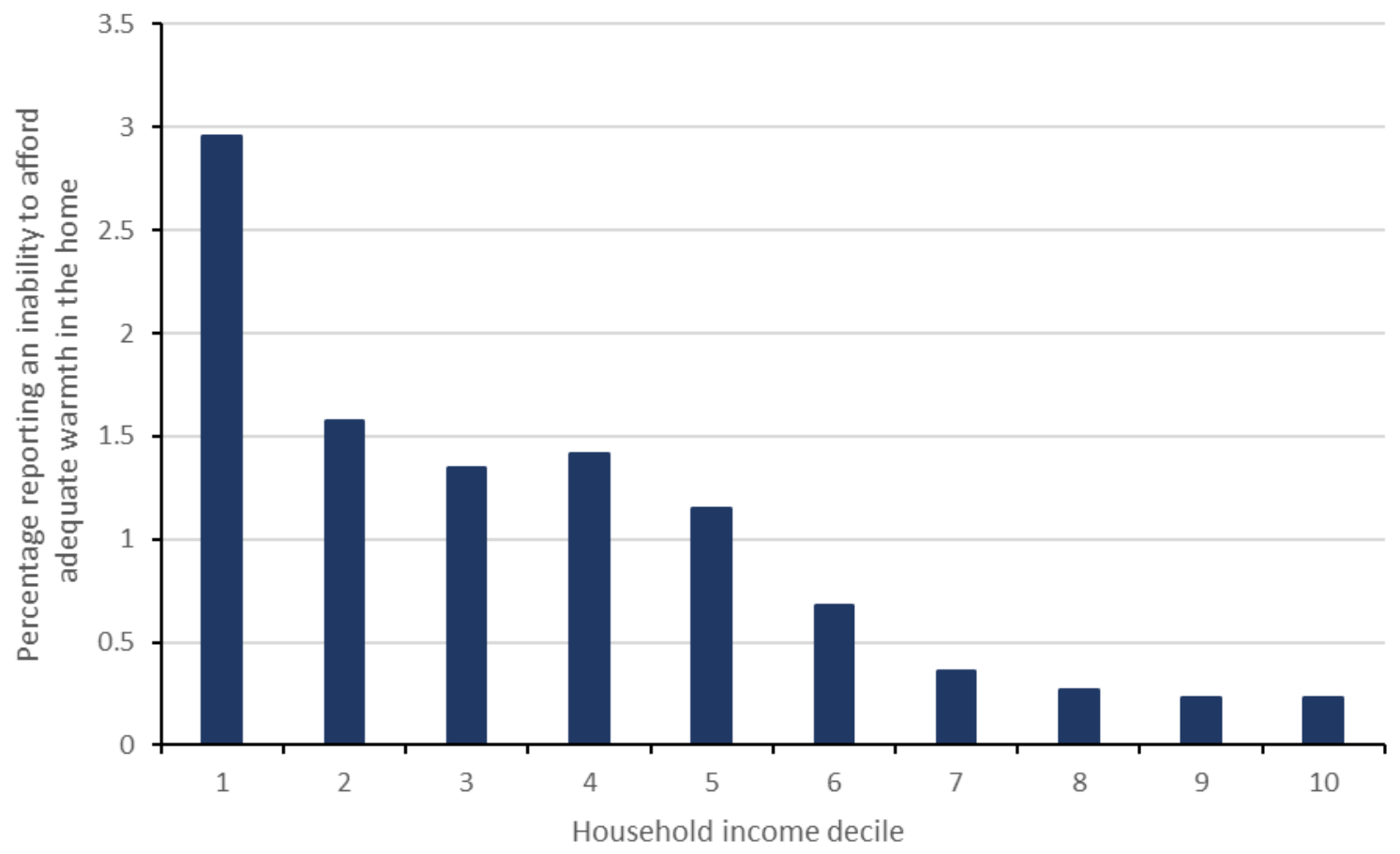

Figure 12: Percentage of observations where an inability to afford adequate warmth in the home is reported by household income decile, pooled data 2001-02 to 2008-09

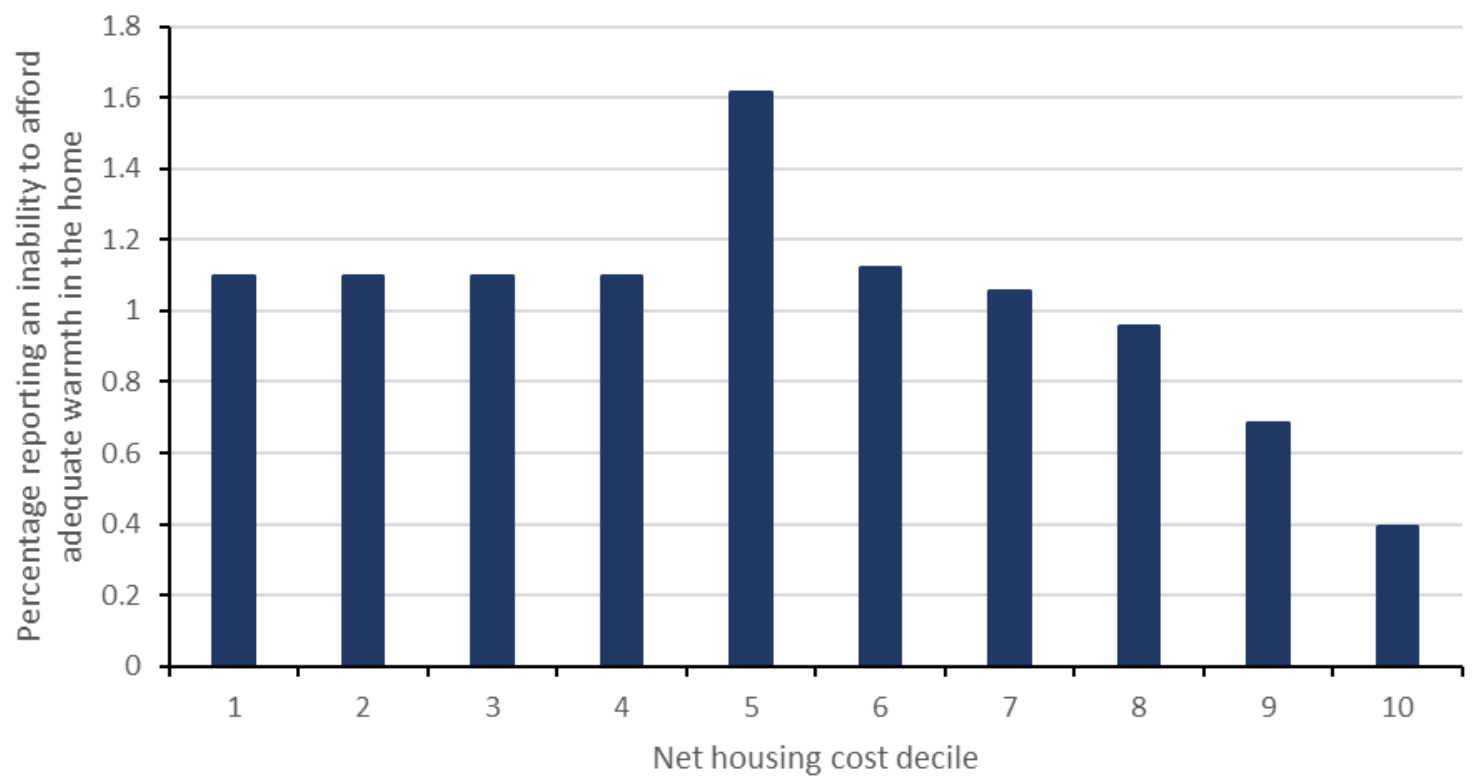

Figure 13: Percentage of observations where an inability to afford adequate warmth in the home is reported by net housing cost decile, pooled data 2001-02 to 2008-0973

\footnotetext{
${ }^{73}$ In the first three deciles the net housing costs of all households is zero, while in the fourth decile all but 12 observations involve net housing costs of zero.
} 


\section{References}

Advani, A., P. Johnson, A. Leicester and G. Stoye (2013), 'Household Energy Use in Britain: A Distributional Analysis', IFS Report R85, Institute for Fiscal Studies, London, United Kingdom, available at: https://www.ifs.org.uk/comms/r85.pdf?source=post_page-

Agbim, C., F. Araya, K.M. Faust and D. Harmon (2020), 'Subjective versus objective energy burden: A look at drivers of different metrics and regional variation of energy poor populations', Energy Policy, 144, article 111616

Alem, Y. and E. Demeke (2020), 'The persistence of energy poverty: A dynamic probit analysis', Energy Economics, 90, article 104789

Angelini, V., M. Daly, M. Moro, M.N. Paniagua, E. Sidman, I. Walker and M. Weldon (2019), 'The effect of the Winter Fuel Payment on household temperature and health: a regression discontinuity design study', Public Health Research, 7(1), pp. 1-60

Awaworyi Churchill, S.A. and R. Smyth (2020), 'Ethnic diversity, energy poverty and the mediating role of trust: Evidence from household panel data for Australia', Energy Economics, 86, article 104663

Awaworyi Churchill, S.A., R. Smyth and L. Farrell (2020), 'Fuel poverty and subjective wellbeing', Energy Economics, 86, article 104650

Baker, P., R. Blundell and J. Micklewright (1989), 'Modelling Household Energy Expenditures Using Micro-Data', Economic Journal, 99(397), pp. 720-738

Baker, P. and R. Blundell (1991), 'The Microeconometric Approach to Modelling Energy Demand: Some Results for UK Households', Oxford Review of Economic Policy, 7(2), pp. 54-76

Beatty, T.K.M, L. Blow, T.F. Crossley and C. O'Dea (2014), 'Cash by any other name? Evidence on labelling from the UK Winter Fuel Payment', Journal of Public Economics, 118, pp. 86-96

Berthoud, R., M. Blekesaune and R. Hancock (2009), 'Ageing, income and living standards: evidence from the British Household Panel Survey', Ageing and Society, 29, pp. 1105-1122

Boardman, B. (1991), 'Fuel poverty: from cold homes to affordable warmth', Belhaven Press, London, United Kingdom

Boardman, B. (2011), 'Quality of life benefits (problems) that are hard to measure', presentation to IEA, Dublin, 27 January available at: https://iea.blob.core.windows.net/assets/imports/events/163/PRES9_BOARDMAN.pdf

Bohr, J. and A.C. McCreery (2020), 'Do Energy Burdens Contribute to Economic Poverty in the United States? A Panel Analysis', Social Forces, 99(1), pp. 155-177

Charlier, D. and S. Kahouli (2019), 'From Residential Energy Demand to Fuel Poverty: Incomeinduced Non-linearities in the Reactions of Households to Energy Price Fluctuations', The Energy Journal, 40(2)

Chaton, C. and E. Lacroix (2018), 'Does France have a fuel poverty trap?', Energy Policy, 113, pp. 258268

Crawford, I., S. Smith and S. Webb (1993), 'VAT on Domestic Energy', Institute for Fiscal Studies, London, United Kingdom, available at: http://discovery.ucl.ac.uk/17291/1/17291.pdf 
Deller, D. (2018), 'Energy Affordability in the EU: the Risks of Metric Driven Policies', Energy Policy, 119 , pp. $168-182$

Deller, D. and C. Waddams Price (2017), 'Report into UK Energy Expenditure Shares - A Long Term View', Centre for Competition Policy, University of East Anglia, available at: http://competitionpolicy.ac.uk/documents/8158338/18232983/UK+Energy+Expenditure+Shares +A+Long+Term+View.pdf/a252cb67-719c-4d51-b006-b30909162730

Deller, D. and C. Waddams Price (2018), 'Energy Affordability in the UK: Corrected Energy Expenditure Shares 1992-2014', Centre for Competition Policy Working Paper 18-8, available at: http://competitionpolicy.ac.uk/documents/8158338/24898393/CCP+WP+18-

8+complete.pdf/4960a073-a343-53c8-9aa2-d5017f78651e

Department for Business, Energy and Industrial Strategy (BEIS) (2017), 'Fuel Poverty Dataset Documentation', July 2017, available at: http://doc.ukdataservice.ac.uk/doc/8228/mrdoc/pdf/8228_2015_fuel_poverty_dataset_docume ntation.pdf

Department for Business, Energy and Industrial Strategy (BEIS) (2018), 'Do households move in and out of fuel poverty?', Energy Trends: special feature article, 20 December 2018, available at: https://assets.publishing.service.gov.uk/government/uploads/system/uploads/attachment data/ file/766091/Do households move in and out of fuel poverty.pdf

Department for Business, Energy and Industrial Strategy (BEIS) (2019), 'Consultation on the Fuel Poverty Strategy for England', July 2019, available at: https://assets.publishing.service.gov.uk/government/uploads/system/uploads/attachment_data/ file/819606/fuel-poverty-strategy-england-consultation.pdf

Department for Business, Energy and Industrial Strategy (BEIS) (2020), 'What are households' perceptions of fuel poverty?', Energy Trends: special feature article, 25 June 2020, available at: https://www.gov.uk/government/publications/energy-trends-june-2020-special-feature-articlewhat-are-households-perceptions-of-fuel-poverty

Department of Energy and Climate Change (DECC) (2009), 'Annual Report on Fuel Poverty Statistics 2009', October 2009

Department of Energy and Climate Change (DECC)/BRE (2016), 'Fuel Poverty - Methodology Handbook', June 2016, London, United Kingdom

Dominy, N. and E. Kempson (2006), 'Understanding older people's experiences of poverty and material deprivation', Research Report No 363, Department for Work and Pensions, London, United Kingdom, available at: https://www.bristol.ac.uk/medialibrary/sites/geography/migrated/documents/pfrc0606.pdf

Dubois, U (2012), 'From targeting to implementation: The role of identification of fuel poor households', Energy Policy, 49, pp. 107-115

Fergus, P. and C. Chalmers (2020), 'BMI: A Behavior Measurement Indicator for Fuel Poverty Using Aggregated Load Readings from Smart Meters', draft book chapter, available at: https://arxiv.org/ftp/arxiv/papers/2002/2002.12899.pdf 
Fizaine, F. and S. Kahouli (2019), 'On the power of indicators: how the choice of fuel poverty indicator affects the identification of the target population', Applied Economics, 51(11), pp. 10811110

Hamilton, I.G., A. O'Sullivan, G. Huebner, T. Oreszczyn, D. Shipworth and A. Summerfield (2017), 'Old and cold? Findings on the determinants of indoor temperatures in English dwellings during cold conditions', Energy and Buildings, 141, pp. 142-157

Healy, J.D. and J.P. Clinch (2002), 'Fuel Poverty in Europe: A Cross-County Analysis using a new Composite Measurement', Environmental Studies Research Series Working Paper ESRS 02/04, University College Dublin, available at: http://citeseerx.ist.psu.edu/viewdoc/download;jsessionid=FB32A6315CE9FDD6D64F653B8024C7 9F?doi=10.1.1.636.5158\&rep=rep1\&type=pdf

Heindl, P. (2015), 'Measuring fuel poverty: General considerations and application to German household data', FinanzArchiv: Public Finance Analysis, 71(2), pp. 178-215

Heindl, P. and R. Schuessler (2015), 'Dynamic properties of energy affordability measures', Energy Policy, 86, pp. 123-132

Hills, J. (2012), 'Getting the measure of fuel poverty - Final Report of the Fuel Poverty Review', Centre for Analysis of Social Exclusion, CASE report 72, London, United Kingdom, available at: https://www.gov.uk/government/uploads/system/uploads/attachment_data/file/48297/4662getting-measure-fuel-pov-final-hills-rpt.pdf

Huchuk, B., W. O'Brien and S. Sanner (2018), 'A longitudinal study of thermostat behaviours based on climate, seasonal, and energy price considerations using connected thermostat data', Building and Environment, 139, pp. 199-210

Huebner, G.M., I. Hamilton, Z. Chalabi, D. Shipworth and T. Oreszczyn (2018), 'Comparison of indoor temperatures of homes with recommended temperatures and effects of disability and age: an observational, cross-sectional study', BMJ Open, 8(5), pp. 1-7

Huebner, G.M., Z. Chalabi, I. Hamilton and T. Oreszczyn (2019), 'Determinants of winter indoor temperatures below the threshold for healthy living in England', Energy and Buildings, 202, article 109399

Hughes, C., S. Natarajan, C. Liu, W.J. Chung and M. Herrera (2019), 'Winter thermal comfort and health in the elderly', Energy Policy, 134, article 110954

Kennard, H.R., G.M. Hebner and D. Shipworth (2020), 'Observational evidence of the seasonal and demographic variation in experienced temperature from 77,743 UK Biobank particpants', Journal of Public Health, 42(2), pp. 312-318

Liddell, C. and C. Morris (2010), 'Fuel poverty and human health: A review of recent evidence', Energy Policy, 38(6), pp. 2987-2997

Liddell, C., C. Morris, S.J.P. McKenzie and G. Rae (2012), 'Measuring and monitoring fuel poverty in the UK: National and regional perspectives', Energy Policy, 49, pp. 27-32

Llorca, M., A. Rodrgiuez-Alvarez and T. Jamasb (2020), 'Objective vs subjective fuel poverty and selfassessed health', Energy Economics, article 104736 
Longhi, S. (2014), 'Residential Energy Use and the Relevance of Changes in Household Circumstances', Institute of Social and Economic Research, University of Essex, Working Paper No. 2014-22, May 2014, available at: https://www.iser.essex.ac.uk/research/publications/working-papers/iser/2014-22.pdf

Meier, H. and K. Rehdanz (2010), 'Determinants of residential space heating expenditures in Great Britain', Energy Economics, 32(5), pp. 949-959

Meier, H., T. Jamasb and L. Orea (2013), 'Necessity or Luxury Good? Household Energy Spending and Income in Britain 1991-2007', The Energy Journal, 34(4), pp. 109-128

Meier, A., L. Reiner, A. Draken, T. Ueno, M. Pritoni and D. Baldewicz (2019), 'What can connected thermostats tell us about American heating and cooling habits?', Lawrence Berkeley National Laboratory paper, available at: https://escholarship.org/uc/item/9bc8b7mr

Meyer, S., H. Laurence, D. Bart, L. Middlemiss and K. Marechal (2018), 'Capturing the multifaceted nature of energy poverty: Lessons from Belgium', Energy Research and Social Science, 40, pp. 273-283

Moore, R. (2012), 'Definitions of fuel poverty: Implications for policy', Energy Policy, 49, pp. 19-26

Ntaintasis, E., S. Mirasgedis and C. Tourkolias (2019), 'Comparing different methodological approaches for measuring energy poverty: Evidence from a survey in the region of Attika, Greece', Energy Policy, 125, pp. 160-169

Office for Budget Responsibility (2019), 'Economic and fiscal outlook', CP 50, March 2019, available at: https://cdn.obr.uk/March-2019 EFO Web-Accessible.pdf

Oreszczyn, T., S.H. Hong, I. Ridley and P. Wilkinson (2006), 'Determinants of winter indoor temperatures in low income households in England', Energy and Buildings, 38, pp. 245-252

Palmer, G., T. MacInnes and P. Kenway (2008), 'Cold and Poor: An analysis of the link between fuel poverty and low income', Report by the New Policy Institute, available at: https://www.npi.org.uk/files/2213/7536/2395/fuel_poverty.pdf

Papada, L. and D. Kaliampakos (2016), 'Measuring energy poverty in Greece', Energy Policy, 94, pp. 157-165

Phimister, E., E. Vera-Toscano and D. Roberts (2015), 'The Dynamics of Energy Poverty: Evidence from Spain', Economics of Energy and Environmental Policy, 4(1), pp. 153-166

Poggi, A. and M. Florio (2010), 'Energy deprivation dynamics and regulatory reforms in Europe: Evidence from household panel data', Energy Policy, 38, pp. 253-264

Pudney, S. (2008), 'Heaping and leaping: Survey response behaviour and the dynamics of selfreported consumption expenditure', Institute for Social and Economic Research, ISER Working Paper Series, No. 2008-09, available at: https://www.iser.essex.ac.uk/research/publications/working-papers/iser/2008-09.pdf

Roberts, D., E. Vera-Toscano and E. Phimister (2015), 'Fuel poverty in the UK: Is there a difference between rural and urban areas?', Energy Policy, 87, pp. 216-223

Scott, S., S. Lyons, C. Keane, D. McCarthy and R.S.J. Tol (2008), 'Fuel Poverty in Ireland: Extent, Affected Groups and Policy Issues', The Economic and Social Research Institute, Working Paper 
No. 262, October 2008, available at: https://www.esri.ie/system/files?file=media/fileuploads/2015-07/WP262.pdf

Summerfield, A.J., T. Oreszczyn, J. Palmer, I.G. Hamilton, F.G.N. Li, J. Crawley and R.J. Lowe (2019), 'What do empirical findings reveal about modelled energy demand and energy ratings? Comparisons of gas consumption across the English residential sector', Energy Policy, 129, pp. 997-1007

Thomson, H. and C. Snell (2013), 'Quantifying the prevalence of fuel poverty across the European Union', Energy Policy, 52, pp. 563-572

Thomson, H., C. Snell and C. Liddell (2016), 'Fuel poverty in the European Union: a concept in need of definition?', People, Place and Policy, 10(1), pp. 5-24

Thomson, H., S. Bouzarovski and C, Snell (2017), 'Rethinking the measurement of energy poverty in Europe: A critical analysis of indicators and data', Indoor and Built Environment, 26(7), pp. 879901

Tirado Herrero, S. (2017), 'Energy poverty indicators: A critical review of methods', Indoor and Built Environment, 26(7), pp. 1018-1031

Trinomics (2016), 'Selecting Indicators to Measure Energy Poverty - Final Report', Report for DG Energy, European Commission, ENER/B3/2015-507, available at: https://ec.europa.eu/energy/sites/ener/files/documents/Selecting\%20Indicators\%20to\%20Meas ure\%20Energy\%20Poverty.pdf

Vadodaria, K., D.L. Loveday and V. Haines (2014), 'Measured winter and spring-time indoor temperatures in UK homes over the period 1969-2010: A review and synthesis', Energy Policy, 64, pp. 252-262

Waddams Price, C., K. Brazier and W. Wang (2012), 'Objective and subjective measures of fuel poverty', Energy Policy, 49, pp. 33-39

Walker, R., Liddell, C., McKenzie, P. and Morris, C. (2013), 'Evaluating fuel poverty policy in Northern Ireland using a geographic approach', Energy Policy, 63, pp. 765-774 